Report No: AUS0000471

\title{
Strengthening Links between Social Protection and Disaster Risk Management for Adaptive Social Protection in Nepal
}

November 2018

Social Protection and Jobs

(4) WORLD BANKGROUP 
(C) 2018 The World Bank

1818 H Street NW, Washington DC 20433

Telephone: 202-473-1000; Internet: www.worldbank.org

Some rights reserved

This work is a product commissioned by The World Bank. The findings, interpretations, and conclusions expressed in this work do not necessarily reflect the views of the Executive Directors of The World Bank or the governments they represent. The World Bank does not guarantee the accuracy of the data included in this work. The boundaries, colors, denominations, and other information shown on any map in this work do not imply any judgment on the part of The World Bank concerning the legal status of any territory or the endorsement or acceptance of such boundaries.

\section{Rights and Permissions}

The material in this work is subject to copyright. Because the World Bank encourages dissemination of its knowledge, this work may be reproduced, in whole or in part, for non-commercial purposes as long as full attribution to this work is given.

Attribution-Please cite the work as follows: "World Bank. 2018. Strengthening Links between Social Protection and Disaster Risk Management for Adaptive Social Protection in Nepal. (C World Bank."

All queries on rights and licenses, including subsidiary rights, should be addressed to World Bank Publications, The World Bank Group, 1818 H Street NW, Washington, DC 20433, USA; fax: 202-522-2625; e-mail:

pubrights@worldbank.org. 


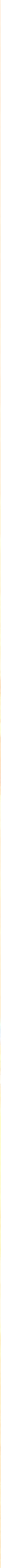

\section{Social Protection and Disaster}

\section{Risk Management for Adaptive}

\section{Social Protection in Nepal}

Final report in support of the 'Review of policies, systems and programs in social protection and shock response for adaptive social protection in Nepal' 


\section{Preface}

The Nepal office of the World Bank has contracted the Centre for International Development and Training at the University of Wolverhampton, United Kingdom, and the Nepal Institute for Social and Environmental Research, to carry out a technical assistance (TA) project that enhances the understanding of disaster risk management (DRM) and social protection (SP) programs and delivery systems to assess how SP programs could improve risk management and preparedness and better respond to shocks. The work aims to contribute to the continued evolution of SP and improved shock response in Nepal through the production of recommendations for improving policies, systems, institutions, and programs in SP to tackle key development in Nepal.

The overall objective of the work is the production of a range of reviews and recommendations on possible policy, programmatic, and institutional measures to make SP programs in Nepal-in particular Social Security Allowances (SSAs), and public works programs (PWPs) at the outset of the project the Karnali Employment Programs (KEP) and Rural Community Infrastructure Works (RCIW) and later the new Prime Minister's Employment Program)-more adaptive.

Underpinning this overall objective will be a set of analytical activities-a risk profile; reviews of policies, systems, institutions, and programs working on SP and shock response; case studies of earthquake, landslide, fire, and flood; the identification of international good practice; and consideration of cross-cutting issues including institutional structures and the engagement of nonstate actors. This report draws together the profiling and review activities and offers recommendations for actions to support adaptive social protection (ASP) in the future.

\section{Acknowledgements}

This report was written by Rachel Slater, Anita Ghimire, and Dani Baur. We are grateful to Rachel Roland, Reshma Shakya, Canford Chiroro, Sarmila Mainali, and Pranav Adhikari for their contributions to consultations, fieldwork, and analysis and to Shaheen Akter for statistical analysis. We thank Jyoti Pandey, (Social Protection Specialist), Soyesh Lakhey (Consultant), Jasmine Rajbhandary (Senior Social Protection Specialist), and Basant Raj Gautam (Consultant) at the World Bank for guidance, insights, and support during the research process and the many stakeholders at community, local government, district, and central levels that took time to provide insights about disasters, SP, and DRM in Nepal. The work was funded through the World Bank-executed Rapid Social Response Trust Fund, supported by Australia, Norway, the Russian Federation, Sweden, and the United Kingdom. The authors alone are responsible for the analysis and views presented here.

Cover photograph: Copyright Rachel Slater. 


\section{Executive Summary}

A key challenge in Nepal is the intersection of predictable chronic or seasonal poverty and vulnerability, with rapid-onset and acute shocks. Nepal in the last few decades has epitomized the 'perfect storm' in which a number of different factors - disasters, conflict, political uncertainty, and challenges to economic growth-coincide with deleterious effects on people's well-being and development progress. While social protection (SP) is playing an increasing role in tackling chronic and seasonal poverty and wider vulnerability and exclusion, recent disasters in Nepal, particularly in 2015, highlight how making SP more flexible and adaptive could allow a more effective and efficient development and humanitarian response.

The World Bank in Nepal contracted the Centre for International Development and Training at the University of Wolverhampton, United Kingdom, and the Nepal Institute for Social and Environmental Research, to carry out the technical assistance (TA) project 'Review of policies, systems and programs in social protection and shock response for adaptive social protection in Nepal'. The overall objective of the work is to make recommendations on possible policy, programmatic, and institutional measures for more adaptive social protection (ASP). The analysis was delivered using a mixed-methods approach. An analysis of existing data (including the Household Risk and Vulnerability Survey [HRVS] data) was used to understand the scope and coverage of existing programs and their links to disasters and shocks. A desk review of literature explored legislation and policies, program documentation and official implementation guidelines, and evaluations and research. Interviews took place with key informants at the national, district, and local government levels as did focus group discussions (FGDs) and individual interviews, especially with recipients of SP programs, at the ward or village level in the districts of Bardiya, Humla, Saptari, and Sindhupalchok.

The year 2018 (or 2074/2075 in Nepal) is both a particularly difficult moment to assess the existing policies, programs, and systems for shock response in Nepal and a particularly opportune one. The transition to a federal system means that some implementing institutions are tying up while other fledgling tiers of government are embarking on delivering disaster risk management (DRM) or SP for the first time. Some government staff are being deployed from district to local government assignments and embarking on new roles often with new or different responsibilities. Recently elected new local government leaders are conceiving disaster management strategies in their locales, considering how to best support the most excluded and vulnerable people in their constituencies, and seeking to work out the best use of the resources available to them. The new Disaster Risk Reduction and Management Act (DRRM - 2074) provides the new legislative framework for managing disasters, but implementation is only just beginning.

Despite the substantial difficulties, there is also a great opportunity-to assess how far the emerging new systems for SP might link to the emerging policies, systems, and institutional and financing arrangements for DRM at a moment when it is still possible to influence the arrangements. Thus, this is an apt moment to look at new ways of enabling Nepal to tackle the greatest of its challenges (poverty, vulnerability, and climate change). The transition to a federal political system and the decentralization of mandates to the local government level, precisely at a time when the urgency of tackling disasters and climate change has never been greater, presents a rare opportunity to influence, and perhaps shift, the policy discourse. 


\section{Findings}

Nepal ranks high on the list of disaster-prone countries, with further shocks associated with health, political instability, and economic shocks. Particular household and individual features (such as being a female-headed household or having a person over age 70 in the household) do seem to affect exposure to some shocks, but these are political, economic, and health-related shocks and not natural disasters.

In the SP sector, Nepal has made substantial progress in the past few decades to establish a suite of SP programs; however, the SP system remains rather fragmented and there is limited coverage of the poorest in Nepal, which has implications for the extent to which SP can be made more flexible, adaptive, and able to contribute to DRM. Progress with strengthening management information systems (MIS) and payments systems is ongoing and will be critical to make SP more adaptive. For example, given that the Social Security Allowances (SSAs) are paid three times a year, there is potential to improve timings of payments-particularly in the Terai districts-to better align with flood risks and the risk of cold waves. Using SP to deliver shock response has been demonstrated as feasible following the 2015 earthquake. However, other areas of ASP have received less attention. Rather less progress has been made to maximize the roles of SP in disaster mitigation, preparedness, and recovery, but there is substantial potential for SP to contribute more to disaster mitigation by increasing household resilience.

The transition to a federal political system and decentralized mandates and responsibilities for SP at the local level present challenges for the delivery of SP, and there are gaps in ensuring accountability and oversight. Similarly, in the DRM sector, it will take time before the arrangements provided for in DRRM - 2074 are implemented, especially at the local level. The act lays out the roles and responsibilities of the three tiers of government, plus districts, particularly the establishment of committees. It also highlights the importance of covering the full DRM cycle-disaster mitigation, preparedness, response, and recovery. In practice, perhaps because of the extent of damage to buildings during the 2015 earthquake and the 2017 floods, policy attention and program resources are skewed toward the rehabilitation of buildings, including targeting resources aimed at ensuring people's basic consumption using criteria associated with shelter rather than the availability of food. Drought shocks in particular require a different focus in response. Challenges with targeting appear to be creating divisions and disputes, and a lack of collective action, in some communities. Improvements in the communication of targeting processes and decisions would go some way to address this.

The lessons from international experiences with ASP stress the importance of coherent and coordinated rather than fragmented SP systems, the need for high coverage of poverty-targeted programs if SP is to prove useful for disaster response, and the importance of pre-positioning of resources at different levels to deal with contingency. The lessons about disaster mitigation, preparedness, and recovery are fewer but stress the importance of having at least one sound poverty-targeted program and ensuring that the mix of programs and instruments are suitable both for crisis response as well as for combating chronic poverty and inequality.

Pulling together the findings from the reviews of SP and DRM systems in Nepal, lessons from international experience allow an assessment of what sort of arrangements for ASP might work best 
for Nepal. Most important of all, building household resilience to reduce the impact of shocks is critical-and programs need to be adequate, especially in terms of the size of transfers, if they are to help achieve greater resilience and mitigate shocks. Addressing the limited focus on chronic and transient poverty within Nepal's existing SP system would represent a critical step forward in achieving resilience.

Because they remain predominantly targeted based on demographic categories, the extent to which expanding the coverage of existing SP programs can support disaster response is limited. However, Nepal's recent experiences of disasters might provide an entry point for a serious dialogue about the prospects for poverty-targeted transfers in Nepal. Rethinking some SP programs will allow them to be more adaptive and support household resilience building, as will expanding the vision of programs such as public works to integrate them directly with climate change adaptation practices, DRM, and rural/agricultural development.

Increasing regular payments or making extraordinary payments following a disaster will only be useful where the shock is experienced by most people in a given district or municipality, and when delivered alongside and coordinated with other humanitarian responses. Estimates based on the HRVS data show that households that are either in receipt of the SSAs or have household members who are eligible for them are no more likely to be exposed to natural disasters-specifically earthquake, flood, fire, drought, and landslide-than those who are not eligible. As a result, if a disaster response is targeted using existing (or expanded) SSA or public works programs (PWPs) eligibility, there are significant inclusion and exclusion errors: the majority of households that receive SP are not shock affected (inclusion error) and most households that are shock affected do not receive SP. The greatest coverage is found for shocks that are very widespread across the population-for example, Figure 21 shows that, in earthquake-affected districts, extraordinary payments to SSA beneficiaries would reach 56.2 percent of all earthquake-affected households. There are other reasons to consider delivering shock response through the existing SP-notably the challenges faced by many SP recipients (who are often socially excluded) in accessing disaster relief in the current targeting and damage assessment system.

\section{Implications and Recommendations}

Overall, the key implication for ASP in Nepal is that 'one size' will not fit all. There is no single SP program that offers a 'best bet' for ASP. Different programs have different useful features, for example, some are useful because they are targeted to the households that are most likely to experience shocks, while others are not targeted in such a way but reach many shock-affected households simply on account of their greater coverage. The distinctions between covariant and idiosyncratic shocks, the fact that some disasters are slower onset than others, the fact that Nepal's existing SP programs have very differentiated coverage in different parts of the country and are targeted very differently, and the ways in which different shocks (earthquake versus fire and drought versus flood) are experienced mean that it will be necessary to consider options for a range of different situations.

\section{Recommendations for ASP policies, institutions, and systems}

Continue existing efforts to strengthen SP systems-particularly information and payment systems. There are strong arguments for continued investments in making the SP system itself work 
better in Nepal-especially strengthening beneficiary registries. Continuing the shift from annual to rolling enrolment for the SSAs is a core foundation of flexibility. Ensuring that payments are made reliably and predictably and shifting payment times so that transfers arrive just before seasonal shocks are likely to be hit would be a useful way of building on existing systems strengthening efforts. A key part of strengthening SP systems will be the clear articulation in SP guidelines of how the system will first promote household resilience building and then, second, be flexible and able to support an emergency response.

Clarify and make provision in guidelines and regulations for SP representation in DRM decision making and vice versa. International experience demonstrates the importance of a formal regulatory framework to allow institutional coordination between SP and DRM agencies. In the immediate term, it is recommended that the working group developing the Disaster Management Authority (DMA) regulations incorporate a specific SP role into the DMA and that those responsible for revising SSA guidelines include mechanisms for incorporating both the goals of resilience building (for disaster mitigation) and flexibility (for response and recovery).

Continue the switch to electronic payments and mobile banking to ensure that funds reach beneficiaries as rapidly as possible. This has the concomitant implication that more banking would need to be available locally-including using new technologies supporting mobile banking and epayment systems - to allow a more rapid payment of emergency support through local systems.

Increase attention and resources for mitigation and preparedness. The focus on recovery, and particularly the reconstruction process for buildings and homes, leaves little attention paid to mitigation and preparedness. It is important to ensure that more focus and clarity is created at the central level-notably in the National Disaster Risk Reduction and Management Executive Committee and Authority (the latter is more widely called the DMA)-on disaster mitigation and preparedness. This could be achieved through more explicit differentiation of actions related to mitigation and preparedness, and the associated resource allocation mechanisms for them and will need to filter down to the local level to allow a clear understanding of roles and responsibilities, and funding streams, in these areas.

Pre-positioning resources for shock response. Specific examples are (a) holding contingency budgets or pre-positioning financial resources not just at the central level but at all tiers of government and (b) based on an analysis of the role of the Nepal Food Corporation, ensuring food stocks are in place in remote areas where shocks are anticipated so they can be sold or distributed. Maintaining food stocks in remote rural areas is also critical to ensuring that other cash transfer programs are effective. Cash transfers do not work if there is no food available in local markets at reasonable prices.

\section{Recommendations for ASP program design and implementation}

Consider expanding SP payments temporarily post disaster. There are a number of ways to further explore expanding SP payments. Expanding payments to existing beneficiaries would provide a mechanism for reaching households that otherwise struggle to access support following disasters. Cash and in-kind benefits provided following the 2015 earthquake appear to have resulted in shockaffected beneficiaries being significantly less food insecure than households affected by the earthquake but not in receipt of SP. When receiving SSAs during shocks, beneficiaries found that 
they were part of the solution to a household's troubles, rather than being seen as a burden on the household. For programs basing targeting on poverty and food insecurity (for example, PWPs), there is also scope to temporarily increase the PWP wage rate.

Recognize that increasing transfer levels will have both pros and cons. As much as the targeting of the SSAs appears to be widely accepted, there is a risk that targeting a shock response through the SSAs could create serious resentment and, potentially, worsen exclusion. Tackling this will require far better communication than has been the case thus far. The trade-offs between acceptable targeting and speed of response are particularly acute in a post-conflict setting such as Nepal where grievances (in this case about access to emergency support) can endure for a long time and potentially undermine political stability.

Expand SP as one of a complementary set of mechanisms for emergency response, not as a substitute for other humanitarian responses. SP should not be an alternative to a wider shock response but could work well alongside other complementary humanitarian response. Routing part of an emergency response through existing SP would reduce the caseload of needs assessment and targeting that would be required at the local level during the response. Only households not in receipt of SP would require assessment with the potential to significantly speed up the assessment process.

Begin a dialogue on potential policy and program options for poverty-targeted SP. In Nepal, there are few SP programs providing transfers that explicitly target poverty. While PWPs target using poverty proxies such as Human Development Index (HDI) indicators and food insecurity, the remainder of programs target based on social and demographic categories such as gender, age, and ethnicity. Yet, poverty-targeted SP programs are key to ASP. Given substantial progress toward establishing SP in Nepal over the last decade, and the pressing need to tackle vulnerability and impoverishment amid increasing threats from natural disasters, this is an appropriate moment to begin a dialogue on how a poverty-targeted SP program might work for Nepal.

Consider integrating PWPs more with existing climate change adaptation, DRM, and agriculture/rural development programs. There is substantial opportunity to link public works initiatives to wider actions seeking to adapt and protect livelihoods, especially agricultural livelihoods in the context of threats from climate change and to broader infrastructure investments.

Rethink the assessment criteria for targeting response and recovery. The review found that damage to housing was the primary criteria driving the targeting of response and recovery with far less attention paid to consumption needs. Given that this focus was leading to some unintended outcomes at the local level-particularly households with no mechanism to meet their basic needs or maintain their livelihoods receiving no support because their homes were not fully destroyed-a refocus of the assessment criteria away from physical housing and toward consumption is suggested with inputs from across all clusters.

\section{Conclusion}

The recommendations presented here are intended to support a dialogue about options for making SP more adaptive in Nepal and discussion about the roles that various stakeholders-government, donors, and nongovernmental organizations (NGOs)-might play in that process. The actions woven 
into these recommendations-increasing payments, expanding coverage, establishing new programs, and so on-have different levels of ambition, with varied potential outcomes. The more ambitious the action, the greater the potential for supporting all four pillars of the approach of the Government of Nepal (GoN) to DRM.

Table 1. Mitigation, preparedness, response, and recovery outcomes from recommended actions

\begin{tabular}{|c|c|c|c|c|}
\hline \multirow[t]{2}{*}{ Recommended Actions } & \multicolumn{4}{|c|}{ Outcomes } \\
\hline & Mitigation & Preparedness & Response & Recovery \\
\hline \multicolumn{5}{|l|}{ Policy, institutional, and systemic } \\
\hline $\begin{array}{l}\text { Strengthen SP systems - particularly systems } \\
\text { for identification, payment, targeting, and } \\
\text { management processes. }\end{array}$ & $\mathrm{x}$ & $\mathrm{x}$ & $\mathrm{x}$ & $\mathrm{x}$ \\
\hline $\begin{array}{l}\text { Make provision in guidelines for SP } \\
\text { representation in DRM decision making and } \\
\text { vice versa. }\end{array}$ & $x$ & $\mathrm{x}$ & $x$ & $\mathrm{x}$ \\
\hline $\begin{array}{l}\text { Put in place a contingency and financing } \\
\text { strategy for the financing of responses to } \\
\text { shocks. }\end{array}$ & & & $x$ & \\
\hline $\begin{array}{l}\text { Clarify the procedures for expanding SP- } \\
\text { especially early warning criteria for triggering } \\
\text { expanded payments or other predetermined } \\
\text { responses to shocks. }\end{array}$ & & $x$ & $x$ & \\
\hline $\begin{array}{l}\text { Expand electronic and mobile banking } \\
\text { services for SP payments. }\end{array}$ & $x$ & $\mathrm{x}$ & $x$ & $x$ \\
\hline $\begin{array}{l}\text { Put in place a national social registry for the } \\
\text { identification of potential beneficiaries when } \\
\text { shocks occur. }\end{array}$ & & $x$ & $\mathrm{x}$ & \\
\hline \multicolumn{5}{|l|}{ Programmatic } \\
\hline Attach DRM messages to SP payments. & $x$ & $\mathrm{x}$ & $\mathrm{x}$ & $x$ \\
\hline $\begin{array}{l}\text { Ensure pre-positioning of food stocks using } \\
\text { Nepal's Public Food Distribution System } \\
\text { (PFDS) and manage food depot prices flexibly. }\end{array}$ & $x$ & $x$ & $\mathrm{x}$ & $x$ \\
\hline Expand temporarily SSA benefit levels. & $x$ & & $\mathrm{x}$ & $x$ \\
\hline $\begin{array}{l}\text { Expand (temporarily) coverage of cash } \\
\text { transfers to shock-affected households. }\end{array}$ & $x$ & & $\mathrm{x}$ & $\mathrm{x}$ \\
\hline Expand public works payments and coverage. & $x$ & & $\mathrm{x}$ & $x$ \\
\hline $\begin{array}{l}\text { Establish a national poverty-targeted SP } \\
\text { program to address chronic poverty and } \\
\text { increase the resilience of the poor to shocks. }\end{array}$ & $x$ & $x$ & $x$ & $x$ \\
\hline $\begin{array}{l}\text { Use public works as part of integrated climate } \\
\text { change/rural development/disaster } \\
\text { management response. }\end{array}$ & $\mathrm{x}$ & $\mathrm{x}$ & $\mathrm{x}$ & $x$ \\
\hline
\end{tabular}

The four key messages from the review are as follows:

First, the variation in shocks-from those that come with little or no warning to those that are seasonal and those that have a slow onset; from those that affect very few people in specific locations to those that are generalized across the population; from those that cause death and injury to those that damage housing and to those that undermine livelihoods-means that there is no single best option for using SP to tackle the major shocks that Nepal faces. Multiple pathways for SP 
will need these differences to be borne in mind and adopt a best-fit approach across a range of circumstances.

Second, the tumultuous changes in Nepal's political and administrative systems mean programs will have to be flexible, not just to the specificities of individual disasters, but also to the constant transition and upheaval in government institutions, particularly at the local level. Assessing capabilities to deliver each of the options will be critical. However, the new arrangements at the local government level may also offer opportunities-in particular to work in a more integrated way.

Third, while delivering disaster management operations through SP in this rapidly changing context is difficult, it also provides a unique window of opportunity to establish new ways of working that better link SP and responding to shocks not just in terms of immediate disaster responses but also in relation to mitigation, preparedness, and recovery.

Last, the recommendations proposed here purposely encompass some relatively easy to achieve ways of better linking SP and DRM and some rather more ambitious ones. They are meant as the starting point for a dialogue between the government and other development and humanitarian agencies that might, in turn, be reflected in the guidelines that underpin SP and DRM systems, procedures, and programs. 


\section{Contents}

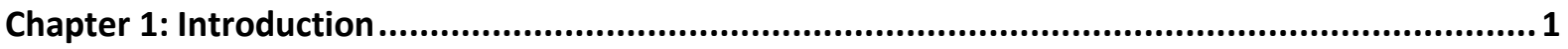

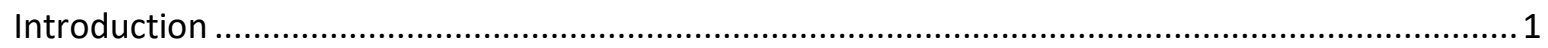

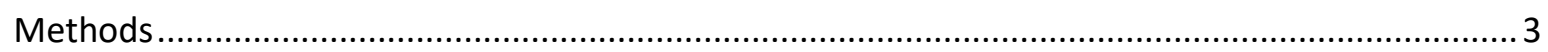

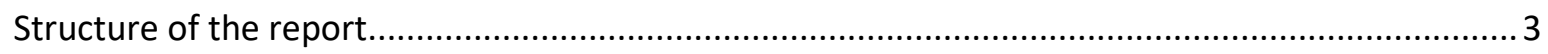

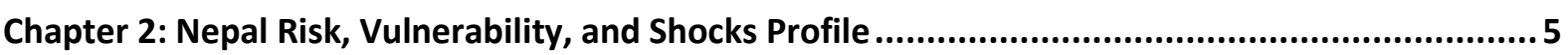

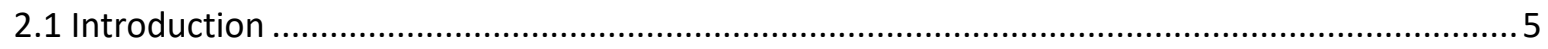

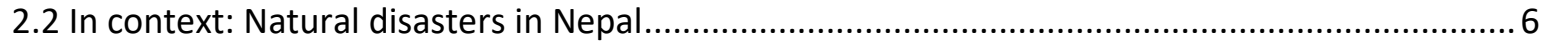

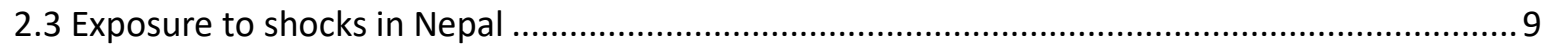

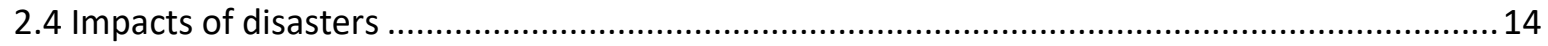

2.4.1 Impacts of disasters by gender and social identity ............................................................... 14

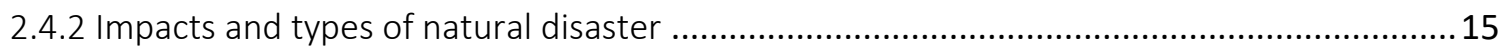

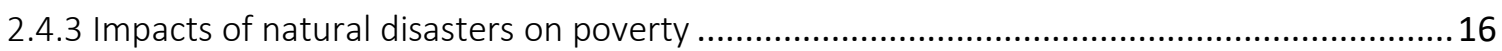

2.5 Responding to natural disasters: managing and coping strategies ......................................... 16

Chapter 3: Review of Social Protection Policies, Programs, and Systems in Nepal ....................... 19

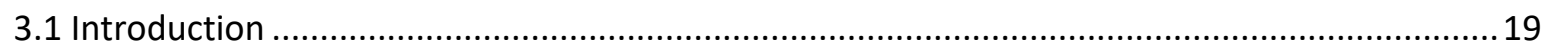

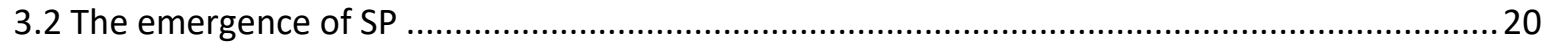

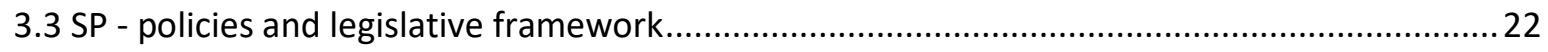

3.4 SP programs

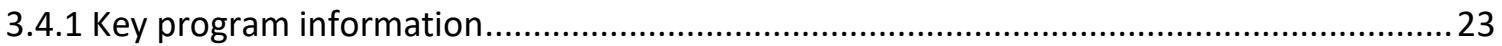

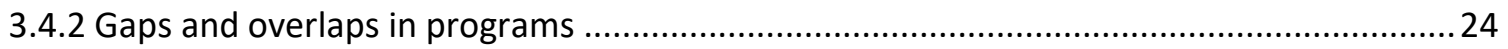

3.4.3 Strengths and weaknesses in general implementation features........................................26

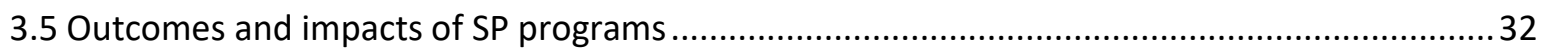

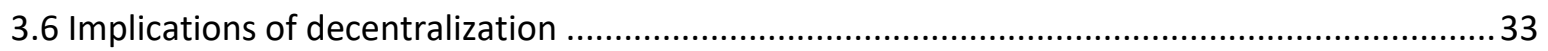

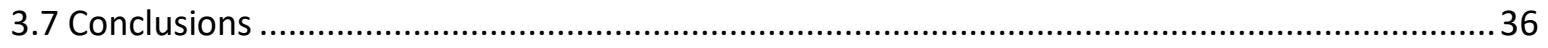

Chapter 4: Review of Shock Response Policies, Programs, and Systems in Nepal .......................... 37

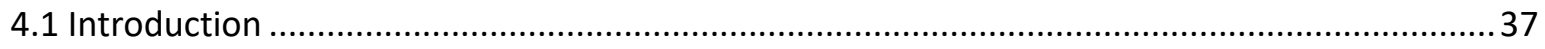

4.2 DRM on paper: legislation and policies for shock response and management..........................37

4.2.1 Distinction between four discrete but overlapping pillars of DRM .....................................37

4.2.2 Articulation of mandates, funding, roles, and responsibilities across the three tiers of

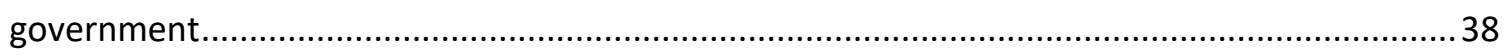

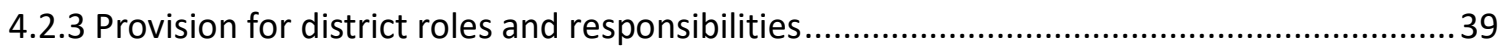

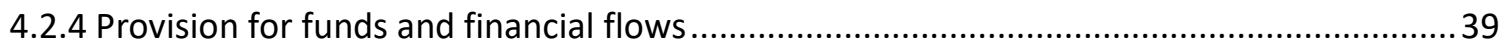

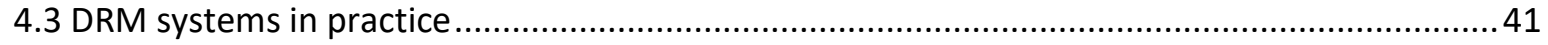


4.3.1 District versus local

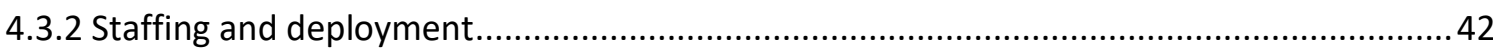

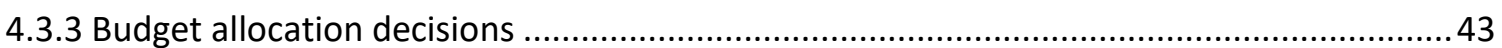

4.4 Experiences of mitigation, preparedness, response, and recovery....................................43

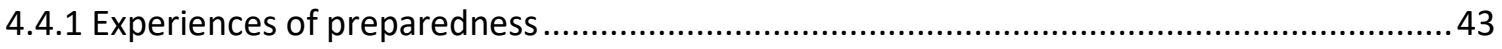

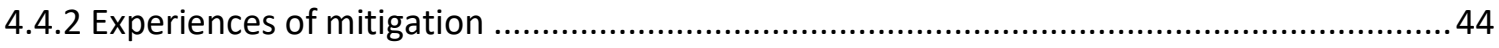

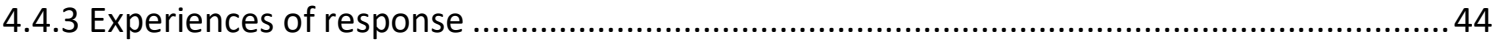

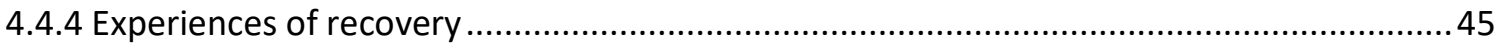

4.5 Communities roles and perceptions ................................................................ 45

4.6 Conclusions: implications for linking SP and disasters ............................................ 46

Case Study: Flooding in Bardiya and Saptari, 2017....................................................... 47

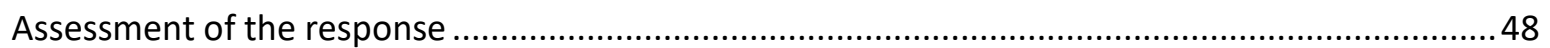

Implications for adaptive social protection ....................................................................... 49

Case Study: Earthquake in Sindhupalchok 2015 ............................................................. 50

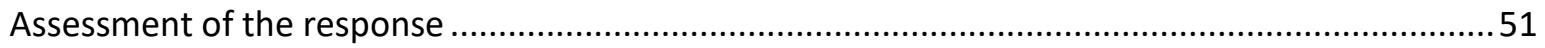

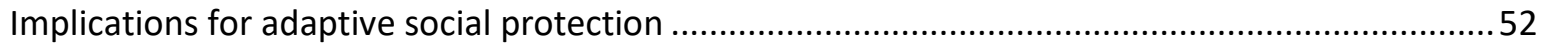

Case Study: Drought in Karnali, 2015-2016 ............................................................. 53

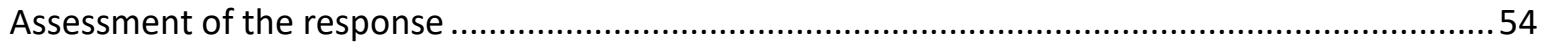

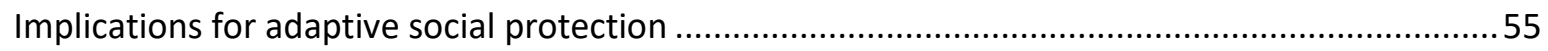

Case Study: Fires and Landslides....................................................................... 56

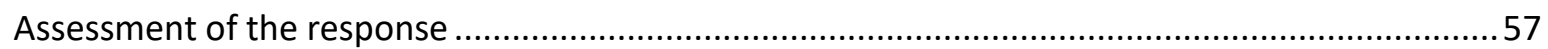

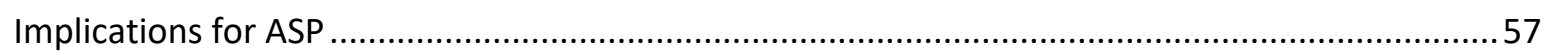

Chapter 5: International Experiences with Adaptive Social Protection ....................................... 58

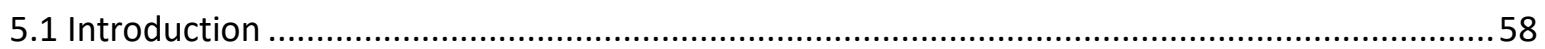

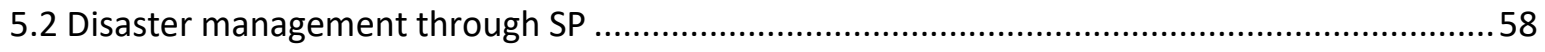

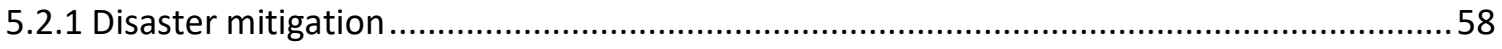

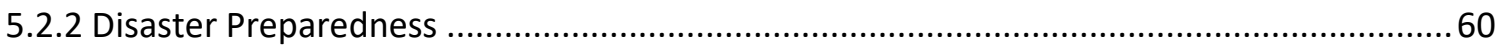

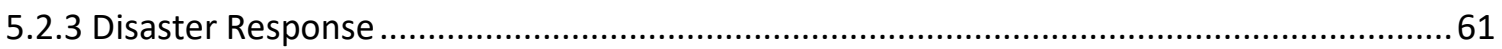

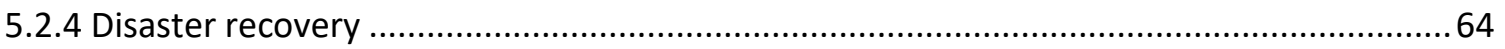

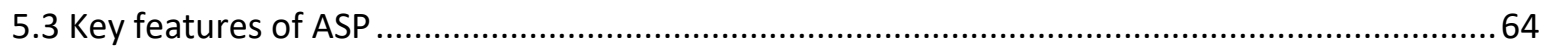

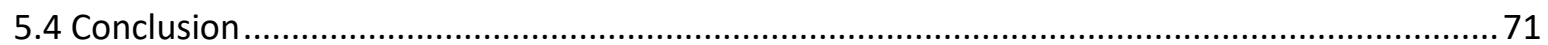

Chapter 6: Analyzing What Might Work in Nepal ............................................................. 72

6.1 What might work for making SP systems more adaptive in Nepal? .................................... 72

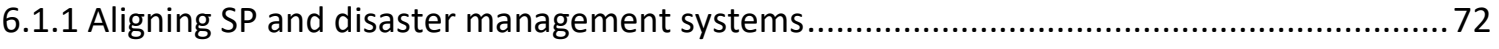


6.1.2 Strengthening institutional coordination

6.1.3 Making SP financing more adaptive .................................................................. 73

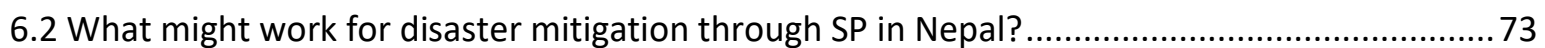

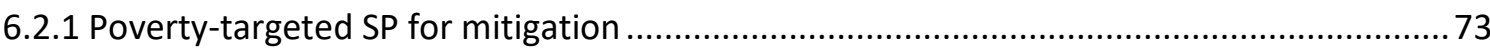

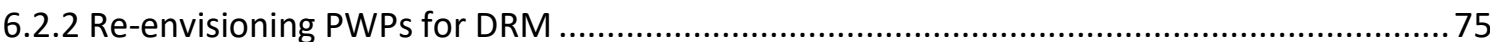

6.3 What might work for disaster preparedness through SP in Nepal? ..................................... 77

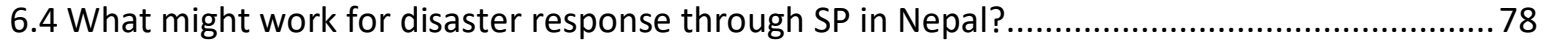

6.4.1 Increase payments / make extra-ordinary payments .......................................... 78

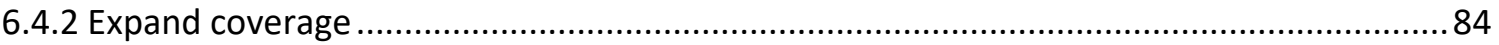

6.4.3 Refocusing and revising programs for effective response ..................................... 84

6.5 What might work for disaster recovery through SP in Nepal? ...........................................86

Chapter 7: Toward Adaptive Social Protection in Nepal - Conclusions and Recommendations ...... 88

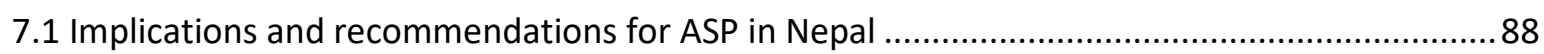

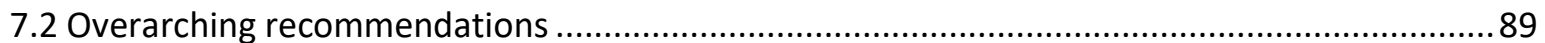

7.3 Recommendations for SP's role in mitigation and preparedness ....................................90

7.4 Recommendations for response and recovery ...........................................................

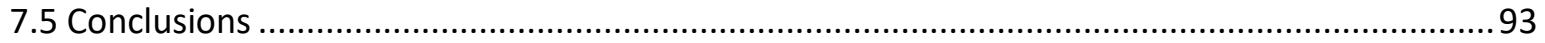

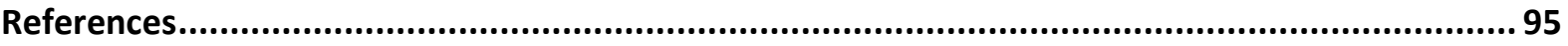

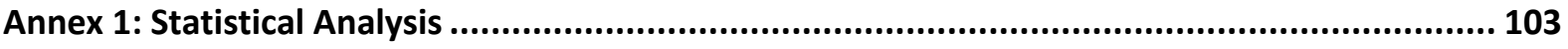

Annex 2: Case Study Figures ....................................................................... 105 
List of Boxes

Box 1 Characteristics of Adaptive Social Protection $\quad 1$

Box 2 Types of Vulnerability in Nepal 25

Box 3 Competing for engineers: earthquake versus flood 42

Box $4 \quad$ Ethiopia's Productive Safety Net Programme (PSNP) 62

Box $5 \quad$ Kenya's Hunger Safety Net Proramme (HSNP) 63

Box $6 \quad$ Coverage of different types of vulnerability in Nepal's SP system 74

Box 7 Behaviour change communications during the 2015 earthquake in Nepal 77

List of Figures

Figure 1 Historical data on selected natural disasters and epidemics in Nepal 9

Figure 2 Geographical distribution of Shocks in HRVS sample districts 10

Figure 3 Social vulnerability to natural hazards in Nepal 12

$\begin{array}{lll}\text { Figure } 4 & \text { Growth in the number of SSA Beneficiaries - 1998-2016 } & 21\end{array}$

Figure 5 Beneficiaries of selected SP/social security programs across wealth quintiles 26

$\begin{array}{lll}\text { Figure } 6 & \text { SSA Payment authorization and fund flow } & 30\end{array}$

$\begin{array}{lll}\text { Figure } 7 & \text { Public Food Distribution System fund flow } & 30\end{array}$

Error! $\quad$ DRM roles, responsibilities and relationships in April 2018

Reference

source not

found.

Figure $9 \quad$ Fund flow mechanism as understood by respondents in April 2018

Figure $10 \quad$ Flood affected districts in Nepal $\quad 47$

Figure 11 Categories of earthquake-affected districts $\quad 50$

Figure 12 Earthquake damage in Sindhupalchok (red = most severe) 50

Figure 13 Agricultural drought conditions in the mid and far west 53

Figure $14 \quad$ NeKSAP food security indicators $\quad 54$

Figure 15 Nepal Road Network, $2016 \quad 55$

Figure 16 Landslide risk in Nepal 56

Figure 17 Prevalence of forest fires, 1971-2011 56

Figure 18 Institutional arrangements for Ethiopia's PSNP 62

Figure 19 SP programs during DRM stages, Pantawid Pamiliya Pilipino Program, Philippines 64

Figure 20 Funds and resource allocation for FONDEN $\quad 69$

Figure 21 Coverage and exclusion and inclusion errors using SSAs for earthquake response 82 in most severely affected districts

Figure 22 Coverage and inclusion and exclusion errors for district-level flood response 82

Figure 23 Coverage, exclusion, and inclusion for district-level drought response 83

Annex

Annex Figure $1 \quad$ DRM and ASP service delivery in event of flood 105

Annex Figure 2 DRM and ASP service delivery in event of earthquake 106

$\begin{array}{llr}\text { Annex Figure } 3 & \text { DRM and ASP service delivery in event of drought } & 107\end{array}$

$\begin{array}{llr}\text { Annex Figure 4 } & \text { DRM and ASP service delivery in event of landslide } & 108\end{array}$

Annex Figure $5 \quad$ DRM and ASP service delivery in event of fire 109

List of Tables

Table 1

Mitigation, preparedness, response, and recovery outcomes from

vii

Table $2 \quad$ Summary Risk Profile for Nepal 9

Table $3 \quad$ Types and location of natural and human-induced hazards in Nepal 11

Table $4 \quad$ Nepal districts ranked according to an overall climate change vulnerability 14

Table $5 \quad$ Selected SP programs in Nepal focusing on assistance 
Table 6

Participant numbers for selected PWPs 2006/07 to 2016/17

Table 9

Typologies of mechanisms by which SP can support shock response

Table 10 Households affected by shocks: differences between SP beneficiary and

These non-beneficiary households

estimates

suggest large

gaps in

coverage and substantial

exclusion and

inclusion

errors if

shock-

responsive SP

is targeted

using the

same lists as

regular SP

programs.

However, the

estimates are

based on 50

districts in

the HRVS and

so, for more

robust

estimates we

explore in

more detail

on a district-

by-district,

shock-by-

shock, and

program-by-

program

basis whether

delivering

shock

response

through SP,

as well as

supporting

disaster-

affected

people, might 
tackle the

structural

vulnerabilities

that underpin

poverty in an

effective way.

Table 11

Table 12

Coverage and exclusion and inclusion errors for shock response routed

Table 13

through expanded SP programs

Mitigation, preparedness, response, and recovery outcomes from

Annex

Annex Table 1

recommended actions

Annex Table 2

Exposure to shocks and gender of household head

age

Exposure to shocks by age group of household head

Annex Table 3

\section{Acronyms and Abbreviations}

$\begin{array}{ll}\text { ASP } & \text { Adaptive Social Protection } \\ \text { CBO } & \text { Community-based Organization } \\ \text { CDO } & \text { Chief District Officer } \\ \text { DAO } & \text { District Administration Office } \\ \text { DDC } & \text { District Development Committee } \\ \text { DDPP } & \text { District Disaster Preparedness Plan } \\ \text { DMA } & \text { Disaster Management Authority } \\ \text { DMC } & \text { Disaster Management Committee } \\ \text { DMF } & \text { Disaster Management Fund } \\ \text { DoCR } & \text { Department of Civil Registration } \\ \text { DRC } & \text { Disaster Response Committee } \\ \text { DRM } & \text { Disaster Risk Management } \\ \text { DRR } & \text { Disaster Risk Reduction } \\ \text { DRRM } & \text { Disaster Risk Reduction and Management Act } \\ \text { DSWD } & \text { Department of Social Welfare and Development } \\ \text { EMOP } & \text { Emergency Operation (of WFP) } \\ \text { ETCTP } & \text { Emergency Top-up Cash Transfer Program } \\ \text { EWS } & \text { Early Warning System } \\ \text { FEWS } & \text { Flood Early Warning System } \\ \text { FGD } & \text { Focus Group Discussion } \\ \text { GAM } & \text { Global Acute Malnutrition } \\ \text { GDP } & \text { Gross Domestic Product } \\ \text { GLOF } & \text { Glacier Lake Outburst Flood } \\ \text { GoN } & \text { Government of Nepal } \\ \text { HDI } & \text { Human Development Index } \\ \text { HFIAP } & \text { Household Food Insecurity Prevalence Scales } \\ \text { HRVS } & \text { Household Risk and Vulnerability Survey } \\ \text { HSNP } & \text { Hunger Safety Net Program } \\ \text { ICGTF } & \text { Inter-Cluster Gender Task Force } \\ \text { ICIMOD } & \text { International Centre for Integrated Mountain Development } \\ \text { ILO } & \text { International Labour Organization } \\ & \end{array}$




\begin{tabular}{|c|c|}
\hline INFORM & Index for Risk Management \\
\hline INGO & International Nongovernmental Organization \\
\hline KEP & Karnali Employment Program \\
\hline LAPA & Local Adaptation Plans of Action \\
\hline LGBTI & Lesbian, Gay, Bisexual, Transgender, and Intersexed \\
\hline LGOA & Local Government Operation Act \\
\hline LIC & Low-income Country \\
\hline MIS & Management Information System \\
\hline MoA & Ministry of Agriculture \\
\hline MoAC & Ministry of Agriculture and Cooperatives \\
\hline MoCTS & Ministry of Commerce, Trade and Supplies \\
\hline MoF & Ministry of Finance \\
\hline MoFAGA & Ministry of Federal Affairs and General Administration \\
\hline MoHA & Ministry of Home Affairs \\
\hline MoLESS & Ministry of Labour, Employment and Social Security \\
\hline MoLMCPA & Ministry of Land Management, Cooperatives and Poverty Alleviation \\
\hline NAPA & National Adaptation Plan of Action \\
\hline NDC & National Disaster Council \\
\hline NDMA & National Disaster Management Authority \\
\hline NeKSAP & Nepal Food Security Monitoring System (Nepal Khadhya Surakshya Anugaman Pranali) \\
\hline NFC & National Food Corporation \\
\hline $\mathrm{NFI}$ & Non-food Item \\
\hline NGO & Nongovernmental Organization \\
\hline NRA & National Reconstruction Authority \\
\hline NRC & Nepal Red Cross \\
\hline PETS & Public Expenditure Tracking Survey \\
\hline PFDS & Public Food Distribution System \\
\hline PIU & Program Implementation Unit \\
\hline PMDRF & Prime Minister's Disaster Relief Fund \\
\hline POS & Point-of-sale \\
\hline PSNP & Productive Safety Net Program \\
\hline PWP & Public Works Program \\
\hline $\mathrm{RCIW}$ & Rural Community Infrastructure Works \\
\hline RFM & Risk Financing Mechanism \\
\hline RRN & Rural Reconstruction Nepal \\
\hline SAARC & South Asian Association for Regional Cooperation \\
\hline SP & Social Protection \\
\hline SSA & Social Security Allowance \\
\hline TA & Technical Assistance \\
\hline UNICEF & United Nations Children's Fund \\
\hline VAM & Vulnerability Assessment Monitoring \\
\hline VAWG & Violence against Women and Girls \\
\hline $\mathrm{VCl}$ & Vegetation Condition Index \\
\hline VDC & Village Development Committee \\
\hline WFP & World Food Programme \\
\hline
\end{tabular}

\section{Glossary and Notes}

Lakh One hundred thousand $(100,000)$

Crore One crore is equal to 10 million $(10,000,000)$. One crore can also be referred to as 100 lakh. 


\section{Chapter 1: Introduction}

\section{Introduction}

A key challenge in Nepal is the intersection of predictable chronic or seasonal poverty and vulnerability, with rapid-onset and acute shocks. Nepal in the last few decades has epitomized the 'perfect storm' in which a number of different factors-disasters, conflict, political uncertainty, and challenges to economic growth-coincide with deleterious effects on people's well-being and development progress. While social protection (SP) is playing an increasing role in tackling chronic and seasonal poverty and vulnerability, experiences in Nepal, particularly in 2015, highlight how making SP more flexible and adaptive could allow a more effective and efficient development and humanitarian response.

The Nepal office of the World Bank has contracted the Centre for International Development and Training at the University of Wolverhampton, United Kingdom, and the Nepal Institute for Social and Environmental Research to carry out the technical assistance (TA) project 'Review of policies, systems and programs in social protection and shock response for adaptive social protection in Nepal'.

The overall objective of the work is to make recommendations on possible policy, programmatic, and institutional measures for more adaptive social protection (ASP) (Box 1).

Underpinning this overall objective is a set of analytical activities-a risk profile; reviews of policies, systems, institutions, and programs working on SP and shock response; case studies of earthquake, landslide, fire, and flood; the identification of international good practice; and consideration of cross-cutting issues including institutional structures and the engagement of non-state actors. Together these profiles and reviews will lead to the production of recommendations to support ASP in the future. The analysis presented here aims to contribute to the continued evolution of SP and improved shock response in Nepal through the production of recommendations for improving policies, systems, institutions, and programs in SP to tackle key development in Nepal.

\section{Box 1 Characteristics of Adaptive Social Protection}

- An emphasis on transforming productive livelihoods as well as protecting and adapting to changing climate conditions rather than simply reinforcing coping mechanisms

- Grounding in an understanding of the structural root causes of poverty in a particular region or sector, permitting more effective targeting of vulnerability to multiple shocks and stresses

- Incorporation of rights-based rationale for action, stressing equity and justice dimensions of chronic poverty and climate change adaptation in addition to instrumentalist rationale based primarily on economic efficiency

- An enhanced role for research from both the natural and social sciences to inform the design and implementation of SP policies and measures in the context of the burden of both natural disasters and changing climate-related hazards

- A longer-term and dynamic perspective for SP programs that takes into account the changing nature of shocks and stresses.

Source: Davies et al. $(2008,111)$.

There is a burgeoning evidence base on shocks and disasters in Nepal, but evidence across the various types of shocks - natural, environmental, health, political, and economic-is unequal. In this 
review, we focus in particular on disasters, though noting that many so-called 'natural' disasters are the result of people's interactions with the natural environment. Where people live, how they live, and, in particular, how they utilize and manage land, water, and vegetation resources influences the magnitude of and people's exposure to natural hazards and allows a natural hazard to translate into a disaster. We focus predominantly on shocks that are covariant in nature (those that are shared across a specific population) rather than idiosyncratic (those affecting a single individual or household) (Farrington, Slater, and Holmes 2004; Holzmann and Jorgensen 2001). We also remain cognizant of the fact that it is not only natural hazards that affect households in Nepal and so place our analysis in the context of wider economic, social, and health shocks. In practice, this means thinking about the economic blockade and how subsequent increases in transport costs in 2015 affected responses to earthquake and drought and what might be done about this in the future. Although the analysis focuses on natural disasters, an ASP system would also be critical to address other types of shocks-price shocks triggered by changes in international prices, shocks resulting from financial crises, or shocks of a more political nature for instance.

SP encompasses a very broad range of programs. Here, the focus is on selected social safety netsnamely cash transfers, especially the Social Security Allowances (SSAs), and public works programs (PWPs), such as Rural Community Infrastructure Works (RCIW) and the Karnali Employment Program (KEP) that closed during the finalization of this work.

The year 2018 (or 2074/2075 in Nepal) is both a particularly difficult moment to assess the existing policies, programs, and systems for shock response in Nepal and a particularly opportune one. The transition to a federal system means that some implementing institutions are tying up while other fledgling parts of the government are embarking on disaster risk management (DRM) or SP for the first time. Some government staff are being deployed from district to local government assignments and embarking on new roles often with new or different responsibilities. Recently elected new local government leaders are conceiving disaster management strategies in their locales, considering how to best support the most excluded and vulnerable people in their constituencies, and seeking to work out the best use of the resources available to them. The 2017 Disaster Risk Reduction and Management Act (DRRM - 2074) provides the new legislative framework for managing disasters, but implementation is only just beginning.

Despite the substantial difficulties, there is also a great opportunity-to assess how far the emerging new systems for SP might link to the emerging policies, systems, and institutional and financing arrangements for DRM at a moment when it is still possible to influence the arrangements. There appears to be "a willingness on the part of government to address poverty, social exclusion, and the economic and social displacement resulting from natural disasters, using social protection transfers as a tool" (Koehler and Mathers 2017, 351). Although decentralization is in full swing, many arrangements are in limbo at this moment, and so, there is an opportunity to ensure that links between SP and DRM are maximized, particularly at the local government level as staff are being deployed and roles are being designated. Thus, this is an apt moment to look at new ways of allowing Nepal to tackle the greatest of its challenges (poverty, vulnerability, and climate change). The transition to a federal political system and the decentralization of mandates to the local government level, precisely at a time when the urgency of tackling disasters and climate change has never been greater, presents a rare opportunity to influence, and perhaps shift, the policy discourse. 
There is, of course, a balancing act involved between aspiration and practicality. Progress with SP in the last decade or so has partly been possible because policy and program changes were "in each case administratively relatively simple to implement" even in Nepal's "unstable and highly competitive political environment" (Jones 2012, 252). The challenge will be to propose options for strengthening links between SP and DRM that are feasible despite the upheaval associated with the monumental shift to the three tiers of government in Nepal.

\section{Methods}

The analysis presented here was based on a mixed-methods approach. Analysis of existing data (including the HRVS-see Walker, Khadka, and Pandey 2017) was used to understand the scope and coverage of existing programs and their links to disasters and shocks. A desk review of literature explored legislation and policies, program documentation and official implementation guidance, and evaluations and research. Interviews took place with key informants at the national, district, and local government levels as did focus group discussions (FGDs) and individual interviews, especially with the recipients of SP, at the ward or village level.

Four districts were selected to capture a range of geographical, socioeconomic, and political contexts and to allow a focus on a range of SP programs and different types of shocks. Saptari and Bardiya both offered opportunities to assess the SSAs and provided key insights about experiences of floods. Humla allowed analysis of drought and to some extent landslides, floods, and hailstorms and a focus on the implications of remoteness, plus additional insights about both the KEP and the RCIW project. Further fieldwork took place in Sindhupalchok to better understand people's experiences of SP receipt in the aftermath of the 2015 earthquakes and the 2014 landslide. Case studies of the main natural disasters-flood, fire, earthquake, landslide, and drought are provided as complements to this analysis.

\section{Structure of the report}

The next chapter of the report provides an overview of the main natural hazards that Nepal faces and the context in which they translate into disasters. It then considers what factors influence exposure to shocks and the impacts of disasters. Following this, the ways in which people cope with disasters and manage risks are explored, with specific attention paid to different types of shocks and their impacts in different parts of the country and among different groups of people. While this report focuses exclusively on natural disasters, other types of shocks also affect poor and vulnerable households and could be addressed in part with ASP interventions.

Chapters 3 and 4 review the policies, systems, institutions, and programs that make up Nepal's SP and DRM sectors, respectively. For SP, the emergence of programs following the Peace Accord is explored to explain the relatively fragmented SP system that Nepal has today and to highlight the conditions in which programs are revised or new programs are taken up. The system in 2018-in particular, the ways in which processes of registration and enrolment, targeting, and resource allocation take place-are assessed. People's experiences of receiving SP are then discussed, drawing on evidence from fieldwork at the district and local government levels in Bardiya, Humla, Saptari, and Sindhupalchok. In relation to DRM, assessing the current sector and systems is rather like trying to hit a moving target. The emergence of DRRM - 2074means that systems for DRM are currently being reconfigured. We assess progress toward a new system and what that means for 
operations and resources at the time of research. As part of the review of DRM systems, institutions, policies, and programs, we present four case studies of responses to flood, earthquake, drought, and, jointly, landslide and fire. The latter case study brings together two shocks that may appear rather different, but both share a critical feature for this study-namely that they are largely idiosyncratic and most often experienced by only one family or household at a time.

In Chapter 5, experiences from other international SP systems are brought together to assess what is known about what works and what needs to be in place for SP to be an effective part of the DRM toolbox. Chapter 6 draws together findings from the preceding reviews and analyzes what sorts of ASP systems might work best for Nepal and what would need to be in place for them to operate. The final chapter concludes with a set of recommendations that the Government of Nepal (GoN), together with its donor partners, might consider to make SP more adaptive and allow it to contribute more to alleviating the worst effects of disasters and shocks on poor and vulnerable people. 


\section{Chapter 2: Nepal Risk, Vulnerability, and Shocks Profile}

\subsection{Introduction}

Barca and O'Brien $(2018,5)$ suggest that "Vulnerability and needs assessments are an essential component of decision making about whether or not social protection is a suitable vehicle for addressing a shock". Similarly, Aryal $(2012,147)$ notes that "Exploring disaster vulnerability in a particular geographical location is an important starting point towards building resilience." The profile of risk, shocks, and vulnerability presented here seeks to provide the foundation for subsequent analysis of Nepal's SP and DRM systems. It builds on data analyzed from the first wave of the HRVS. Both our own analysis and Walker, Khadka, and Pandey (2017) draw on the DesInventar Disaster Information System to understand the major disasters and shocks that are relevant in Nepal. The aim is to use this analysis to (a) frame the problem (how to make SP more adaptive/responsive) and (b) ensure that any recommendations about future actions in relation to SP are directly aligned with the realities (scale, probability, location, exposure, and impact) of hazards in different parts of Nepal.

The paper begins with a brief framing of the Nepal context in which disasters emerge and then outlines the key hazards facing the country. We then explore what drives exposure to hazards, their impacts on people, and the ways in which people seek to manage or cope with disasters. In this analysis, risk is conceptualized as a combination of the interaction of hazard, exposure, and vulnerability, implying that any increase in either hazard, vulnerability, or exposure would lead to an increase in the level of risk.

Schneiderbauer and Ehrlich $(2004,5)$ noted that "Definitions of the most common terms within disaster studies, such as 'hazard', 'vulnerability', 'resilience' and 'coping capacity' continue to be debated." In 2018, the debate has not been concluded, not least because different definitions are appropriate in different contexts, including when applied to ASP. In this study, we use the following definitions from United Nations (2016):

Hazard. A process, phenomenon, or human activity that may cause loss of life, injury, or other health impacts; property damage; social and economic disruption; or environmental degradation.

Risk. The potential loss of life, injury, or destroyed or damaged assets that could occur to a system, society, or a community in a specific period, determined probabilistically as a function of hazard, exposure, vulnerability, and capacity.

Vulnerability. The conditions determined by physical, social, economic, and environmental factors or processes that increase the susceptibility of an individual, a community, assets, or systems to the impacts of hazards.

Disaster. A serious disruption of the functioning of a community or a society at any scale due to hazardous events interacting with conditions of exposure, vulnerability, and capacity, leading to one or more of the following: human, material, economic, and environmental losses and impacts. 
In the case of the work on ASP, there is also the inclusion of the terminology of 'shocks' - which is similar to disaster but not automatically given the same implied severity. The key thing to note is that disasters result from a combination of exposure to hazards and vulnerability. So, hazards do not always result in disasters. As Wisner et al. $(2003,47)$ note "Disasters are a result of the interaction of both [hazard and vulnerability]; there cannot be a disaster if there are hazards but vulnerability is (theoretically) nil, or if there is a vulnerable population but no hazard event." Hazards such as earthquakes do not become disasters if they do not destroy buildings and livelihoods and result in loss of lives. Similarly, individuals could be exposed to an epidemic but not fall ill. SP can play a role in reducing vulnerability and increasing resilience and is therefore one key tool in preventing hazards from leading to disasters.

\subsection{In context: Natural disasters in Nepal}

In the last 45 years, an average of about 900 people were killed, more than 131,000 families were affected, and about 500 disaster incidents occurred annually in Nepal. The environmental and economic losses are beyond our calculation.

(Speech by H.E. Arjun K. Karki made at the fifth session of the Global Platform for Disaster Risk Reduction, May 2017, Cancun, Mexico)

Nepal is one of the most disaster-prone countries in the world. Its geographical location, climatic conditions, and high levels of poverty, which undermine its capacity to respond to shocks and surprises, leave it 20th on the list of disaster-prone countries. Globally, Nepal ranks 4th, 11th, and 30th on vulnerability to climate change, earthquake, and flood hazard, respectively (Koirala 2014). The country experiences all recognized hazards, except tsunamis, and in recent years has encountered high-magnitude and high-intensity natural hazards such as floods, landslides, mudslides, earthquakes, fires, hailstones, windstorms, lightning strikes, cloudbursts, droughts, glacier lake outburst floods (GLOFs), avalanches, and epidemics, such as cholera, dysentery, dengue fever, and Japanese encephalitis (Aryal 2012; MoHA 2018; UNISDR 2015). Such high exposure to hazard risk accounts for the country's economic vulnerability and has resulted in mortality and morbidity and loss of property and physical infrastructure thereby disrupting economic development (MoHA 2018). Nepal is also exposed to other types of risks-political or economic for instanceresulting from its economic structure and exposure to international prices for some commodities and from its political history.

A number of factors form the backdrop to Nepal's high exposure and sensitivity to natural and human-induced hazards:

Challenging geographical environment. On the basis of topography, Nepal has three regionsmountain, hill, and Terai (Plain)-which account for 15 percent, 68 percent, and 17 percent of the proportion of landmass, respectively, and are exposed to different types of hazards depending on the terrain. The mountainous, rugged terrain comprising the sharp vertical landscapes of the Himalayas are associated with high risk of landslides, soil erosion, and debris flow. Variations in elevation produces flood risk, while marked climatic regions account for the spatial and temporal spread of risks, such as floods, droughts, and fires (Tombrink 2017). Given that Nepal is located on the boundary of the Tibetan and Indian plates means that the country is exposed to seismic activity and risk of earthquakes (Aryal 2007). 
Constrained human development. Although between 2003/2004 and 2010/2011 the percentage of people living below the poverty line in Nepal halved, there is significant churning in poverty with many people clustered around the poverty line and at risk of sliding back into poverty. Poverty severity is greater among specific ethnic and caste groups (especially Dalits) and is more prevalent in rural than urban areas and in the mountains compared to Terai areas-though there are many people living in poverty on the Terai because the population there is far greater. Nepal had a Human Development Index (HDI) of 0.458 in 2011 ranking it 157th out of 187 countries, second last after Afghanistan in the South Asian Association for Regional Cooperation (SAARC). The HDI, which measures the quality of life, varies significantly across Nepal. According to the Nepal Living Standards Survey, there is an association between caste and income, as well as the HDI. The Hill Chhetris have an HDI of 0.507 compared to 0.400 for the Madhesi Dalits. The per capita income of the Hill Brahman is estimated at 1.7 times higher than that of the Dalits in general and twice as high as that of the Madhesi Dalit (Central Bureau of Statistics 2010; UNFPA 2017). Variation in the HDI is a key predictor of vulnerability to hazards (Asian Disaster Reduction Centre 2000).

Changing population size and distribution. Nepal's population is at around 29 million in 2018. While 17 percent of the population was urban in 2011, the rate of urbanization has been rapid with the number of municipalities increasing from 58 to 217 between 2011 and 2015 and with 42 percent of the national population living in municipalities. This rapid urbanization has not been supported by sufficient capacity to provide safe housing nor water management systems, thereby exposing a large share of the population to significant physical risks. Along with urbanization, the proportion of people living in the mountain and hill regions compared to the Terai has been declining, dropping from 62 percent in the mountain and hill regions combined in 1971 to 50 percent in 2011 and projected to reach 47 percent by 2031 (UNFPA 2017). This mobility is likely to change the patterns of exposure to hazards (GoN 2010; UNFPA 2017) as "people gravitate towards areas with highpotential" (for livelihoods) (Aryal 2012, 149) and reduce exposure to drought but increase exposure to floods.

Political upheaval. In the last few decades, Nepal has been undergoing a transition from a unitary to a federal system of government. This transition, starting with the Maoist insurgency from 1996 that sought to replace the royal parliamentary system with a socialist republic, was characterized by political instability and a protracted civil war. Conflict resulted in more than 13,000 deaths, more than 200,000 people displaced at the height of the conflict, and destruction of public infrastructure (UNDP Nepal 2009). Following a peace agreement in 2006, the establishment of a democratic constitution in 2007 and 2015 and elections in 2017, the government has embarked on a decentralization program, including the transfer of some DRM responsibilities from the central to local governments. It is yet to be seen how far local governments have the sufficient DRM implementation capacity. The World Bank estimates that the transition will cost the government 3-4 percent of gross domestic product (GDP) over the next four years (World Bank 2018). Continued political tensions-manifested in protests and blockades-have had direct economic and social costs including magnifying the impact of covariate and idiosyncratic shocks mainly on the poor and vulnerable.

Precarious livelihoods. Nepal's people are heavily reliant on agriculture with the sector (including forestry and fishing) contributing nearly a third of GDP but providing livelihoods for more than twothirds of the population (USAID 2018). This dependence on agriculture, particularly for the rural 
poor, means that there is high exposure to climate-related hazards. Aryal (2012)-using DesInventar data pre-dating the 2015 earthquake-finds that there is a greater likelihood of disasters occurring in populated areas, particularly in areas with agricultural production. Whether or not an assessment of shocks in Nepal incorporates the rarer earthquake event, the structural shift in Nepal's economy in the last decade, toward a greater dependence on remittances from migration, somewhat mitigates the threat of climate-related hazards undermining agricultural and other livelihoods. However, economic activities that contribute to natural hazards are a persistent feature of Nepal's economy: deforestation, construction of roads, water leakage, and infrastructure failure are key factors that trigger floods and landslides. In addition, confined monsoon rainfall often translates to deleterious effects, affecting local and macroeconomic activity (Dahal 2012; Khanal, Shrestha, and Ghimire 2007).

Climate change. Nepal is rated as one of the most vulnerable countries in the world to climate change. Evidence shows that for 1975 to 2005 , the mean annual temperature increased by $0.06^{\circ} \mathrm{C}$ while the mean rainfall declined by $3.7 \mathrm{~mm}$ ( -3.2 percent) per month per decade (MoPE 2016). Mean annual temperature is predicted to increase between $1.3^{\circ} \mathrm{C}$ to $3.8^{\circ} \mathrm{C}$ by the $2060 \mathrm{~s}$ and $1.8^{\circ} \mathrm{C}$ to $5.8^{\circ} \mathrm{C}$ by the 2090s. While average annual precipitation could reduce by the range of 10 percent to 20 percent across the country, its distribution may become more pronounced such that seasonal flooding is intensified (MoPE 2016).

Exposure to price shocks and inflation. Together, the factors above also leave Nepal heavily dependent on imports such as food and fuel. In 2008, the total number of people at risk of hunger increased by 50 percent (from 6 million to over 9 million people) over a period of six months (WFP [2009] cited in UNICEF [2014]). These effects are buffered by remittances receipts in Nepal from international migrants but are still estimated to have a strong negative impact on vulnerable households. Food prices in Nepal are strongly influenced by those of India (Mishra, Poudel, and Mishra 2016) and subject to inflationary pressure when, as was the case in 2015, there are blockades or disruptions to supply. These have had a substantial impact on health and well-being (Budhathoki and Gelband 2016; Lamichane 2015).

Overall, the broad context through which hazards in Nepal translate into disasters is summed up well using the INFORM (Index for Risk Management) Risk Index (Error! Reference source not found.). The composite index assesses exposure, vulnerability, and coping in the face of a broad range of hazards. Relative to its neighbors, Nepal is rated as being at high risk (5.1 out of 10) although lower than some regional neighbors (India, 5.4; Bangladesh, 5.8) (INFORM 2018). Over a three-year period, the score for INFORM risk remained unchanged, but there are changes in the components of the index: hazard and exposure increased to rank Nepal at 42nd out of 191 countries; vulnerability has decreased over the last three years (Nepal ranks 67th); and no changes were observed for lack of coping capacity.

Disaggregating the index is insightful and shows how a combination of human development, economic, and environmental factors affect Nepal's risk profile. For example, Nepal ranks poorly for underweight children below 5 years (11th position), physical exposure to earthquakes (4th), and domestic food price level index (6th). On food price volatility, Nepal scored as 31st globally. More favorable risk indicators included agriculture stress (114th globally) and relative proportion of population affected by drought (77th). The vulnerability score was influenced predominantly by 
uprooted people (score of 5.2), vulnerable groups (4.6), inequality (4.3), and consequences of deprivation (4.1).

Table 2: Summary Risk Profile for Nepal

\begin{tabular}{|c|c|c|c|}
\hline & Value & Rank & Trend (3 years) \\
\hline INFORM Risk & 5.1 & 41 & $>$ \\
\hline Hazard \& Exposure & 5.4 & 42 & $\uparrow$ \\
\hline Vulnerability & 4.2 & 67 & $\downarrow$ \\
\hline Lack of Coping Capacity & 5.9 & 51 & $\Rightarrow$ \\
\hline
\end{tabular}

Source: INFORM 2018

\subsection{Exposure to shocks in Nepal}

This section presents data on natural hazards and epidemics in Nepal. DesInventar provides historic data on natural hazards (excluding drought). Figure 1 shows that fire has accounted for nearly a quarter of all reported shocks between 1971 and 2013 in Nepal. This is closely followed by floods, epidemics, and landslides. Historically, epidemics have contributed to the greatest number of reported deaths while floods have caused the greatest damage to housing. Floods have also, historically, resulted in the greatest number of people indirectly affected.

Figure 1: Historical data on selected natural disasters and epidemics in Nepal
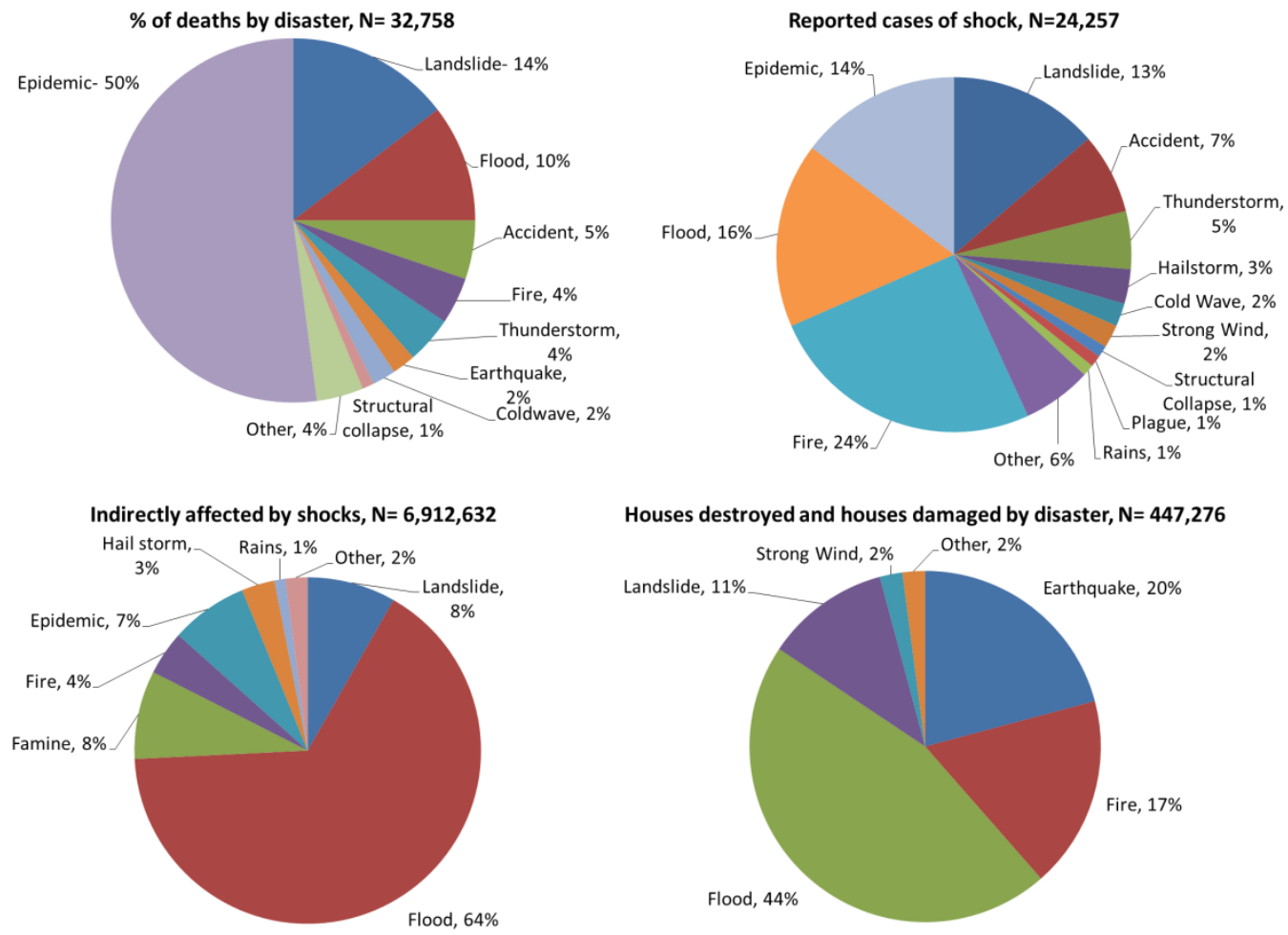

Source: DesInventar (2018) 
Figure 2: Geographical distribution of Shocks in HRVS sample districts

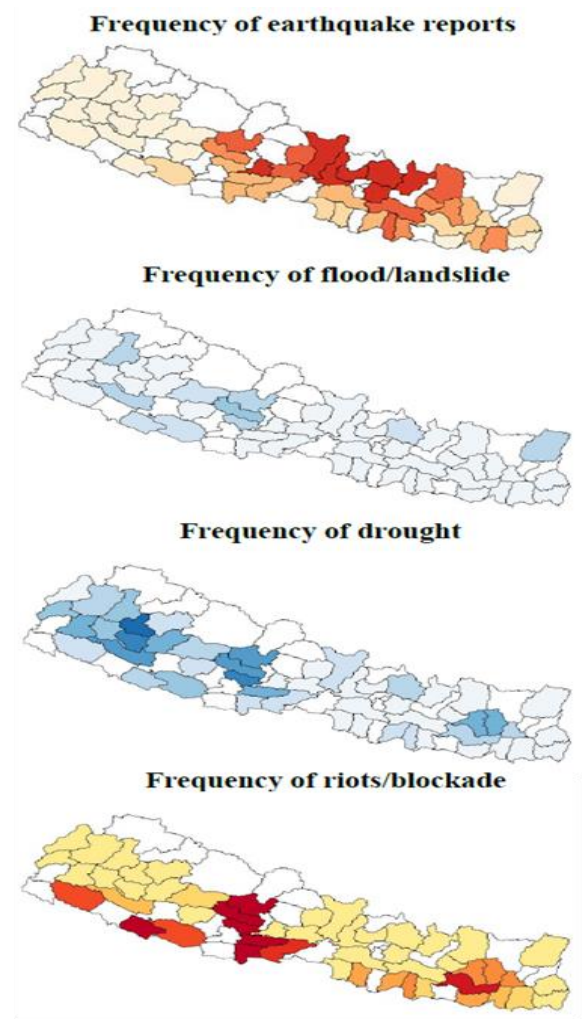

Source: Walker et al 2017. Note: Districts shaded in white were not cover by the HRVS sample.

According to INFORM (2018), Nepal ranks high on exposure to hazards, with both natural hazards (5.3 out of 10) and human-induced hazards (5.3). In particular, the level of exposure is the highest for earthquakes (9.9) and floods (6.5). While flood exposure is higher in the plains, drought exposure appears more universal and with less incidence (2.9). Storms and hailstorms are common in the hill region (INFORM 2018). Nepal has significant variations in the extent to which households are exposed to hazards, even within relatively small, bounded, and discrete geographical locations or socioeconomic settings.

Understanding which different locations and socioeconomic groups are exposed to these hazards and why they are of critical strategic importance, though there is absence of a robust vulnerability mapping and multihazard risk assessment in Nepal, undermines the effectiveness of DRM responses (Gautam 2017).

Geographical exposure. Hazard exposure and the frequency with which hazards are experienced vary geographically across Nepal. Figure 2 shows the recent geographical distribution of earthquakes, floods and landslides, droughts, and riots/blockades in Nepal. Following Dixit (1996), the relative level of hazard exposure by location is shown in Table 3. The mountain and hill regions are more exposed to landslide risk, while the Terai region is the most exposed in terms of flood risk. In the case of floods, the area inundated and the area used for paddy fields varies by river basin, with Bagmati, Narayani, and Rapti suffering the highest impact under different flood return periods (MoAC 2009). Earthquake exposure in 2015 was focused north of the Kathmandu valley, but all of Nepal is equally exposed in the long term.

Nepal's challenging geography, as described previously, is reflected in exposure to hazards. A key insight from the HRVS Wave 1 analysis is that spatial distributions of well-being, livelihoods, and remoteness matter most for the exposure to (and impact of) different types of shocks. Regression analysis demonstrates that specific households within geographic areas were more likely to report certain shocks because of the predominance of certain livelihoods in those places. Walker, Khadka, and Pandey (2017) note that households most commonly engaged in agriculture - that is, those in the middle three quintiles - reported agriculture-related shocks such as drought, flood, and livestock or harvest losses more frequently. For earthquakes, they found that the poorest quintile and those without their own farming operations were less likely to be affected by earthquakes-perhaps because they had less land and housing that could be damaged. For political and economic shocks, in this case riots and blockades, they found a smaller impact on those that owned farms and disproportionate exposure of the poorest quintile. This is consistent with the nature of livelihoods among that quintile: households were more likely to be landless wage laborers who were net consumers of food depending on the local economy to make a living. 
Table 3: Types and location of natural and human-induced hazards in Nepal

\begin{tabular}{|l|l|}
\hline Type of Hazard & Distribution \\
\hline Natural & All of Nepal is a high-hazard earthquake zone \\
\hline Earthquake & Terai (sheet flood), middle hills \\
\hline $\begin{array}{l}\text { Landslide and landslide } \\
\text { dam breaks }\end{array}$ & Hills and mountains \\
\hline Debris flow & $\begin{array}{l}\text { Hills and mountain, severe in areas of elevations greater than 1,700 m that are } \\
\text { covered by glacial deposits of previous ice age }\end{array}$ \\
\hline GLOF & $\begin{array}{l}\text { Origin at the tongue of glaciers in Higher Himalayas and higher mountains; flows } \\
\text { reach up to middle hill regions }\end{array}$ \\
\hline Avalanche & Higher Himalayas \\
\hline Fire (forest) & Hills and Terai (forest belt at the foot of southernmost hills) \\
\hline Drought & All over the country \\
\hline Storms/hailstorm & Hills \\
\hline Human-induced hazards & \multicolumn{2}{|l|}{} \\
\hline Epidemics & Terai and hills, also in lower parts of mountain region \\
\hline Fire (settlements) & Mostly in Terai, also in middle hill region \\
\hline Accidents & Urban areas, along road network \\
\hline Industrial/technological & Urban/industrial areas \\
\hline Social disruptions & Follows disaster-affected areas and politically disturbed areas \\
\hline Source: Dixit 1996 (with modifications)
\end{tabular}

Source: Dixit 1996 (with modifications).

Patterns for idiosyncratic shock (such as illness or the death of a household member) were influenced more by geography than by individual and household characteristics. Walker, Khadka, and Pandey (2017) suggest that the patterns for illness and injury were similar to those of drought and reflected the effects of geographical remoteness, especially in the western hill districts, on morbidity and mortality.

Population distribution. Geographical exposure is underpinned by population distributions and densities. As Aryal (2012) notes, while the greatest number of disaster events is recorded in the mountain/middle hills areas, by far, the greatest number of casualties (before the earthquake) were in the Terai areas. The absolute increase in population and mobility in favor of hazard-prone locations appears to have increased the total proportion of the population and assets exposed (ESCAP 2012). In Nepal, migration, including urbanization, to areas with better access to services and employment, is one of the key processes shaping population exposure to risk in Nepal.

In particular, the downhill migration to areas of known flood hazard risk, for example, from the middle hills to the lower land, and subsequent construction of houses on former river beds are a significant concern for DRM (GoN 2011; Jaquet et al. 2016; Massey, Axinn, and Ghimire 2010). This movement is likely to both shift and increase the proportion of the population exposed to hazards (GoN 2010; UNFPA 2017). 
Socioeconomic exposure. Gautam (2017) maps social vulnerability ${ }^{1}$ and exposure to disasters in Nepal and finds a quarter of all districts rate as either very high (6 districts) or high (18 districts) in terms of vulnerability to disasters. It is suggested that differences in regional HDI and the influence of who had access and control over productive resources play a significant role in determining who is affected by hazards.

Figure 3: Social vulnerability to natural hazards in Nepal

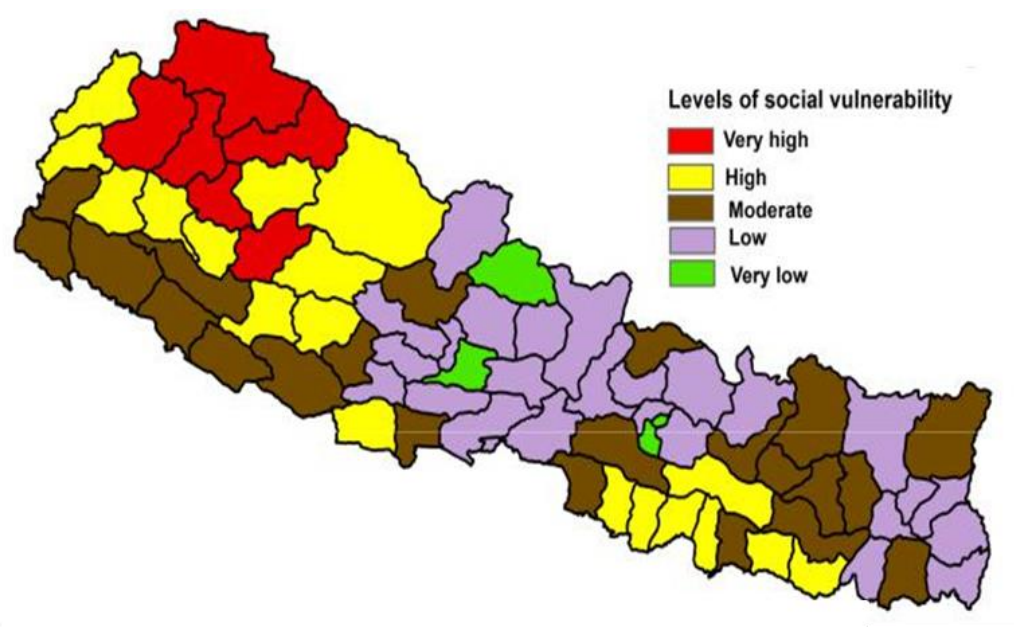

Source: Gautam 2017.

Drawing on the HRVS data, Walker, Khadka, and Pandey (2017) focus their analysis on the two proxies for well-being - 'welfare' which is based on an asset index and organized into quintiles and food insecurity (based on two measures). Measures of assets and food insecurity work in the same direction, with food insecurity found disproportionately among the poorest asset quintile. Exposure to shocks is shared across asset quintiles rather than being concentrated among the lower quintiles. Poorer households are actually marginally less likely to report most types of shocks-perhaps because people tend to report experiencing a shock only when it affects them and a key part of being affected is damage to or loss of assets. By definition, poorer households have fewer assets that can be damaged or lost. Using either measure of food insecurity shows that shock-affected households are more food insecure than those not affected by shocks. This tells us that either food insecurity leads to greater exposure or that exposure to shocks increases food insecurity or that there is an iterative interaction between the two. Analysis following the second wave will provide greater insights.

Gender is at the heart of social vulnerability. There is limited evidence to suggest that women are more exposed to shocks themselves, except where there are many more women than men because of labor migration from Nepal. Mann Whitney Wolcoxon rank-sum and Kruskal-Wallis tests drawing on the HRVS Wave 1 data find that specific individual and household characteristics make little difference to exposure to natural disasters and far more difference to exposure to health, political,

\footnotetext{
${ }^{1}$ Social vulnerability is an index-based approach with components including percentages of households without telephone service; population with cellular phone service; households without at least one means of information services (TV, internet, or radio); women; female-headed households with no shared responsibility; people with at least one disability; population under age 14 and over age 60; households with no toilet; house with no electricity; and population density, household size, and numbers of illiterate people (Gautam 2017).
} 
and economic shocks. For example, female-headed households are more likely than male-headed households to be exposed to the death of family members and unexpected higher prices, but less likely to be exposed to riots/blockades (Annex Table 1). This makes sense given that fewer women than men work away from the home and so are indirectly rather than directly exposed to riots and blockades by their knock-on effects (such as high prices).

Age also makes a difference to exposure: surprisingly, exposure to shock is not higher for households with young children (under 5) except for excessive higher prices ( 
Annex Table 2). We find households with an older head are more exposed to both fuel shortages and disease or injury of a household member-the latter being expected but the former being rather difficult to explain, except perhaps if we assume that older people are more dependent on petrol-powered transport than others who can travel more easily as pedestrians or cyclists (

Annex Table 3).

From the HRVS data, the relationship between caste/ethnicity and exposure to shocks was less clear. In the case of 2015, Adivasi/Janjati and Dalit households were more likely (compared to Brahmin/Chhetri households) to report experiencing an earthquake, but this is because the more severely earthquake-affected areas had a higher proportion of Janjati households and not because, across Nepal, Janjati households are more exposed. However, they were less likely to experience harvest failure, most likely because they tend to have less access to or ownership of agricultural land and depend more heavily on other sources of income to meet their consumption needs.

Risk exposure accentuated by climate change. Most hazards outlined in the hazard profile are directly influenced by climatic variables, primarily temperature and precipitation. While climate change impacts are economy-wide, specific sector concerns for Nepal include agriculture, hydroelectricity, forestry, and public health and water-induced disasters. For example, Lutz et al. (2016) estimate that in rivers of the Upper Ganges, the precipitation and glacier/snow melting by 2050 will increase and likely lead to more and larger floods. Changes in climate variables are associated with increased frequency of disasters including flash floods to which 1.9 million people are highly vulnerable and a further 10 million are exposed (MoPE 2016). Changes such as those linked to monsoons will expose more people to poverty and magnify inequality, with significant implications for vulnerability to a range of covariate and idiosyncratic shocks, unless sufficient response and adaptive capacity is built (Dixit 2017).

Nepal's high vulnerability to climate change risks is influenced by the high level of dependence by the economy and livelihoods on climate-sensitive economic activities and insufficient institutional, technological, and financial resources for adaptation and mitigation (MOPE 2016). Vulnerability to climate change effects is also influenced by both the nature (and complexity) of the topography and level of human development (MoE 2010). Nepal's National Adaptation Plan of Action (NAPA) identifies five categories of vulnerability to climate change (Table 4), with variations being attributed to differences in the level of sensitivity of economic sectors to climate stress and prevalence of disparity.

Table 4 Nepal districts ranked according to an overall climate change vulnerability index

\begin{tabular}{|l|l|}
\hline Vulnerability Ranking & Districts \\
\hline Very high (0.787-1.000) & $\begin{array}{l}\text { Kathmandu, Ramechhap, Uduyapur, Lamjung, Mugu, Bhaktapur, Dolakha, Saptari, } \\
\text { Jajarkot, }\end{array}$ \\
\hline High (0.601-0.786) & $\begin{array}{l}\text { Mahotari, Dhading, Taplejung, Siraha, Gorkha, Solukhumbu, Chitwan, Okhaldhunga, } \\
\text { Achham, Manang, Dolpa, Kalikot, Khotang, Dhanusha, Dailekh, Parsa, Salyan }\end{array}$ \\
\hline Moderate (0.356-0.600) & $\begin{array}{l}\text { Sankhuwasabha, Baglung, Sindhuli, Bhojpur, Jumla, Mustang, Rolpa, Bajahang, Rukum, } \\
\text { Rauhrat, Panchtar, Parbat, Dadeldhura, Sunsari, Doti, Tanahu, Makwanpur, Myadgi, } \\
\text { Humla, Bajura, Baitadi, Bara, Rasuwa, Nawalparasi, Sahlahi, Sindhupalchok, Darchula, } \\
\text { Kaski }\end{array}$ \\
\hline Low (0.181-0.355) & $\begin{array}{l}\text { Nawuot, Dhankuta, Kanchapur, Bardiya, Kapilbastu, Terhathum, Gulmi, Pyuthan, Surkhet, } \\
\text { Arghakanchi, Morang, Dang, Lalitpur, Kailali, Syanja, Kavrepalanchowk }\end{array}$ \\
\hline Very low (0.000-0.180) & Ilam, Jhapa, Banke, Palpa, Rupandehi \\
\hline
\end{tabular}




\subsection{Impacts of disasters}

Hazards become disasters when they have a negative impact on people and their livelihoods. The impact of shocks in Nepal is magnified by low coping capacity, with challenges noted in the INFORM index in the areas of governance, institutional, disaster risk reduction (DRR), and infrastructure (INFORM 2018). The high prevalence of poverty, churning around the poverty line, low per capita GDP, and other social deprivations imply that the incidence of a hazard translates rapidly to a disaster (WFP 2018). A review of disasters in Nepal shows that disasters have had a massive social, economic, and developmental impact. Three dissections of this impact are important and insightful here-by type of disaster, by social/demographic category, and by poverty status.

\subsubsection{Impacts of disasters by gender and social identity}

Gendered impacts of shocks prevail in Nepal as they do in other parts of the world, especially South Asia (Chew and Ramdas 2005). At a global level, Bradshaw and Fordham $(2013,3)$ note, that "Available data, though limited, indicates that women are more likely to die than men after a largescale disaster...It is inequities in the everyday, and not just in times of disaster, that create greater risk and reduce life chances for women and girls." There is also empirical evidence from many countries, which shows that it is often the secondary outcomes of disasters that women are disproportionately exposed to. Neumayer and Plumper $(2007,551)$ argue that "the differential impact of natural disasters [is explained] not merely by recourse to different physical exposures and biological or physiological gender differences, but also by the different socially constructed vulnerabilities that derive from the social roles men and women assume, voluntarily or involuntarily, as well as existing patterns of gender discrimination." Assessing differences in life expectancy, including in Nepal, Neumayer and Plumper $(2007,561)$ find that "disaster impact is contingent on the vulnerability of affected people, which can and often does systematically differ across economic class, ethnicity, gender, and other factor." Dhungel and Ojha (2012) concur for Nepal, noting that a range of factors "contribute to women's vulnerability to disaster in Nepal, including their livelihood activities and domestic work burden, gender discrimination that limits their opportunities to speak out, and social norms that restrict their access to outside agencies offering assistance." Standing, Parker, and Bista (2016) note the escalation in violence against women and girls (VAWG), trafficking, and other gender-based threats following the 2015 earthquake while the Inter-Cluster Gender Task Force (ICGTF 2015) notes the disproportionate number of women killed or injured at that time.

Knight and Sollom $(2012)$ and Knight and Welton-Mitchell $(2013,57)$ find that those identifying as lesbian, gay, bisexual, transgender, and intersexed (LGBTI) in Nepal risk "being perceived as lower priority for rescue efforts; families with same-sex partners being excluded from distribution of food and other basic supplies; and difficulty visiting injured partners and claiming the bodies of deceased loved ones." Alongside gender, and intertwined with it, is ethnicity, with Muldoon et al. (2017) finding that, in the case of the 2015 earthquake, membership of specific ethnic and gender groups affected experiences during the earthquake-especially in terms of increased post-traumatic stress symptoms.

\subsubsection{Impacts and types of natural disaster}

The 2015 earthquake resulted in 9,000 deaths and about US\$7 billion in damage (NPC 2015) and, according to the Nepal HRVS data, had the strongest effect on households with larger houses, which were more susceptible to physical damage, and farm owners, as opposed to those in the poorest 
quartiles (Walker, Khadka, and Pandey 2017). In comparison, Walker, Khadka, and Pandey (2017) also find that the blockade in 2015, which magnified the impact of the earthquake, disproportionately affected the poorest quartile but also affected other better-off households because of their higher consumption of fuel.

Over the 30-year period (1983-2013) water-induced disasters, primarily landslides and floods, resulted in losses worth US\$235.8 million, along with over 8,000 deaths and 228,561 houses destroyed (Gaire, Delgado, and Gonzalez 2015). The risk of such disasters is accentuated by Nepal's hydrology, in which 80 percent of the annual rainfall is received in less than three months (Gaire, Delgado, and Gonzalez 2015). Direct impacts are felt by farmers in general and communities living in the Terai region, which is relatively more exposed.

Drought-abnormally low or poorly distributed precipitation leading to water shortage-presents a major source of vulnerability, especially for those practicing rainfed agriculture in Nepal in the hill and mountain areas. Panthi et al. (2015) find that rural households in mountain zones exhibit greater vulnerability to drought due to their limited adaptive capacity. The impacts of drought are wide ranging. In 2008/09, the winter drought resulted in falls in the production of wheat (13.1 percent down) and barley (16.4 percent down) compared to the previous year. Nepal experienced a negative production balance of more than 100,000 MT leaving annual food price inflation at 17 percent, twothirds of affected rural households experiencing food shortages, and an additional caseload for the World Food Programme (WFP) of 707,000 people (Ministry of Agriculture and Cooperatives, World Food Programme, Food and Agriculture Organization of the United Nations 2009).

Fire/hail/lightning and harvest loss both disproportionately affected households engaged in agriculture, with the impact being higher for better-off households and those living in remote locations. The HRVS (Walker, Khadka, and Pandey 2017) also reports that farming practices, which can vary with ethnicity, may have had an influence on hazard impact.

Those working in agriculture with their own land are, by nature, more exposed to crop losses because of drought, flood, hailstorms, and so on. However, in some cases, dependence on agriculture has a mitigating function whereby households in remote rural areas and those with agricultural land have their own production to buffer themselves against some shocks. For example, the disruption to food supply and rising prices resulting from the blockades in 2015 had less impact on farming households. In contrast, poor households who are more likely to find their livelihoods in the labor market, either in urban or rural areas, were far more exposed to price inflation and supply disruptions.

\subsubsection{Impacts of natural disasters on poverty}

While there is a plethora of anecdotal evidence about the links between disasters and poverty in Nepal, rather less empirical evidence exists. The HRVS study (Walker, Khadka, and Pandey 2017) is one of few recent, country-wide studies of the relationship between shocks and wellbeing. They find a statistically significant difference in mean food insecurity for many of the shocks. For example, 19 percent of households that were not shock-affected in the poorest quintile were moderately or severely food insecure, compared to 36 percent of shock-affected households. They note "significantly higher rates of food insecurity among shock-affected poorer households, for flood/landslide, drought, riots/blockade, livestock loss and disease/injury" (p. 46). At the same time, 
they suggest that, in response to shocks, there is a strikingly higher propensity to reduce food intake among households in the lower quintiles. This points, in turn, to a deleterious impact on food security. These insights are useful but, as noted above, causation and therefore the extent to which shocks affect poverty-cannot be discerned from a single wave. Other assessments highlight strong relationships between the occurrence of natural disasters and poverty, but, again, the direction of causation is not always clear.

Joshi, Piya, and Kaharjan (2017) use panel data to show that the occurrence of natural disasters increased the risk of households moving into poverty in the Baitadi district of the far-western hills in Nepal. They find that a "significantly higher proportion of households $(29.2 \%)$ that suffered as a result of climate-related natural disasters (especially floods, landslides, and hailstorms) were chronically poor. The vast majority $(91.3 \%)$ of chronically poor households in the study areas were affected by climate-related natural disasters. The chronically poor households constituted only $5.9 \%$ of the total number of non-affected households. By contrast, a significantly higher proportion of non-poor households (50\%) were not affected by climate-related natural disasters, with non-poor households constituting only $25 \%$ of the total number of affected households" (p. 213).

Lee (2016) notes that both exposure to and impact of disasters in Nepal is strongly linked to poverty through 'poverty traps' whereby poor households were unable to relocate to safer places even when they knew they were living in a disaster-prone geographical area. The existing empirical literature also supports the notion of an intersection between poverty, ethnicity, and disasters, particularly because lower-caste households have fewer alternative sources of income through social networks that they can fall back on following a shock (Shrestha 2016; Wagle 2016). However, it is not just chronic or structural poverty that is influenced by disasters. Wagle (2016) examines poverty dynamics and their socioeconomic determinants between 1996 and 2011 in Nepal and finds that while chronic/structural poverty accounts for about 17 percent of the population, more than twothirds of people are subject to transient poverty. Thus, while disasters can contribute toward poverty traps, disasters appear to also be important in driving churning or transient poverty.

\subsection{Responding to natural disasters: managing and coping strategies}

How people manage or cope with the impact of disasters varies by the type of shock, by individual and household characteristics, and by the geographical/structural contexts (for example, the types of livelihoods that are feasible in a given area).

Drawing on the HRVS data, Walker, Khadka, and Pandey (2017) note strong differences between coping strategies following the 2015 earthquake compared with other shocks. High levels of external assistance following the earthquake meant that reductions in food and non-food consumption were less than for other shocks. There was also more support from neighbors and friends following the earthquake. Children's schooling was interrupted more frequently for earthquakes than other shocks-though this is more likely the result of damage to classrooms.

Some of the findings about coping strategies may also reflect household and individual characteristics. Across a range of shocks, richer households were less likely to cut spending or borrow, and the poorest quintile was more likely to receive government or nongovernmental organization (NGO) assistance. Sudmeier-Mieux et al. (2012) note stark differences in preparedness for and coping strategies following landslides in two villages in Dolakha district, one higher caste 
(Chhetri) than the other (Thami). In a similar way, Paudel and Ryu (2018) find that children in highcaste households have been able to mitigate the effects of the earthquake with no impact on their education in the long run, but infants from low-caste households destined to be 17.6 percent less likely to complete middle school. For girls, the negative impacts are greater than for boys.

The use of different coping strategies is also underpinned by existing structural constraintsespecially those related to geography and socioeconomic status. In terms of geography, for example, households in remote areas were less likely to draw on savings, most probably because they had less access to banking facilities compared to more accessible areas (Walker, Khadka, and Pandey 2017). Households in all parts of the Terai (that is, from far western to eastern) were more likely than those in the mountain regions to cut schooling, though it is not clear why. Structural constraints may be entrenched following disasters, making it harder for already disadvantaged households to recover than others. He et al. $(2018,68)$ find that in Gorkha district, following the 2015 earthquake, vulnerability of households accumulated over time: "The pre-earthquake disadvantages poorly prepare them for adapting to disasters and adversely militate their recovery...The immediate impacts of the earthquake including asset loss and damage, and livelihood interruptions deprived households of vital entitlements that could have been relied on for recovery...and temporary relocation raises challenges of people's health and permanent residence, which further exacerbates the vulnerability."

Drawing on evidence from respondents in earthquake-affected Dolakha district, Epstein et al. (2018) found that farming households made rapid changes to their livelihoods to survive in the year following the 2015 earthquakes: "The need for cash during the first year rose sharply. As farm land dedicated to food grains fell, some families drew on commercial crop sales and off-farm income and remittances, and others sought wage opportunities locally. Selling draught animals and other livestock was necessary for some households, in part for cash and in part in response to the reduction in planted area. Access to farm labour fell as priority was given to house reconstruction and relief efforts as government and donor aid came in; the labour that remained for agricultural work became expensive. With the increase of wage labour rates (by up to $50 \%$ ) for post-earthquake reconstruction, the poorest households reported increased wage earnings."

It is not entirely clear to what extent shocks in Nepal lead to long-term changes in livelihoodseither positive or negative-but Epstein et al. (2017) find potential for disasters to transform and change livelihoods in the long term. Drawing on the same evidence base from Dolakha, they suggest that the adoption of labor-saving cash crops as part of a postdisaster recovery is accelerating an ongoing transition toward more market-focused agricultural activities in subsistence communities in Nepal. In a similar vein, Sudmeier-Mieux et al. (2012) find that damage to livelihoods following landslides in Dolakha triggered labor migration decisions in households. 


\section{Chapter 3: Review of Social Protection Policies, Programs, and Systems in Nepal}

\subsection{Introduction}

This chapter explores the SP policies, systems, and programs in Nepal to assess where the most appropriate opportunities are for making SP more adaptive and flexible in the face of the shocks and disasters identified in the previous chapter, as well as a broader set of covariate shocks to which they might be exposed, such as political and global economic crises. It is complemented by a similar review of the DRM systems in Nepal. There are many reviews of SP in Nepal (Khadka 2017; Koehler 2014; Roelen and Chhetri 2016; Sijapati 2017; World Bank 2014); so, in this paper, we focus on capturing the current situation in Nepal, links to DRM, and the implications of the transition to a federal political system for SP policies and programs.

$\mathrm{SP}$ is generally viewed as comprising noncontributory social assistance and social security that is contributory, usually through taxation. In this report, when we refer to SP, we are focusing specifically on social assistance programs unless stated otherwise-especially those in Table. The report draws on lessons from both the RCIW and KEP. Although the RCIW has been devolved to the local level and the KEP has closed, both programs were operational at the time of research and thereby provide important lessons for ASP in the future, especially the Prime Minister's Employment Program.

Table 5: Selected SP programs in Nepal focusing on assistance

\begin{tabular}{|l|l|}
\hline SP & Details \\
\hline $\begin{array}{l}\text { Senior Citizens } \\
\text { Allowance }\end{array}$ & $\begin{array}{l}\text { Allowance for all Dalits and Karnali residents over the age of 60 and all others over } \\
\text { the age of 70 (NPR 1,000 per month for the allowance and NPR 1,000 per month } \\
\text { for old age medical treatment) }\end{array}$ \\
\hline $\begin{array}{l}\text { Allowance } \\
\text { Disability Allowance }\end{array}$ & $\begin{array}{l}\text { Allowance for single women } 60 \text { years or older and widows of any age (NPR 1,000 } \\
\text { per month). }\end{array}$ \\
\hline $\begin{array}{l}\text { Endangered Ethnicities } \\
\text { month if partially disabled }\end{array}$ & $\begin{array}{l}\text { Allowance for those that belong to one of 10 endangered ethnic groups (NPR 2,000 } \\
\text { per month). }\end{array}$ \\
\hline Child Protection Grant & $\begin{array}{l}\text { NPR 400 per month per child under 5 for up to } 2 \text { children per mother for all Dalit } \\
\text { families and all families in selected districts }\end{array}$ \\
\hline RCIW & $\begin{array}{l}\text { Self-targeted PWP for food security in selected food-insecure districts; mainly } \\
\text { unskilled and low skilled works in rural roads, micro projects, and livelihood } \\
\text { support programs }\end{array}$ \\
\hline KEP & $\begin{array}{l}\text { Employment guarantee scheme aimed at providing employment in all five districts } \\
\text { of Karnali plus Bajura; households without any employed member are eligible }\end{array}$ \\
\hline $\begin{array}{l}\text { Basic Level Education } \\
\text { Scholarships }\end{array}$ & $\begin{array}{l}\text { Basic education scholarships for girls identified as Dalit, disabled, or targeted } \\
\text { (marginalized) groups }\end{array}$ \\
\hline $\begin{array}{l}\text { Secondary Level } \\
\text { Education Scholarships }\end{array}$ & $\begin{array}{l}\text { Scholarships for Dalits, disabled, marginalized, conflict-affected, and other targeted } \\
\text { groups }\end{array}$ \\
\hline $\begin{array}{l}\text { Public Food Distribution } \\
\text { System (PFDS) }\end{array}$ & $\begin{array}{l}\text { Transportation subsidy on essential food (rice, lentils, and so on) by the Food } \\
\text { Corporation in 30 remote districts. }\end{array}$ \\
\hline $\begin{array}{l}\text { Mid-Day Meal Program } \\
\text { (Food for Education) }\end{array}$ & $\begin{array}{l}\text { Mid-day meals to children in preprimary and primary schools in 19 selected } \\
\text { districts }\end{array}$ \\
\hline
\end{tabular}




\begin{tabular}{|l|l|}
\hline SP & Details \\
\hline $\begin{array}{l}\text { Nutritional Supplement } \\
\text { for Pregnant Women } \\
\text { and Under Fives }\end{array}$ & $\begin{array}{l}\text { Iron and folic acid tablets to pregnant woman; Vitamin A capsules to children ages } \\
6-59 \text { months, and deworming tablets to children ages 12-59 months }\end{array}$ \\
\hline $\begin{array}{l}\text { Integrated Child Health } \\
\text { and Nutrition Program }\end{array}$ & $\begin{array}{l}\text { Fortified flour distribution - a nutritional supplement for all children ages 6-23 } \\
\text { months in 5 districts in Karnali and Solukhumbu }\end{array}$ \\
\hline $\begin{array}{l}\text { National Tuberculosis, } \\
\text { AIDS, and Sexually } \\
\text { Transmitted Infections } \\
\text { Control Program }\end{array}$ & Food supplement for tuberculosis and AIDS patients \\
\hline $\begin{array}{l}\text { Free Treatment for } \\
\text { Target Groups }\end{array}$ & $\begin{array}{l}\text { Free treatment for the poor, those under age 15, those over 75 and endangered } \\
\text { ethnicities for cancer, heart diseases, and dialysis }\end{array}$ \\
\hline
\end{tabular}

Source: Adapted from World Bank 2014.

The next section of the chapter places SP in its historical context and situates it in the current decentralization process. Subsequently, Nepal-specific programs are discussed with a focus on overlaps and gaps in coverage (in relation mainly to exposure to shocks) and strengths and weaknesses in implementation including payment systems. The impacts of SP are discussed in relation to the four pillars of Nepal's DRM framework-mitigation, preparedness, response, and recovery. The next section places what is known about SP programs in Nepal in the context of the decentralization processes and assesses findings, particularly from fieldwork in Bardiya, Humla, and Saptari, about the implementation of SP under a decentralized system. Three major challenges are identified regarding (a) oversight, (b) financial flows and fiduciary risks, and (c) capacity and administrative arrangements at the local government level. The conclusions identify key priorities for strengthening existing SP so that it can reach its potential in supporting DRM in Nepal.

\subsection{The emergence of SP}

The evolution of Nepal's SP system has been described in detail in various places (for example, see GoN 2012a; Khadka 2017; Koehler 2014; Sijapati 2017). Understanding by what pathways and mechanisms SP might contribute to DRM requires, in turn, a solid understanding of what drives decisions to invest in and support SP and of DRM at different moments in time. As Jones $(2012,240)$ has noted "understanding the conditions under, and the process by which such perceived political advantages emerge and are acted on is of central importance for understanding the trajectory of social policy as part of social and economic development." The high coverage of the RCIW in the years immediately following the Peace Accord, in part driven by renewed willingness by international agencies to fund programs, provides a case in point (Table 6). The growth of social transfer programs in Nepal has been rapid by low-income country (LIC) standards (see for example Figure 4 for the growth of SSAs). This growth was driven because SP emerged at a particularly pivotal moment in Nepal's recent history: a new political settlement saw a restructuring of power relations in Nepal that brought in groups previously excluded on the basis of caste/ethnicity and geography. There are a number of key insights from this process.

First, the emergence of the current suite of programs in Nepal has been largely a result of the nature of the political settlement in Nepal and the establishment of a clientelist system of politics after 2013, which saw frequent switches in power between various political parties and coalitions (Drucza 2016; Schjødt 2017). Decisions about SP were generally made at the central level by a small number of actors and reflected coalition negotiations at specific moments in time. For example, the process of establishing the under-five child grant took place following the resignation of the Maoist Prime 
Minister, and notable elements-for example, making it universal for Dalit households-reflected compromises between coalition partners (Jones 2012, 247). The importance of elections is also noted: "evidently, SP initiatives in Nepal are influenced more by populism and less by concrete evidence or fiscal calculations" (Sijapati 2017, 32). While the nature of this evolution has resulted in substantial programs providing genuine support to vulnerable individuals, it has also led to a fragmented system.

Figure 4: Growth in the number of SSA Beneficiaries - 1998-2016

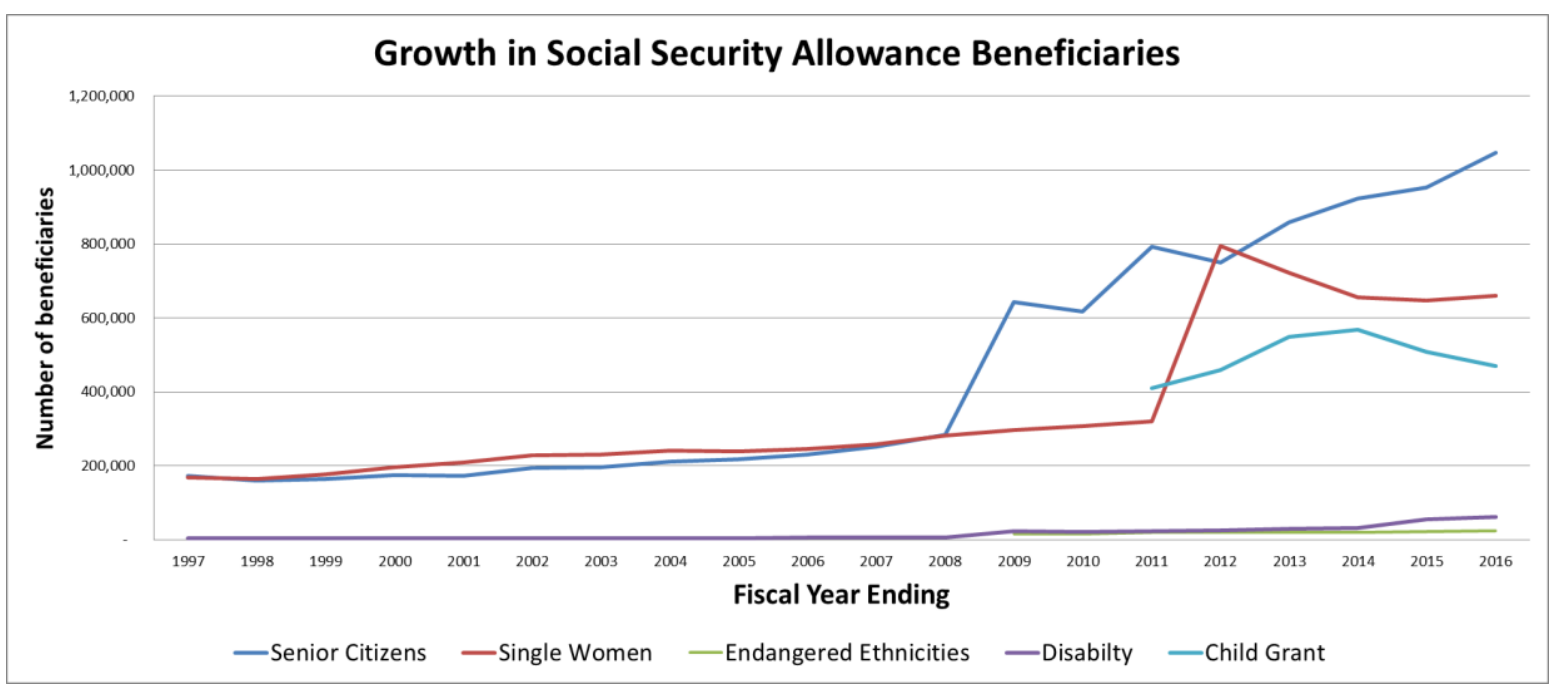

Source: Administrative data from Department of Civil Registration

Table 6: Participant numbers for selected PWPs 2006/07 to 2016/17

\begin{tabular}{|c|c|c|c|c|c|c|c|c|c|c|c|}
\hline \multirow[b]{2}{*}{ Program } & \multicolumn{11}{|c|}{ Financial Year } \\
\hline & 06/07 & 07/08 & 08/09 & $09 / 10$ & $10 / 11$ & $11 / 12$ & $12 / 13$ & $13 / 14$ & $14 / 15$ & $15 / 16$ & $16 / 17$ \\
\hline RCIW & 265,000 & 265,000 & 265,000 & 265,000 & 159,000 & 169,000 & 132,500 & 145,750 & 166,950 & 166,950 & 136,210 \\
\hline KEP & 60,539 & 67,999 & 71,005 & 75,304 & 73,848 & 73,413 & 61,058 & 66,615 & 40,844 & 16,206 & 19,170 \\
\hline TOTAL & 325,539 & 332,999 & 336,005 & 340,304 & 232,848 & 242,413 & 194,008 & 212,365 & 207,794 & 183,156 & 157,244 \\
\hline
\end{tabular}

Source: Administrative data from Ministry of Federal Affairs and General Administration

Second, as a result of shifting coalitions among political parties, the process of program development has been rather disjointed with different ministries, drawing on support from different international development agencies, each with different objectives being established at different moments. Although there was a "shared interest to improve the country's socioeconomic conditions after the end of the civil conflict" (Rabi et al. 2015, 8), the SP sector in Nepal is crowded with multiple interpretations of 'vulnerability' (Sijapati 2017) that underpin different programs.

Third, as is common in post-conflict countries (UNDP/UNCDF 2014), substantial emphasis has been placed on the role of SP in contributing to state building-particularly by enhancing the visibility and output legitimacy of the state (Holmes and Upadhya 2009; KC et al. 2014; Slater and Mallett 2017; Upreti et al. 2012). Yet, notwithstanding the importance of the political settlement that underpinned investments in SP in the 2000s, Nepal's programs are not viewed as particularly transformative in nature - that is, many of Nepal's programs do not explicitly and overtly do much to tackle underlying 
structural poverty and power relations. Rather they provide a signal of the presence of the state and its respect for particular groups, especially senior citizens. In this vein, Jones $(2012,245)$ notes that the "expansion of public spending using the existing state machinery has proved a more immediately feasible strategy for providing tangible benefits to voters than long-term structural reform in the economy or political system." Similarly, Sijapati (2017, 31), referring to Upreti et al. (2012), notes the "political positioning of SP as a panacea" and the lack of alignment between (a) the framing of SP as an instrumental tool with multiple applications and objectives from public food provision through basic social services to overcoming social exclusion and other forms of inequalities and (b) the limited evidence of impact in these areas.

Overall, "the current set of SSA programmes represents the outcome of a set of separate budgetary initiatives, the precise characteristics of which have depended on the political context of the time of adoption, but all of which have been subsequently retained and extended. The approach that has been followed to date has been to introduce instruments on an initially limited basis in terms of the numbers of beneficiaries who are eligible, and then progressively to extend this depending on the budgetary context and other priorities" (Jones 2012, 246). This goes some way toward explaining the challenges that have faced all partners in establishing a National Social Protection Framework to bind the system together "The Government has recognized the importance of consolidating some of these disparate programs, but this recognition is yet to translate into concrete policy commitments or actions" (World Bank 2016a, 2).

\subsection{SP - policies and legislative framework}

The policies and legislative framework for SP are discussed in some length (see for example, Khadka 2017; Koehler 2011; Roelen and Chhetri 2016; Sijapati 2017; World Bank 2014; and others). Building on the interim constitution of 2007, the 2015 Constitution provides the foundation for SP in Nepal, particularly article 43 "Senior citizens, single women, people with disabilities, children and citizens of endangered ethnicity in an economically poor, incapacitated or helpless state have the right to social security, as provided in the law' (Khadka 2017, 3).

Provision for senior citizens is found in the Social Security and Protection of Senior Citizens Act while other cash transfers are delivered under the Social Security Program Guidelines 2075 (GoN 2018). The absence of an act of parliament covering the SSAs until recently, ${ }^{2}$ PWPs, and other forms of social assistance together has a number of implications: first, it held back the translation of the constitutional commitments to SP into an overarching strategic plan; second, by extension that this allows continued fragmentation-especially of management information systems (MIS) and coverage; and finally, that the tasks associated with delivering SP are not statutory, with implications for the funding, allocation, and prioritization of tasks at the local government level that is discussed in more detail in the following paragraphs.

More recently Carraro and Lakhey (2018) have described the overarching policy framework following the shift to a federal political system and accompanying decentralization of roles and mandates. They suggest that some clarity is found in the 2017 Local Government Operation Act (LGOA 2074) regarding mandates and roles ascribed to different levels of government. So, while

\footnotetext{
${ }^{2}$ The GoN has approved the Social Security Act 2075, which provides a legal basis for the cash transfers.
} 
responsibility for some of the specific tasks associated with delivering the SSAs are clear, there remain gaps, notably that there is far less clarity on responsibilities for public works and that the overall policy framework for SP remains opaque. Whether or not this presents a problem for SP is debatable, but the challenges of making SP more adaptive are certainly constrained by the lack of a framework to allow clear interlinks with shock and DRM to become a policy reality.

Notwithstanding the clarity provided in the LGOA, however, Carraro and Lakhey (2018) also note that SSA guidelines need to be further developed not only to recognize the new operational environment under devolution, but also to address some of the current limitations-as of February 2018 , the emerging guidelines were being finalized.

\subsection{SP programs}

\subsubsection{Key program information}

The elements of SP that we are interested in this work-notably noncontributory transfers including through PWPs-occupy one of four pillars of social security identified by the International Labour Organization (ILO) (Khadka 2017). The full SP portfolio cost, including social security, was estimated to be around 3.20 percent of GDP in 2015/2016 with a budget in 2017/2018 of 3.58 percent of GDP, though about two-thirds of this was on public sector pensions (World Bank estimates). Social assistance (predominantly cash transfer) programs amounted to just over 1 percent of GDP in 2015/2016, with an estimated increase in 2017/2018 to 1.38 percent of projected GDP (World Bank estimates).

The circumstances of SP's emergence and evolution highlighted previously have resulted in a large number of largely fragmented SP programs. A selection of these is provided in Table, showing the target beneficiaries and benefits received. The programs span cash and in-kind transfers (with many of the latter underpinned by health and nutrition objectives), plus subsidies and stipends, especially to support education. At the outset of this project, the focus was on the two PWPs, KEP and RCIW, and on the SSAs comprising support for senior citizens, widows/single women, people with disability, endangered ethnicities, and households with children under five years that are either in Karnali region or are Dalit. Following fieldwork in Humla, the PFDS was also assessed because it was cited as a critical source of support during drought.

The five SSA programs (senior citizens, single women, disability, children under five, and endangered ethnicities) are based on tackling lifecycle or idiosyncratic risks, and so, coverage is primarily on demographic and household criteria. There are exceptions to this, for example, that the under-five child grant is, in most districts, targeted at Dalit households but in the districts of Karnali is universal. In the case of the old age allowances, eligibility begins at 70 for most, but for Dalits and people in Karnali, eligibility starts at 60 years.

For the two main PWPs (RCIW and KEP), targeting was first by district, selecting those districts with the lowest HDI. Households were then selected in specific village development committees (VDCs) (and from 2018 in rural municipalities and wards) using measurements of household food gaps and levels/types of employment. The geographical allocation of food stocks for the PFDS draws on data supplied by the District Administration Office (DAO) and NGOs/International Nongovernmental Organizations (INGOs) and takes into account the geographical remoteness of districts and whether they are risk prone. This information is subsequently used to calculate the amount of food stock 
directed to each location. Beneficiary districts are chosen on an annual basis by the Executive Board comprising representatives from the Ministry of Home Affairs (MoHA), Ministry of Commerce, Trade and Supplies (MoCTS), Ministry of Finance (MoF), and Ministry of Agriculture and Livestock Development (MoALD).

Table 7: Eligibility and targeting of main social transfer programs

\begin{tabular}{|c|c|c|c|c|}
\hline & Targeting & Geographic & Household & Individual \\
\hline & Old age allowance & $\begin{array}{l}60 \text { and above for districts } \\
\text { in Karnali }\end{array}$ & & $\begin{array}{l}70 \text { and above } \\
60 \text { and above for Dalits }\end{array}$ \\
\hline & $\begin{array}{l}\text { Single women's } \\
\text { allowance }\end{array}$ & & & $\begin{array}{l}\text { Widowed women of } \\
\text { any age and widowers } \\
60 \text { years or over }\end{array}$ \\
\hline & Disability & & & $\begin{array}{l}\text { Individuals with } \\
\text { disability classified } \\
\text { according to severity }\end{array}$ \\
\hline & $\begin{array}{l}\text { Endangered } \\
\text { ethnicities }\end{array}$ & & $\begin{array}{l}\text { Specific ethnic/caste } \\
\text { groups }\end{array}$ & \\
\hline $\begin{array}{l}\frac{\varepsilon}{\frac{1}{0}} \\
\frac{0}{0} \\
\frac{0}{2}\end{array}$ & $\begin{array}{l}\text { Under-five child } \\
\text { grant }\end{array}$ & $\begin{array}{l}\text { All households with } \\
\text { children under five in } \\
\text { Karnali districts (Dolpa, } \\
\text { Humla, Jajarkot, Jumla, } \\
\text { Kalikot, and Mugu). In } \\
2017 \text {, it was expanded to } 3 \\
\text { additional districts- } \\
\text { Achham, Bajhang, and } \\
\text { Rautahat. It is expected to } \\
\text { be expanded to } 6 \text { new } \\
\text { districts in } 2018 / 2019 \text {. }\end{array}$ & $\begin{array}{l}\text { Dalit households (up } \\
\text { to two children per } \\
\text { household) }\end{array}$ & $\begin{array}{l}\text { Under five years old and } \\
\text { Dalit }\end{array}$ \\
\hline & $\mathrm{RCIW}$ & $\begin{array}{l}\text { Selected districts based on } \\
\text { food insecurity }\end{array}$ & & \\
\hline & KEP & $\begin{array}{l}\text { All ViDCs in Dolpa, Humla, } \\
\text { Jumla, Kalikot, and Mugu } \\
\text { districts }\end{array}$ & $\begin{array}{l}\text { Household with no } \\
\text { employed or self- } \\
\text { employed member }\end{array}$ & \\
\hline & PFDS & 100 depots in 36 districts & $\begin{array}{l}\text { Self-targeted (with } \\
\text { different grades of } \\
\text { rice available) }\end{array}$ & \\
\hline
\end{tabular}

\subsubsection{Gaps and overlaps in programs}

Given the haphazard evolution of SP, the fragmented policy framework, and the numerous objectives that various programs have, we draw on Sijapati's (2017) differentiation of types of vulnerability to assess gaps in SP programs in Nepal (Box 2). The main focus of Nepal's programs is on lifecycle vulnerabilities with the biggest programs in terms of coverage (senior citizens, widows/single women, and the child grant) defining eligibility largely in terms of demographic criteria. On paper, the current suite of SP programs go some way to addressing historical and structural exclusion, with geographical targeting and eligibility defined by ethnicity/caste and gender being common across programs (see Table 7). For example, both KEP and RCIW explicitly target districts where food security and other HDIs are at their worst. 
Assessments of SP in Nepal find limited impacts on historical and structural exclusion (see for example, Koehler 2014), with three main explanations. First, SP (at current coverage and transfer levels) is tackling symptoms rather than causes of historical and structural exclusion, and it will take complementary programming and substantial social change to achieve anything really transformational. Second, previous assessments have found that a lack of results or impacts on levels of inequality between ethnic groups or genders can also be attributed, in part, to the low levels of transfers made to households, although there have been substantial increases in payments to senior citizens in particular. Koehler (2014), for example, argues that social assistance programs are populist rather than offering meaningful change for households facing structural inequality; the low transfer amount of the social assistance programs allows them to serve as "placebos to the people in lieu of genuine support and structural socioeconomic transformation." Third, as was noted in particular in Bardiya during fieldwork and as described more widely in Holmes et al. (2018), some of the most vulnerable among excluded groups struggle to access SP even if they are eligible-they either do not have the required documents (such as proof of citizenship, marriage, birth, or age) or the knowledge, mobility, and social networks to navigate the application process, or programs such as public works are oversubscribed and they are turned away.

In terms of political violence/unsettled political environment, there is some programming that seeks to address the legacies of violent conflict (for example, cash transfers to the families of those killed, injured, disappeared, and displaced due to conflict, operated by the Ministry of Peace and Reconstruction). Further, given the origins of the conflict in grievances about historical and structural exclusion, existing programs that target, for example, Dalit groups and endangered ethnicities and specific geographical areas go some way to seek to address this type of vulnerability.

\section{Box 2: Types of Vulnerability in Nepal}

Sijapati (2017) identifies five types of vulnerabilities* often associated with households in Nepal.

- Income poverty. Despite a drastic decline in poverty rates from 42 percent in 1995-1996 to 25 percent in 2010-2011, evidence suggests that a substantial share of households in Nepal are near-poor. The prevalence of shocks in Nepal leaves many of them vulnerable to sliding back into poverty. For example, during the food price crisis of 2008 , it is estimated that as much as 30 percent of Nepal's population was experiencing hunger-an increase of 2 million over 2005.

- Historical and structural exclusion based on caste, ethnicity, gender, and geography constitute another form of vulnerability. These horizontal inequalities result in spatial patterns of well-being and poverty. People from indigenous communities, Dalits, and minority religious groups are overrepresented among the chronically poor, as are women who face restrictions to access to education and livelihood opportunities and the near constant threat of gender-based violence.

- Lifecycle vulnerabilities. Nepal faces the twin pressures of both a growing size of elderly people alongside a very young population overall. UNICEF (2010) reports that child malnutrition affects 45 percent of children under 5 years of age in Nepal while the Global Age Watch Index 2013 ranks Nepal 77th out of 91 countries in terms of quality of life and well-being of older people (HelpAge International 2013).

- Political violence and an unsettled constitutional and political environment. Although the decade-long civil war formally ended in 2006, violence remains prevalent in many parts of the country.

- Environmental degradation and recurrent natural disasters are enduring (and perhaps worsening) features of Nepal that have not only led to socioeconomic insecurity but also increased the vulnerability of people, especially those from marginalized sections of the population as described previously.

Source: Adapted from Sijapati $(2017,19-20)$

Note: * The basis for Sijapati's typology of vulnerabilities is SP, rather than risks and disasters according to Chapter 2. 
Overall, the programs that cover income poverty and natural disasters have far less coverage and are mainly small programs of NGOs. The limited focus on poverty, particularly in cash transfer programs, is borne out by World Bank (2013a) (see Figure 5) and confirmed by more recent HRVS data (Walker, Khadka, and Pandey 2017). Unemployment is not covered, except for provision in contributory social security, and announcements in the Government budget speech in July 2012 that KEP becoming an employment guarantee program following the Indian example have not been realized and it has been phased out. Public works beneficiaries continue to make up only a small share of those receiving cash transfers. This raises a critical question for this project about whether a more adaptive SP system in Nepal can be achieved through existing programs or whether a new (and perhaps radically different) set of programs or framework is required.

Figure 5: Beneficiaries of selected SP/social security programs across wealth quintiles

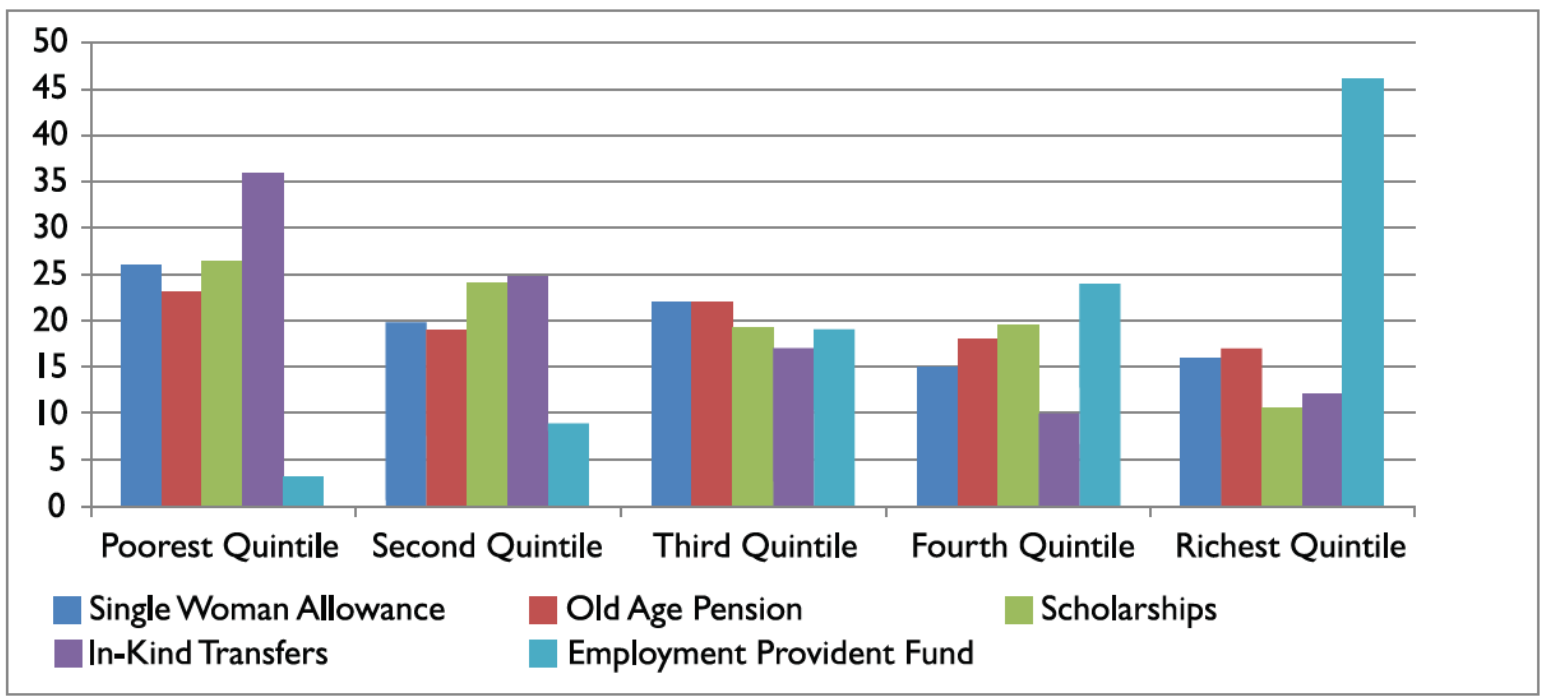

Source: World Bank 2013a cited in Sijapati 2017.

Note: 'In-kind' transfers refer to non-cash transfers, particularly food.

\subsubsection{Strengths and weaknesses in general implementation features}

Schjødt $(2017,24)$ is positive about implementation: “Nepal's SP programmes are overall performing relatively well on these three parameters [right amount of money, to the right people, at the right time], especially when considering the limited capacity of the state and the challenging geography of the country." However, interviews with beneficiaries in Bardiya, Humla and Saptari regarding their experiences of SP suggest there are many challenges to be overcome and improvements to be made-particularly in areas that will influence the potential for SP to be more adaptive and play a greater role in supporting disaster mitigation, preparedness, response, and recovery.

\section{Registration and enrolment}

The different SP programs explored have very different operating systems and so the challenges with registration and enrolment are varied. For the PFDS, people seeking to purchase subsidized rice and other basic goods have to show citizenship documents to prove that they are resident in the locality and are issued a ration card. There are no limits on registration/enrolment. Interviews with the National Food Corporation (NFC) stated that stocks are enough to cover the following proportions of populations in the respective areas: 85 percent-90 percent of people in remote locations (mountains), 50 percent in middle hills, and 35 percent in Kathmandu. The Terai does not 
have selling centers as they produce their own supply and are suppliers of NFC food stocks. In contrast there are limits on the number of beneficiaries in the RCIW and KEP which are calculated nationally. These programs are regularly oversubscribed, and, at municipality/rural municipality level and ward level, officials have to develop further eligibility criteria beyond those in the guidelines to further reduce the number participating to keep payments in line with budgets. This can include making any individual or household in receipt of the SSAs ineligible for the RCIW/KEP.

Carraro and Lakhey $(2018$, vi) highlight some of the challenges associated with registering and enrolling onto the SSA programs: "There are significant differences in the level of service provided across the visited local governments and wards. For example, in one local government, registration is still occurring once a year, and in another in limited periods every four months: for the child grant the implication is that people are forced to visit twice the ward offices, first to register the birth and then again to apply for the child grant. In Rautahat, while paper registration of children under five is taking place, there is a very significant delay in the digitalization of such records and no payments have yet been made in this fiscal year."

Substantial investments are underway in SSA registration systems and improvements to the processes of enrolment (for example the 'Strengthening Systems for SP and Civil Registration Project' (World Bank 2016a). As the World Bank notes (2016a, 3) "The manual and decentralized record keeping of beneficiary information is a major hurdle for addressing issues of duplication, under-coverage, and weak oversight facing the administration of the SSA program...weak administrative systems [have] given rise to a host of problems, both real and perceived, including lingering suspicions of duplication, alleged leakage of funds, and delayed benefit payments." At the local government level in Bardiya, Humla, and Saptari, there was, however, limited evidence of progress with the shift from manual to digital SSA beneficiary lists-perhaps because the new systems were overlapping with the transition from district to local government administered registration and enrolment. The lack of evidence found at local level is confirmed by Carraro and Lakhey $(2018,11)$ who found that in Godawri (Lalitpur) and Rautahat "Local Governments have not yet entered the details of SSA beneficiaries."

New Era (2016) identified substantial under-coverage of eligible SSAs due to administrative and procedural delays, especially in relation to registration processes. Hagen-Zanker, Mallett, and Ghimire (2015) note the substantial challenges-in terms of time and cost-associated with accessing the child grant in practice that result from geographical and bureaucratic barriers. In 2018, our respondents did report improvements in the time it took to receive the first payment, but the challenges getting registered-especially for people with disabilities-remained protracted. The transition to the local government appeared to be improving access to the program: Although the evidence is anecdotal it does suggest that the devolution of some responsibilities to the local level may allow improvements to the efficacy of SSA systems. Lack of citizenship documents were cited as a significant barrier to accessing SP programs (and support during disaster), especially in Bardiya.

For PWPs, registration and enrolment took place at the ward level, with local government staff responsible for ranking households and registering lists of beneficiaries/workers. Compared to SSAs, there appeared to be few challenges associated with the administrative processes of registration and enrolment for PWPs. For PWPs the fundamental challenges were associated with targeting and selecting beneficiaries. While there were nationally established criteria for enrolment in the RCIW 
and KEP, the criteria as defined led to a far longer participant list than resources allowed, so further targeting criteria were introduced at the local level to rank participants and provide a mechanism aligning the number of beneficiaries with the resources available.

\section{Adequacy, funding, and payment systems}

Using panel data from Bardiya, Rolpa and llam, Sturge et al. (2017) found that less than one in five recipients of SP felt that it made a difference to their quality of life because of the low transfer level. Similarly, two evaluations of the child grant find that the levels of support provided are not adequate to have a meaningful impact on child poverty (Adhikari et al. 2014; Hagen-Zanker, Mallett, and Ghimire 2015). World Bank (2014), in analysis focusing largely on the SSAs and before the subsequent increases in benefit amounts, finds only limited impact on poverty of the existing cash transfer programs and puts this down to the low levels of transfers and categorical targeting. At the local level our limited fieldwork generated similar findings-few respondents felt that the benefits at their current levels (Table 8) made a substantial difference to their wellbeing. Using the most recent poverty line data (NPR 19,261 per capita in 2011), the old age, endangered ethnicities, and red card disability allowances would lift individual beneficiaries above the line. Single women's, blue card disability, and under-five allowances would equate to approximately two-thirds, one-third, and onequarter of the individual poverty line. It is important to note that while allowances are meant for individuals, they are, de facto, often used to meet the needs of the whole households, especially in the case of the single women's allowance.

Table 8: Benefit levels of selected SP programs, FY2017-2018

\begin{tabular}{|c|c|}
\hline Program & Benefit Level \\
\hline Old age allowance & $\begin{array}{l}\text { NPR 2,000 per month (including additional support to seek medical } \\
\text { treatment) }\end{array}$ \\
\hline Single women's allowance & NPR 1,000 per month \\
\hline Disability & $\begin{array}{l}\text { NPR 2,000 per month (severely disabled) or NPR } 600 \text { per month (partially } \\
\text { disabled) }\end{array}$ \\
\hline Endangered ethnicities & NPR 2,000 per month \\
\hline Under-five child grant & NPR 400 per month per child (up to a maximum of 2 children) \\
\hline RCIW & NPR 450 per day up to 15 days \\
\hline KEP & $\begin{array}{l}\text { NPR } 450 \text { per day up to } 35 \text { days (equivalent to approx. NPR } 1,300 \text { per } \\
\text { month if all days completed) }\end{array}$ \\
\hline PFDS & $4 \mathrm{~kg}$ of subsidized rice per household member per month \\
\hline \multicolumn{2}{|c|}{$\begin{array}{l}\text { The allowances did prove adequate to produce other effects on intra-household and } \\
\text { intergenerational relations. Respondents receiving SSAs did report that receiving support had } \\
\text { changed their situation in their households, particularly their relationships with other members. This } \\
\text { was found to be particularly important during times of disasters when households are under greater } \\
\text { stress and intra-household conflict and domestic violence is amplified. At these times, the income } \\
\text { from SSAs made recipients part of the solution rather than part of the problem as households sought } \\
\text { to meet their basic consumption needs. }\end{array}$} \\
\hline
\end{tabular}

Adequacy is also undermined by implementation problems. The VDCs assessed as part of a Public Expenditure Tracking Survey (PETS) reported that the funds received were inadequate to cover all eligible SSA households (New Era 2016). They found that 7 percent of SSA beneficiaries were found 
to be underpaid, each receiving, on average, 3.6 percent less than they ought to. Delays in the registration and enrolment process were a driver of the underpayments.

In Humla, wage rates for public works had increased from NPR 450 to NPR 750 per day and were viewed positively by beneficiaries. Despite significant cuts faced by the program in FY2017-2018, there was no lowering of the wage rate back to the NPR 450 rate. To avoid diluting the benefits for individual households by lowering wage rates, the total number of participants was reduced. In particular, in one ward in Simkot rural municipality, those receiving SSAs in the household were deemed ineligible for the KEP to maintain the adequacy of payments made in the KEP. For those receiving disability or old age allowances the exclusion was not as serious as for those who had been receiving the child grant.

In terms of adequacy for the broader developmental objectives of the program, officials commented that the single wage rate made it difficult to attract beneficiaries with skills who could create assets that would make a meaningful difference to people's lives in the local area. They sought to use the KEP in a more developmental way-for example, by attracting more skilled workers who could mentor apprentices. It was also noted that public works (both the RCIW and KEP), for the majority of their years of operation, were so focused on rural road construction that they were missing opportunities to build other assets that might have a stronger impact on people's wellbeing, food security, and future livelihoods. (The RCIW did, around 5 years ago, expand to agriculture and livelihoods activities, but there was no mention of this during fieldwork).

The adequacy of any cash transfer program in remote areas was underpinned by the operation of the PFDS. Markets that allow poor and vulnerable people to purchase food at a reasonable price are an essential feature of the underlying architecture for cash transfer programs to work effectively. In Nepal, there are mechanisms for increasing stocks held at food depots and for adjusting the price, which in turn ensures that those receiving cash transfers have somewhere to buy food when the private sector market does not deliver at a reasonable price. The process of adjusting stocks and prices was rather too slow to adjust to rapid onset shocks, although food depot stocks were released during the 2015 earthquakes for general distribution rather than sale but was useful for slow onset disasters such as drought. In the latter circumstances, there is time to adjust stocks and pricing to ensure the adequate supply of food in local markets using monitoring data of Nepal Food Security Monitoring Systems (Nepal Khadhya Surakshya Anugaman Pranali, NeKSAP) and WFP's Vulnerability Assessment Monitoring (VAM).

\section{Fund flows}

For the SSAs, New Era (2016) reports that delays in receiving updated beneficiary lists and clearing previous payments resulted in a delay to the transfer from the District Development Committees (DDCs) to districts and on to VDCs. The delays are substantial: on average 63 days in 2014/2015 and 32 days in 2015/16 for transfer to districts and 73 and 47 days respectively in the same years to VDCs. Human resource capacity constraints-especially a lack of accountants-were blamed for the delays. Although the new fund flow arrangements are not complicated-certainly no more so than before the transition (Figure 6)-interviews at district, local government, and (new) ward level and with beneficiaries suggested that the timeliness of payments had not improved following decentralization. Some of this was accounted for by the incomplete process of deploying district staff to municipalities and rural municipalities but it seems unlikely that the challenges identified by 
New Era (2016) have been overcome already, only to be replaced by new challenges associated with decentralization. More likely, decentralization has created an additional layer of administrative challenges at this stage in time: the removal of the district layer may simplify the delivery system, but most of the pre-existing challenges identified by New Era were at a more local level and so are unlikely to have disappeared.

Figure 6 SSA Payment authorization and fund flow

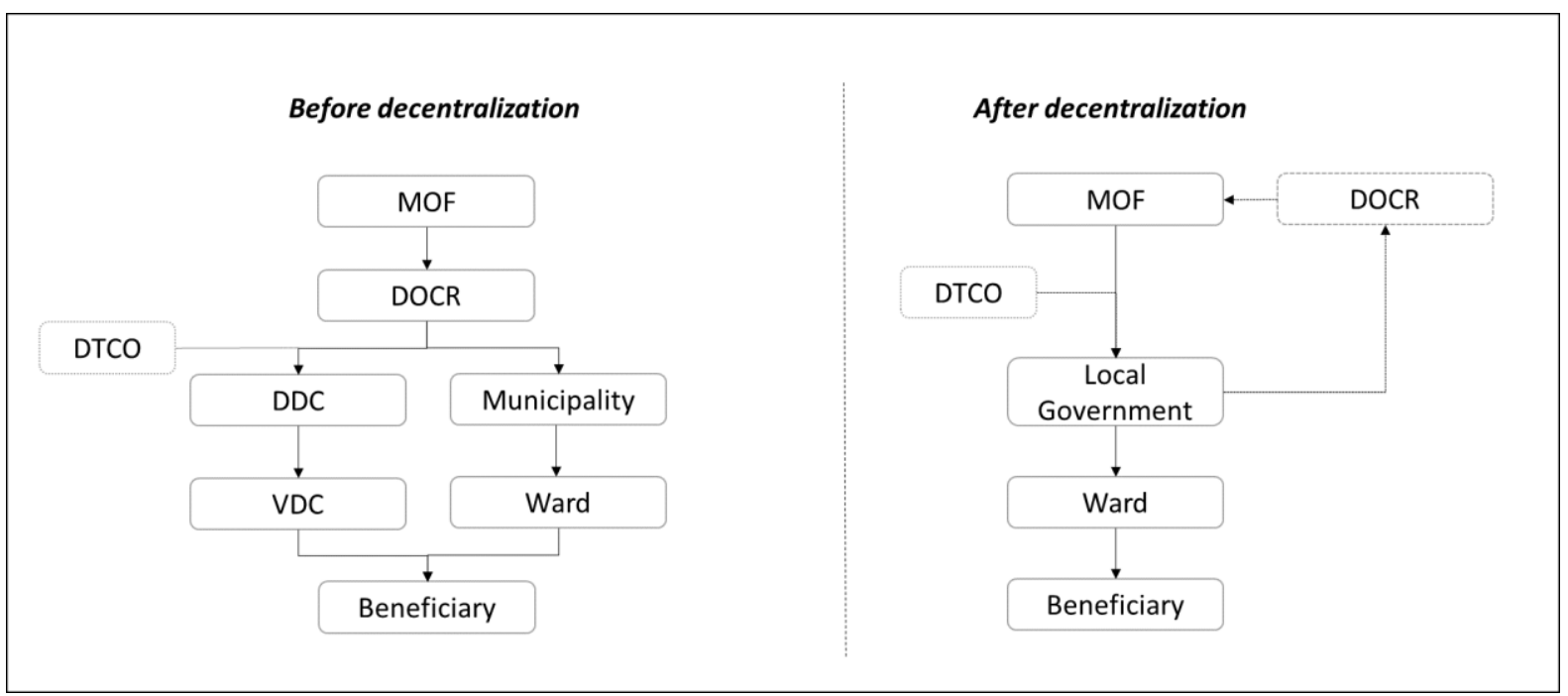

Source: Carraro and Lakhey $(2018,30)$.

For PWPs, the fund flow process, and specifically the size of funds delivered to local levels, was often irregular, notably for the KEP where the major donor cut funding. One respondent noted that "at first the budget was Rs 12 crore and we have planned the activities of 7 rural municipalities according to it. For Simkot the budget was Rs 2 crore 40 lakh and from that money Rs 79 lakh has been taken away. KEP made plans and made a contract with the beneficiaries and even started work according to the previous budget. In two areas, they have even completed the work...In wards 7 and 8 of Simkot rural municipality, work has already been completed. They made plans in July and competed the work in March. They announced the decrease in the budget in April. Now it's the time to give payments but there is no budget and the rural municipality is facing problem. And in other wards work has just been started. People come to ask for their payment in the rural municipality, but they don't have budget." In Humla, the withdrawal of donor funds for the KEP was interpreted locally as resulting from a lack of trust among donor agencies that the funding could be effectively disbursed and accounted for in the new federal system.

For the PFDS, the fund flow is flexible to account for emergencies (Figure 7). In the event of shortages in the availability of

Figure 7: Public Food Distribution System fund flow

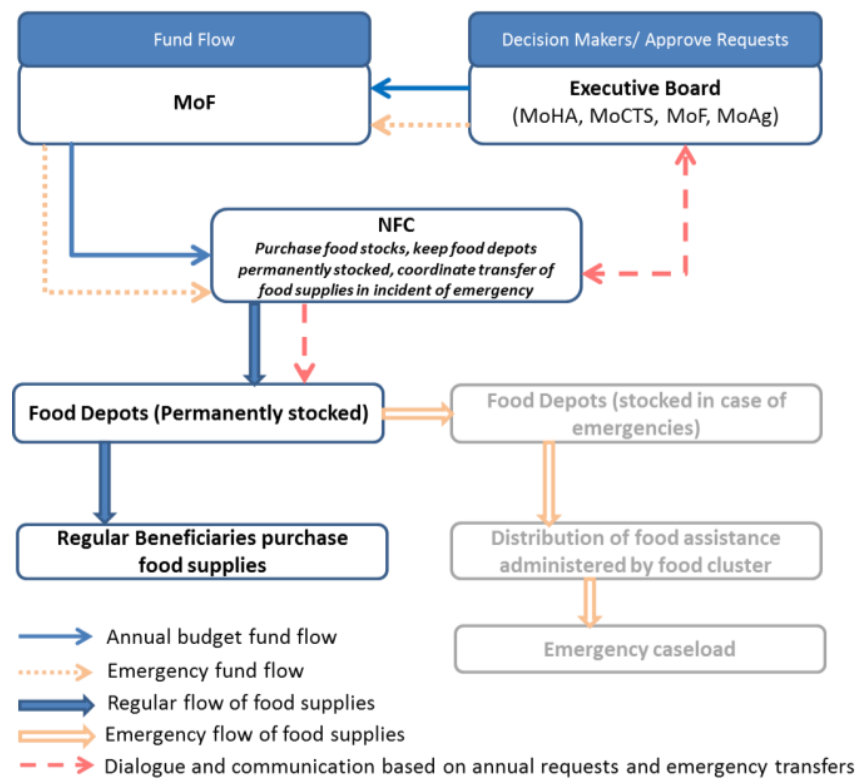


rice at the food depot the NFC issues a request for further resourcing of transport costs to the GoN. A prime example of this is in the incidence of shock: PFDS was used by the GoN to supply and redirect existing stocks to areas affected by the 2015 earthquake and 2017 floods.

\section{Timeliness of payments}

Payments for the KEP are made in instalments but, in the last year, have been unreliable. The KEP began work on projects in 2017/18, only to then learn of a reduction in funding. The result in Humla was that planned projects have been cancelled in some wards, to make up the funding shortfall in other wards where work was already underway.

For the SSAs, there was substantial confusion about the timing of payments. The findings of the PETS (New Era 2016) noted a lack of awareness among beneficiaries about when they were meant to receive SSAs: although only one in every seven beneficiaries received their payments at the right time, 92 percent of recipients felt they received payments on time in $2014 / 2015$. Fast forward to 2018 and very few beneficiaries said that the payments were made on time, but they were unclear when the payment should come.

According to existing government guidelines SSA payments must be made three times a year: the last week of September, the last week of January, and the last week of May, and each time within a two-week window (Carraro and Lakhey 2018). In practice, few beneficiaries and local government officials knew whether payments were supposed to be made either every four months or at three unequally spaced intervals. Payments every four months would not be especially helpful for linking SP to disaster response. However, program timings for payments (as cited by some respondents) were conducive to disaster response: two of the three payments each year aligned with seasonal climate-related shocks. Payments at the start of the financial year (July) align with the monsoon and heightened flood and landslide risk. Payments in winter correspond with the onset of seasonal cold waves on the Terai. Only the payment preceding Dashain (when there are substantial calls on expenditures for festivals and travel to be with family) did not align with seasonal shocks. Payment timings are more relevant to shocks faced on the Terai (flood and cold waves) than in the mountain areas (drought and landslide). Plus, analysis of the HRVS data shows that, frequently, payments are delayed-arriving too late for the monsoon or for cold waves. Lists for beneficiaries also used to be opened only once a year but this is changing to be more regular, although not rolling, registration process.

New Era's (2016) PETS found poor financial record keeping, leakage of SSA funding at the VDC level, and 5 percent of funds spend on ghost beneficiaries. At this earlier stage, the extent to which the problems at VDC level that were identified in the PETS review will be overcome following the transition to a local government is not clear. It has been widely suggested that the existence of elected bodies overseeing the delivery of SP at the local level will allow greater accountability (and this is supported by experiences elsewhere-see for example, De Janvry, Finan, and Sadoulet 2012; Fenwick 2009, 2010; Laws 2016;).

Substantial investments-of financial and human resources and systems infrastructure-are being made to deliver SP transfers direct to beneficiary bank accounts and to reduce the risks of financial mismanagement. In our limited fieldwork we found little progress in the transition to e-payments, and doubts, among both beneficiaries and government officials, about their appropriateness in 
remote rural contexts. Humla, for example, was reported to have only one bank with permanent premises. In other districts, especially Bardiya and Saptari, beneficiaries complained that the costs of travelling to the nearest bank would eat into their allowance, especially old age and disability allowance beneficiaries who often required a companion to support their travel. This finding is echoed in Carraro and Lakhey $(2018,16)$ : "in Rautahat it was reported that while bank payments makes much easier the life of public employees, some people need to make significant travel to reach the bank and suffer as a result."

\section{Summary}

The implementation of SP in Nepal faces a multitude of challenges. While some of these may reflect the uncertainties of mandates, roles, and responsibilities in the context of the ongoing decentralization processes, it is our interpretation that many of the current challenges predate the transition to a federal structure. Instead, new challenges are layered on pre-existing challenges associated with human resource capacity (with reference to both the quantity of staff provided to deliver programs and their specific skills and capabilities), financing of SP, and administrative infrastructure such as the MIS and banking systems.

Overall, the main implication here is that, whatever plans are made to make SP more adaptive and supportive of disaster risk mitigation, preparedness, response, and recovery, the timing of payments will have to be significantly more reliable and accompanied by financing streams and systems for rapid identification of beneficiaries.

\subsection{Outcomes and impacts of SP programs}

High quality evaluations of the impacts of SP in Nepal-especially those that have control groups to ensure that changes are specific to the target population-are few. Furthermore, the evidence on how SP supports disaster mitigation, preparedness, response, and recovery is very rare indeed. Despite this it is possible to identify some findings about the impacts of programs that allow us to infer how they might be useful in responding to various shocks. In this section we explore what is known about the impacts of SP in relation to disaster mitigation and preparedness and disaster response and recovery. Some of the impacts are related to the core function of SP (that is, the transfer) while others are related to specific design features (such as the requirement to be involved in labor which creates assets).

Evidence about the impacts of SP on disaster mitigation is rare, especially in Nepal. Sijapati notes that thus far "the impact of cash transfers in reducing the intensity of poverty and inequality have been very limited', drawing on modelling from the World Bank (2013a, 2014). Vaidya, Regmi and Ghimire (2010) finds similarly disappointing results for the KEP in which only 13 out of 300 recipient households surveyed indicated food sufficiency throughout the year. The most recent evaluation of the RCIW does not measure impacts on food security or poverty in a robust way but instead depends on people's satisfaction with the program. For the child grant in Nepal, Adhikari et al. (2014) find that although households are able to purchase more food (some manufactured, some more nutritious) the impact on food security in terms of overall consumption did not change. Koehler's (2011) review goes as far as to suggest that the level of expenditure on SP may prove difficult to justify given the small reductions in poverty resulting from existing programs. 
There is more positive evidence from qualitative research from Roelen and Chhetri (2016). They suggest that SP programs can have an impact on child poverty and vulnerability indicators. While not directly linked to disasters, we do know that those living below the poverty line, with poor levels of nutrition, lower education levels, and with poor access to health care are often more exposed to shocks. So, SP can play a role in mitigating disasters by disrupting the mechanism by which exposure to hazards, combined with vulnerability or poverty has disastrous consequences for people. In essence, Roelen and Chhetri (2016) and other analyses, for example Hagen-Zanker, Mallett, and Ghimire (2015), show that by tackling the underlying drivers of poverty, inequality, and vulnerability, SP mitigates shocks by reducing their impact on people. Although progress toward this core objective is limited, this is likely to be more about the weaknesses in the specific design features (such as low levels of benefit in many programs), beneficiary targeting choices, and implementation of the programs (such as late payment or under payment of benefits) than a fundamental problem with cash transfer programs themselves. The implication is that SP will only be able to support mitigation with substantial improvements to both design and implementation.

In terms of preparedness, there is also little evidence available. Rabi et al. (2015, 13-14), propose cash transfers "accompanied by behavioral change messages that can contribute to reducing the household's vulnerability to disaster...simple shelter guidance, household preparedness measures, checklists to protect water sources from contamination and key health messages relevant to the rainy season or further earthquakes and other natural disasters."

The evidence base on the role of SP in shock response and recovery is similarly weak with no robust impact evaluations of SP programs' role in responding to natural disasters, especially in Nepal. Lessons from the provision of an emergency top-up cash transfer program (ETCTP) in 2015/2016 to beneficiaries of the SSAs in the most earthquake-affected districts of Nepal do provide useful insights into what is feasible and what the implementation challenges are and are discussed in more detail in Chapter 6.

\subsection{Implications of decentralization}

Cararro and Lakhey $(2018,10)$ provide an excellent overview of the federal system and the opportunities that it is meant to provide

“...the 2015 Constitution provides for a federal and decentralised governance system with non-hierarchical relationships between Federal, State and Local Governments...Through decentralisation and devolution there is a general expectation that this should help to foster different groups identify, empower people, improve service delivery, and reduce poverty and inequality."

At the same time there are clear risks associated with the federalism transition. In this section we review the consequences-both intended and unintended-that the transition to decentralization is having on the SP sector.

Implications for access to SP. It is suggested that relationships at the local level will support access to the program. Carraro and Lakhey (2018) argue that closer links between people eligible for social security and the local government responsible for its implementation should help lower exclusion errors. Schjødt (2017) describes how people previously depended on personal relationships and 
networks that the "decentralized system uses the informal social relations in communities to bridge the gap between citizens and the state."

In practice, at this specific moment, these benefits are not yet realized. The period of transition is certainly creating delays and confusion in the delivery of SP. At the time of this report, the division of power, roles, and responsibilities had been set but the distribution of human and financial resources was very much a work in progress. We found a number of staff had been deployed to local governments, mainly officials below section officer, but many were awaiting instructions from the central government, and others had been borrowed back from municipalities and rural municipalities to deliver essential roles in service delivery. For SP, Carraro and Lakhey (2018) note that only once staff are in place at the local government level can adjustments and improvements be made to programs that will allow ASP.

Implications for roles and responsibilities. Once deployed, it is also not evident that everyone is clear on roles and responsibilities. As it stands, the roles and responsibilities are there on paper but less so in practice. Central-level agencies (specifically Ministry of Federal Affairs and General Administration [MoFAGA]) are primarily responsible for the main social assistance programs - the SSAs and both the KEP and RCIW until their closure. Under federalism, they have a specific mandate for overarching policy and program design (for example eligibility). For the SSAs, local governments are largely viewed by respondents as implementing arms of the central government rather than SSAs being devolved to local governments, but this may change over time as local government take on more independent programming. A number of areas of confusion remain, entangled in the opaque differentiation between exclusive and concurrent powers of different parts of the government. As Khadka $(2017,5)$ notes: "There can be duplication of resource allocation in some areas, and weak allocation of resources in others. It is also likely to create confusion over the role of each level of government. Shared responsibility can result in conflicting policies, lack of mutual coordination and reduced performance. Therefore, the responsibility of every level of government needs to be clearly demarcated and subject to a coordinating mechanism (and/or partnerships) to enforce accountability and encourage fiscal efficiency."

In practice this means overcoming the lack of clarity among stakeholders about operational responsibilities. For example, although on paper it is clear that beneficiary lists for SSAs require data entry at the local level and overall management at the center, it is less clear who owns (or holds master copies) and who maintains the lists among stakeholders. At the local level, respondents reported not having lists, but sending new entries to the central level to be added to the list. The current lack of clarity appears to lead to gaps in functions: in particular, there is no clarity on responsibility for checks and balances in the system. A further opaque area is responsibility for new registrations; while it is clear that the future plan is for this to take place at the local government level, perhaps even at the ward level (and there are clear advantages to that, including for incorporating disaster mitigation, preparedness, response, and recovery into SSA programming), some programs-disability and single women-were registering beneficiaries at district level offices in some places.

Implications for locally appropriate SP. The extent to which local governments can develop their own SP policies and programs remains a moot point among key stakeholders. It is recognized that the SSAs are nationally defined programs. The situation for PWPs is more complex. Decisions about 
the activities undertaken in PWPs and, to some extent, about targeting are taken at the local level. We found evidence in Humla of targeting criteria being adapted at the rural municipality level to adjust to new funding allocations.

Khadka $(2017,6)$ highlights the roles that different levels of government play in SP: "central government has responsibility to determine the overall policies and standards and provide the budget to ensure delivery of all services, the subnational governments are responsible for implementation, particularly the determining of beneficiaries of welfare programmes." The central overarching role is critical where SP meant to achieve redistribution, especially to avoid inequitable benefit levels and coverage in different areas (Carraro and Lakhey 2018). However, there is also acceptance that the substantial geographical variation in social and economic vulnerability across Nepal means that local knowledge can be applied in specific locations to better tackle particularities of vulnerability. Finding an appropriate and equitable balance between central and locally defined eligibility and benefits will be challenging for Nepal-particularly given the limited fiscal space in equalization budgets. There are risks in devolving SP responsibilities to the local level. Carraro and Lakhey (2018) note the risk that some local governments have lower capacity and resources to implement locally appropriate programs and without careful management of equalization grants, inequalities could be reinforced, rather than reduced. Schjødt (2017) stresses that local processes do not always support local citizens-particularly excluded groups. In Saptari, there were highly diverging views on how far the newly elected politicians and the local government secretaries were supporting them.

Implications for implementation capacity. Before the transition to federalism, Khanal $(2014,6)$ had argued that "weak coordination between agencies, poor information management systems and a lack of institutional capacity are all critical problems." There are substantial investments, including through support from international development agencies, in improving institutional capacity to deliver SP, but progress appears to be currently in limbo, as the new institutional arrangements emerge at central, provincial, and, especially, local government levels.

Our findings suggest that while the potential for greater citizen and community-based organization engagement at the local level is widely recognized (see, for example, Schjødt 2017), early indications are that the new local government institutions will likely face the same capacity challenges as the VDCs and wards that preceded them. Kardan et al.'s (2017) assessment of capacity in Kenya and Zambia suggests that the political premium placed on SP led to "additional tasks being carried out by already stretched and understaffed local administrations, and often at the expense of their staff not carrying out other important statutory functions related to social services." The ways forward are including administrative resources to be matched to expansion and geography; revising the job descriptions to cover realistic workloads for staff at the local level-especially those that are covered alongside other roles; assessing whether separate functional units are required; and whether elements of program delivery can and should be outsourced (and what the capacity implications of this would be). Much of this is a priority in Nepal.

A more positive finding is that decentralization, particularly moving technical staff from district to local government level, may allow more integrated working at the local level-particularly of staff who contribute to the implementation of PWPs. Whereas previously, the KEP was implemented through a district-level office, it is likely now that staff at the rural municipality level-for example 
engineers-will work on numerous infrastructure projects in road construction, irrigation, agriculture, and so on, and thus there is an opportunity to create more meaningful and effective assets through public works at the local level. Although the KEP has ended, this logic applies to the new Prime Minister's Employment Programme (PMEP).

\subsection{Conclusions}

Just as emergence of SP depended on a specific moment in Nepal's history (that is, emergence from civil conflict), this is a good moment to look at SP and the role a growing system might play in helping Nepal to tackle the greatest of its challenges (poverty, vulnerability, and climate change). The implications of the political processes and settlements that drove the emergence of SP in Nepal are gaps in program coverage, a wide range of institutions responsible for program delivery, and objectives for individual programs that are difficult to align in a single policy and implementation framework. The different underpinning ideologies and objectives of programs present particular challenges for implementation, especially for linking an already complex SP system with the management of shocks.

Beyond these challenge, while the contribution of SP to disaster mitigation is currently limited there is huge potential, particularly given ongoing work to strengthen implementation systems. The more reliable SP is, the more it can be beneficial for mitigating disasters. Examples include improving the reliability and timeliness of beneficiary identification and of payments, and reducing delays in transferring money, and making payments through electronic means (subject to these being accessible for beneficiaries). Getting the foundations of SP program delivery right also matters for subsequent efforts to scale up. An example of improvement that will support shock response is the transition from a static targeting process (where new beneficiaries are registered and enrolled only annually) to a rolling process where the beneficiary registry is constantly updated. More generally, the list of beneficiaries would need to expand and contract with shocks and would require the registry to be more than only beneficiaries, so that it is easy to identify the additional caseload in times of crises. While there are limited examples of shock responsive SP in disaster response in Nepal, the experiences of the ETCTP in 2015 provide important insights about capacity requirements at the local level, accessibility to payment sites by beneficiaries-especially for people with disabilities, and the potential use of behavior change messaging for disaster mitigation, preparedness, and recovery. 


\section{Chapter 4: Review of Shock Response Policies, Programs, and Systems in Nepal}

\subsection{Introduction}

This chapter explores the policies, systems, and institutions for shock response in Nepal. The objective is to identify, ultimately, how SP might be more adaptive, that is, the roles that SP might play in supporting the various stages in the cycle of DRM. The chapter begins with a summary of the key elements of DRRM - 2074, highlighting the importance of the four distinct pillars of mitigation, preparedness, response, and recovery; the articulation of roles of central, provincial, and local-level governments; the provisions for district roles; and information about funds and finance flows. It then discusses what was learned during consultations and fieldwork about what happens in practice and analyzes the experiences of people to shock response at the local level. The paper concludes with a brief assessment of the implications of the current policies, systems, programs, and institutions for shock response for how SP might be made more adaptive.

\subsection{DRM on paper: legislation and policies for shock response and management}

In a rapidly changing context, DRRM ${ }^{3}-2074$ provides the legal framework for DRM in Nepal, though the regulations were not drafted at the time of research and hence it was not yet articulated how the roles and responsibilities would translate into practice. Figure 8 shows the general understanding articulated by various government actors, with pale arrows denoting areas where greater clarity is need. For example, the mechanisms for reporting and overall oversight are not yet widely understood at central or district and local government level, nor if and how financial flows between the central level and committees, districts, and local governments will work. Until the various committees are established and convened, it is unlikely that progress can be made in this regard.

Four particular features of the DRRM Act are of particular importance for this project.

\subsubsection{Distinction between four discrete but overlapping pillars of DRM}

DRM is, in theory, focused on four pillars: mitigation, preparedness, response, and recovery. At this moment, there is a clear prioritization of and progress in achieving the last two of the four pillars. Far more attention is paid to response and recovery in guidance documents and human and financial resources than to mitigation and preparedness. At the central level, although respondents described a generic system covering the full DRM cycle, they tended to focus the discussion on emergency/immediate response and a subsequent period of response/recovery. There was less articulation of explanation of preparedness (mainly in relation to flood prone areas) and very little on mitigation. At the local government level, the focus was on post-disaster activities, particularly on rebuilding houses. This focus is reflected in the distribution of guidance related to mitigation,

\footnotetext{
${ }^{3}$ For the remainder of this paper we use 'DRRM Act' to refer specifically to the 2074 Act, and 'DRM' to refer to the various stages in the cycle of disaster management.
} 
preparedness, response, and recovery: 23 building code manuals are being revised following the 2015 earthquake with very little in the way of guidance for anything else.

Figure 8 DRM roles, responsibilities and relationships in April 2018

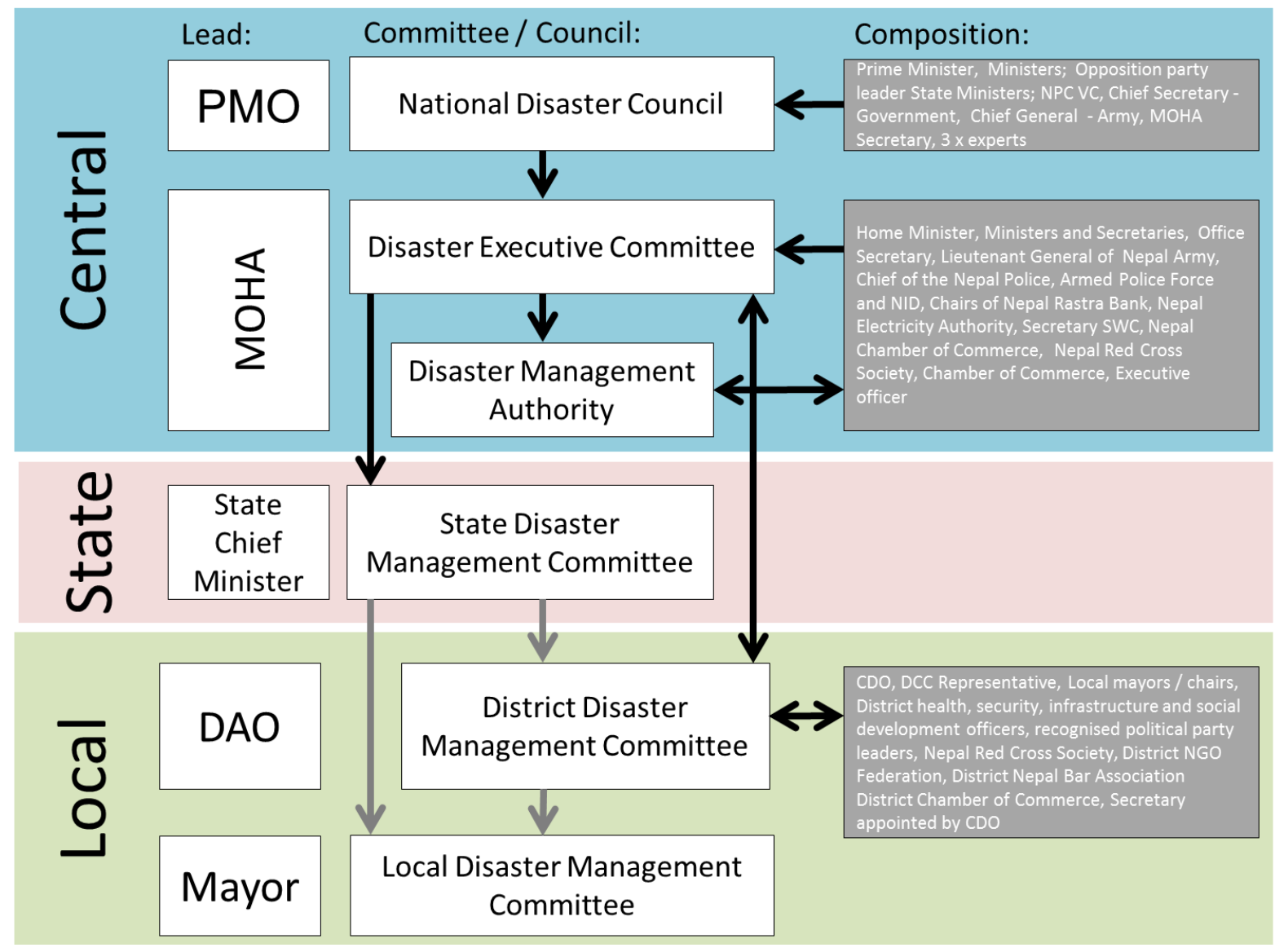

This is mostly likely the result of massive investments by the government and other donors in housing reconstruction following the 2015 earthquake and the challenges of rescue and early response during the 2017 floods. It skews the current overall policy agenda and allocation of resources toward early response and reconstruction.

\subsubsection{Articulation of mandates, funding, roles, and responsibilities across the three tiers of government}

The DRRM Act provides information on the organization of DRM at the central level, particularly the roles of key committees and authorities. The Disaster Management Authority (DMA), an executive agency, will be run from the MoHA with an Executive Committee chaired by the Home Minister. At the time of the consultations in Kathmandu in early April 2018, the DMA had not yet been convened. Above the DMA there will be a National Disaster Council (NDC) chaired by the Prime Minister with responsibility for future policy changes. For mitigation and preparedness functions, there is work to be done to address fragmentation of roles at the central level, especially how the large range of ministries and departments with roles in flood and landslide mitigation and early warning are to be coordinated.

At the subnational level there is provision for a state-/provincial-level structure which is well tasked with coordination responsibilities. However, given that the provincial governments are the last of the three levels to be established (while local government elections were mainly held in mid-2017, 
provincial elections took place in the autumn) it is taking longer for arrangements for provincial DRM mandates to be operationalized. State/provincial Disaster Management Committees (DMCs) were yet to be established or convened. No respondents were able to articulate with certainty how the provisions of the DRRM Act would translate into a mandate between the central and local governments in practice.

There is less clarity in the DRRM Act about the local-level mechanisms, and particularly limited information about specific and precise roles and responsibilities of municipalities, rural municipalities, and wards. Some guidance may be provided through the 2017 LGOA (2074) but there is potential for guidance to be interpreted differently in different municipalities and rural municipalities. Further clarity may be provided by the National Disaster Risk Reduction Policy and Strategic Action Plan which was under discussion when consultations for this research were taking place.

\subsubsection{Provision for district roles and responsibilities}

The DRRM Act lays out broad provisions and is interpreted very differently by respondents. There was no agreement on future roles at the district level among respondents. While the district DMC structure (with the inclusion of municipality mayors and rural municipality chairpersons) was widely viewed as fit for purpose, there was not agreement on whether the district-level coordination process was filling the gap before local government-level disaster committees are formed or whether it would be part of the permanent institutional arrangements.

In contrast, at the central level it was suggested that the local government will take on responsibility for most of the DRM pillars, with support from the coordinating DMA when it is operational. The role of the Chief District Officer (CDO) in disaster management was presented as temporary, while the new systems are established. However, it is notable that the roles of districts are provided for permanently in the act. So, while many functions of the former district administrations are moving to local governments, disaster response remains at the district level with the CDO. It is unclear how response will be coordinated with mitigation, preparedness, and recovery.

\subsubsection{Provision for funds and financial flows}

Figure 9 outlines the fund flow mechanisms that are stipulated in the DRRM Act and various other policy documents. Given the provision of these fund streams in policy there remained some confusion whether they operate in practice, as evidenced by the conflicting views expressed at all three levels of government (central, district, and local). It is expected that this will be clarified in the forthcoming regulations and guidelines.

There are currently three main funding streams identified: (a) the Prime Minister's Disaster Relief Fund (PMDRF), which receives contributions from the government, members of the public, and foreign donors and agencies; (b) the Disaster Management Fund (DMF) at MoHA, both of which are focused on response, and (c) the National Reconstruction Authority (NRA) Fund, ${ }^{4}$ focused on recovery of housing damaged by the earthquake.

\footnotetext{
${ }^{4}$ NRA is a time-bound (5 years) fund set up in 2015 to address post-earthquake reconstruction.
} 
The fund flow of the PMDRF is guided by the PMDRF Operation Regulations 2006 and there are conditions outlined about where the fund can be used and where not. The fund is managed by a regulation committee headed by the vice chairman of the National Planning Commission and secretaries of eight ministries (relating to clusters in response system). An unanimous committee decision triggers the release of funds through MoHA to the CDO who coordinates the District Disaster Relief Fund. The fund is used for rescue and response in coordination with local bodies. The Fund Regulation Committee can also disburse to other entities. This allows disbursals to the new provincial and local structures but thus far the fund has always been routed through MoHA to the DAO.

The DMF is a part of the MoHA budget but it can receive money from the PMDRF. The fund is rolling and routed through the district structures. In the absence of regulations, there is little clarity among stakeholders whether it can or will be routed direct to the local government level. There is also provision for compensation payments to disaster-affected households in the 2017 Rescue and Relief Standard for Disaster Affected - 6th amendment, 2074. This stipulates a minimum compensation for death due to disasters of NPR 4 lakh in mountainous districts, NPR 5 lakh in middle hills, and NPR 7 lakh in Terai districts. The same guideline also calls for establishment of the Regional Disaster Relief Fund with a minimum of NPR 7 lakh. Neither stipulation was mentioned at the district or local level. At the local level, respondents cited two funding systems for types of shock response which are administered upon request from two levels: local government to support response for numerous households affected by shock (covariant shock), and community level to compensate/support individual households that experience shock that affects one or very few households (idiosyncratic shock).

It was unclear among stakeholders what the distinction was between the PMDRF and the MoHA DMF. Both funds were focused on emergency response with funding for mitigation, preparedness, and recovery requirements moving through equalization grants to the local government and so responsibilities and resourcing for all but disaster responses appear to have been shifted to the local government. The links between preparedness at the local level and those activities running across the boundaries of local government constituencies are mentioned in the 2017 LGOA 2074 but will need some time to be understood and for the nuances around actual coordination of funds to be picked out.

At the local level, Figure 9 highlights two types of grant (conditional and equalization) that respondents suggested may be a source of funding for DRM. It was suggested that conditional grants for DRM would be request based, with central-level government officials stating that requests are processed only annually. Funding is otherwise at the discretion of the local government through allocation of its equalization grant. In emergencies, while there is provision on paper for requests from local to district, local to provincial, and local to central, the mechanisms and practice fund transfer from provincial and central level were not wholly understood, nor were examples shared of their operation in practice.

At the time of research (April 2018) no decisions or financial flows seem to be channeled through a province and, except perhaps in the case of a disaster where a more coordinated response was required across district boundaries, it was not clear why a province would need to be involved in the disbursement of funds between the central and local levels. 
Figure 9: Fund flow mechanism as understood by respondents in April 2018

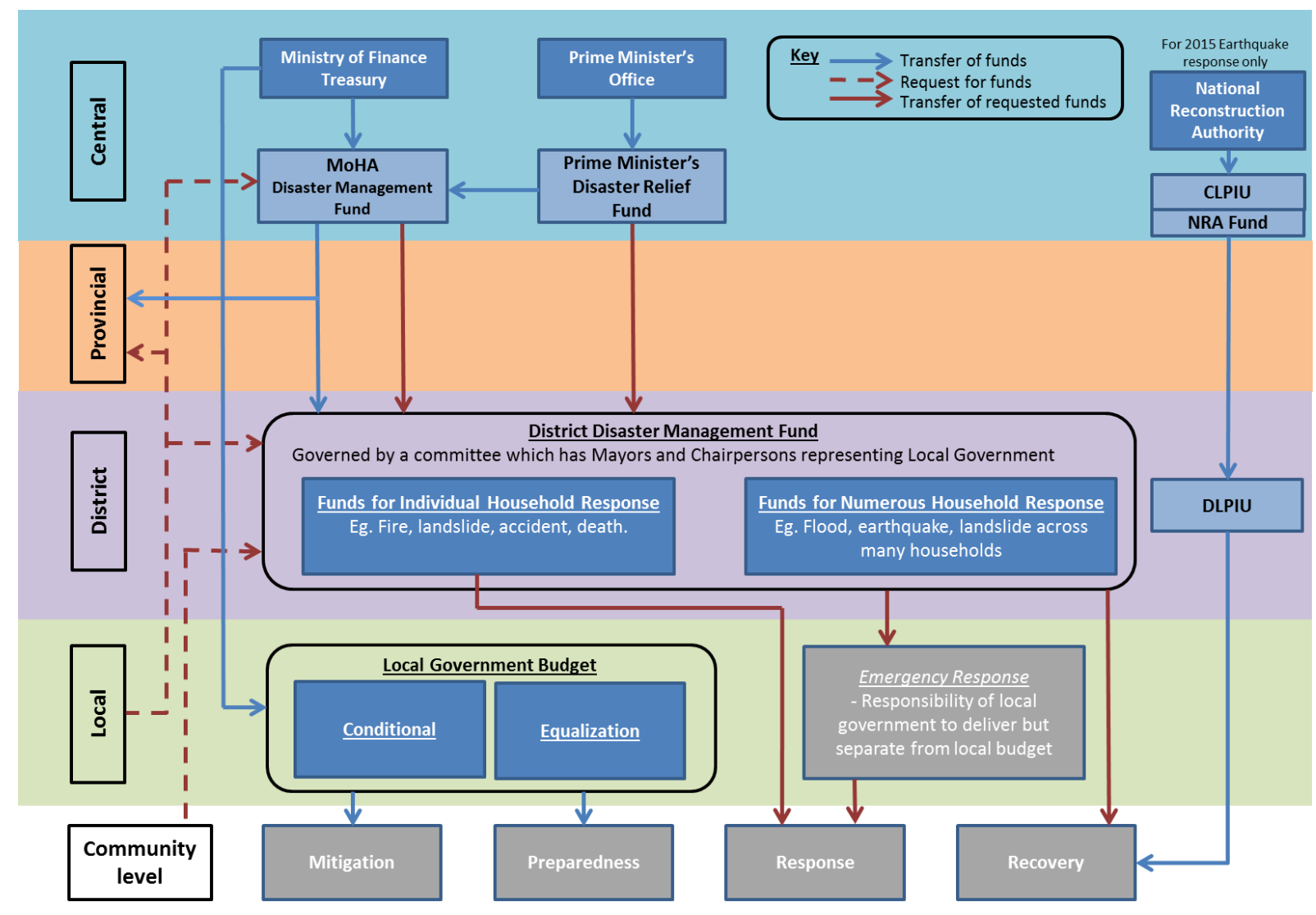

\subsection{DRM systems in practice}

\subsubsection{District versus local}

The current status of the legal instruments and DRM policies provide arrangements in theory given that the institutions, organizations, and functions along with the human resources needed for operations are not yet in place. This is the case particularly at provincial and local government levels but in addition the key central organ, the DMA is also not yet operational, and changes between now and implementation could have further impact on the operationalization of planned local government DRM form and function. There is a consultation on management and institutional arrangements for the DMA at the central level that will be complete in July.

So, what is happening at the local level given the policy and guidelines gap? At the local level there remains heavy dependence on the pre-existing district-level structures. Although many district-level functions were wound up by mid-April 2018, districts and local government staff are still following the District Disaster Preparedness Plans (DDPPs) and planning to convene District Disaster Response Committees (DRCs), headed by CDOs, in the event of a disaster. The composition of the DRCs has adapted to the new decentralized arrangements by incorporating municipality and rural municipality representation onto the committee. The existing response clusters at the district level have also been maintained. At the local government level in the districts we worked, no local government DMCs had yet been convened, though municipality mayors and rural municipality chairpersons were allocating resources from their equalization budgets as contingency earmarked for disaster response. This was particularly the case in the Terai districts. 
The understanding is that at the local level the organization and coordination will be much the same as before the transition to a federal system. The local government DMC will in future be in operational charge of all stages in the DRM cycle. A 'district' DMC will be activated when a disaster occurs, with members brought in by the CDO depending on the nature of the hazard and from relevant geographical areas. The CDO in charge of this will divide the response into clusters and activate policy, army, and officials and coordinate the response with the Nepal Red Cross (NRC).

\subsubsection{Staffing and deployment}

While the 2018 Standard for Rescue and Relief of Disaster Affected (6th Amendment), 2075 makes it mandatory to have 25 well-trained people standby at the regional and local level for rescue and relief activities, the extent to which there is capacity at the district or local government level to provide a disaster response is affected by the current deployment process, described as patchy and uneven by key stakeholders at the district and local level. While there has been progress in training security agencies in search and rescue there is limited search and rescue equipment at the local level. The allocation of staff to municipalities and rural municipalities is underway but as yet incomplete. The rationale for selecting which staff move where is not fully understood, nor do staff understand the criteria by which staffing at the local level is agreed. This is true of both the geographical distribution of specific staff (Box 3 ) and the specialist mix of staff in any given location. Furthermore, the capacity to respond to disasters at the local level will also depend on how effectively staff can be mobilized by either the local government or by the DAO. For example, at the local level security forces cannot be effectively mobilized for response or relief independently of the DAO.

Staff report having no work to do in some places, and too much, or work that they are not qualified to deliver in others. This may result in a change in morale-indeed there are anecdotal reports of staff taking accrued leave rather than taking up their posts and of frequent secondments back to districts after deployment. As yet, the allocation of these personnel is uneven-there are often not enough staff with specific skills to share across all the local governments in the district. This could leave gaps at the local level. There are also opportunities, recognized by officials, in the new system. It is argued that there is potential under the new system for those with specific skills to work across a number of sectors or programs. For examples social and women's development officers could work across a range of social programs providing more holistic services. Engineers or agriculture specialists might work across multiple programs at the local government level-for example across public works and water/irrigation. The ideal scenario would be where this leads to greater integration within and between sectors at the local level, but will certainly require capacity strengthening, particularly for planning (including DRM plans) and specific technical capabilities.

Box 3 Competing for engineers: earthquake versus flood

In the case of housing reconstruction, the Department of Urban Development and Building Construction has 2,000 consultant engineers spread over the 14 earthquake districts to support the NRA in earthquake housing reconstruction. Although flooding also causes loss of shelter, there are far fewer engineers to support post-flood reconstruction and, at the local level, for example, in Saptari where many homes were destroyed in the 2017 floods, there are questions raised about the distribution of support for housing reconstruction.

Source: Interviews with officials in Kathmandu and Saptari. 


\subsubsection{Budget allocation decisions}

There are also gaps in terms of guidelines for budgeting. Staff in one ministry stated that 10 percent of the local government budget should normally be spent on DRM, and elsewhere it was 5 percent of unconditional or 5 percent of the total budget. There are substantial differences in the amounts that have been allocated for DRM activities. Saptari, a rural municipality, earmarked NPR 1 crore (out of a total budget of NPR 31 crore or 10 percent of the equalization budget. In Humla, the allocated share was smaller. In Gulariya in Bardiya, between NPR 10 lakh and NPR 15 lakh has been earmarked for DRM contingency. Although less than 1 percent of the municipality budget, the plan was to build up a contingency fund over time of NPR 2 crore 55 lakh. The building of contingency budgets at the local government level seems appropriate for tackling local shocks but raises questions about mandates and powers under the new federal system. It is important to resolve the extent to which contingency funds can be built up in future from money saved from central allocations (for disaster relief or other purposes) or from fund collection at the local level. A decent size contingency fund at the local level potentially allows for fast deployment of help after a disaster.

\subsection{Experiences of mitigation, preparedness, response, and recovery}

\subsubsection{Experiences of preparedness}

At the central level, we found a reasonably systematic and evidence-led approach to the early warning system (EWS) and strategy hosted by the Department of Hydrology and Meteorology. The rollout of an improved EWS is ongoing and there is recognition of where technology is used, and training needs to take place. Evidence from the district suggests that the execution of the EWS is as stated, in that, in Bardiya, people reported getting text messages during the flood in 2014, while it was less so in Saptari. There appear to be good practices of coordination between the government and the private sector (cell phone companies) and the government and INGOs (for example, Practical Action) in building systems for messaging. Otherwise, people depend on the police and army to warn them, or on word of mouth. Notwithstanding evidence that particular groups risk being left out of the early warning, there have been great improvements in how the EWS for flood works overall and there were no lives lost in 2017 compared with the 400 lives lost in 2008.

On early warning for fire, there is no known formal EWS but again there is evidence of some preparedness activities. In Saptari and Bardiya, community leaders make announcements about avoiding and dealing with fire. They also work with local chapters of NGOs such as Rural Reconstruction Nepal (RRN) and Save the Children and local FM stations. They use pamphlets and public announcement systems to give messages and announcements telling the local population that it is the season for fire. For landslides, we could not find evidence of activity at the district level, though Practical Action has a joint research program with Practical Action India and the International Centre for Integrated Mountain Development (ICIMOD) on testing methods for EWS for landslides. There are no pilots in practice yet but geology, soil, and water analysis is the backbone to the research, which aims at finding algorithms for likely scenarios for a landslide to occur.

For drought, a slow onset disaster, the VAM mechanisms of WFP and NeKSAP provide a systematized EWS for the impacts of drought by tracking food consumption, food availability, and prices. Despite this being the strongest opportunity for ex ante responses to shocks, there is very little to show that it is used to plan a response. It does not appear to influence the allocation of resources for either the RCIW or KEP, for example, though it does influence food stocks held by the 
Nepal Food Corporation. There is no use, as yet, of long term forecasting, despite the rapid growth of this area, especially the increasing efforts to combine weather forecasting with SP in Africa and elsewhere (Costella et al. 2018).

\subsubsection{Experiences of mitigation}

There is far less to say about mitigation activities. This is not to say that mitigation work has not taken place over many decades, but that mitigations are not visible or recognized as such in the communities where they take place. In the case of floods, the emphasis on preparedness does support mitigation, for example, assets such as food are increasingly being stored more safely and documents are stored safely. In the event of a flood, the effects may therefore be reduced. In Bardiya, Humla, and Saptari, this activity appears to be largely down to district-level single women's officers or leaders. Despite mechanisms to protect food and documents, housing is still frequently damaged. Of course, the housing closest to or on the flood plain is the most affected, and the houses closest to the river banks is where the poorest people dwell. Addressing this requires actions to address the deeper roots underlying the causes of poverty and vulnerability and there is relatively little that DRM can do to address this alone. Here the role of SP becomes particularly important.

\subsubsection{Experiences of response}

The current system leaves responders at the local level with far fewer resources than they require. The Saptari CDO noted that requirements for blankets and firewood during cold waves far outstripped the resources delivered from the central level. Needs assessments at the local level and decisions about funding made at the central level do not appear to be well reconciled, leaving local officials struggling to deal with far higher levels of demand for support than they can provide. In both Saptari and Bardiya there were reports of households, particularly female-headed households and other disadvantaged groups, being routinely excluded from relief after their names are removed from lists because the resources are inadequate for the caseload.

The Saptari CDO describes the three stages of disaster response thus: "The full process of collecting data is that in the initial 0-12 hours the task force collects data for the most damaged areas and gives the data to the committee. Within 24 hours, they give another data set which is says how many houses have been destroyed in those areas. In the third stage, between 1-15 weeks into the disaster, they go for door-to-door visits and categorize which houses are fully damaged, which are partially damaged, and which are less damaged." In this final stage, the level of need seems to be predicated on the damage to housing rather than on actual consumption need. It occupies a tricky moment in the transition from relief to recovery and falls between the two. This was the case in both Saptari and Bardiya and, given the amount of time that many households were living under tarpaulins on raised roads away from their homes, it appears to be a flaw in the targeting process. Measures of damage to housing are used as indicators of the need for basic consumption support. Thus, households with houses that were 'fully destroyed' (generally meaning that they lost their walls and roof) received NPR 25,000 while households with houses that were 'partially destroyed' (for example, some or all walls were lost but the roof remained intact) received NPR 1,250 per household member per month for three months. Using destruction of housing, rather than existing food stocks, utensils, and cooking equipment, or even crops destroyed, does not appear to be a sensible indicator of immediate needs. 


\subsubsection{Experiences of recovery}

As discussed above, recovery is a key priority for the Nepal government at this time. In additional to the payments described above, for victims of idiosyncratic shocks, respondents at the central level suggested that a number of payments were made, notably NPR 1 lakh for households which lost a family member and smaller payments of NPR 5,000 for damage caused by a fire or landslide. While the payments for a fire or landslide were repeated regularly at the local level too, there was no mention of the larger payment to support households following the death of a family member.

The primary example is housing reconstruction under the NRA, which awards grants for rebuilding housing. Up to NPR 300,000 can be accessed if the householder can prove that they are the legal owner of the land. The money is released in 3 tranches, as long as building standards meet those of the building codes. However, staff at the Department of Urban Development and Building Construction acknowledged that none of their 31 housing designs can be built and finalized using the available budget and that some co-funding by households is required. The NRA also recognizes the difficulties that those in rural villages and those who also belong to the vulnerable groups face in accessing the funding and making use of it, primarily because they rarely have certificates for the land on which their homes are built nor the labor to do construction work.

For the floods, the MoA established special schemes in 2015 and 2017 to help farmers recover from a flood. These were demand-based programs for replacement seeds, storage gunny bags, and so on. If crops were destroyed, then seeds were provided for the following season. The MoA reported that their staff would be able to list affected households at the local level and assess their agricultural losses. Other support came in the form of substantial subsidies for seed with the MoA paying around 80 percent of the cost of seeds and farmers covering around 20 percent. There are reports of high demand for the subsidized seeds, though, at the district level in Saptari and Bardiya, it was not mentioned among our very small sample of flood-affected households. The seed was a hybrid chosen by the MoA and seen as a conduit to encourage farmers to adopt new technologies. It is up for discussion whether it is an opportune and appropriate moment to introduce new technologies, particularly those that require more inputs, at a time when farmers may be resource and time poor.

\subsection{Communities roles and perceptions}

Using SP measures to support DRM requires policy makers to be mindful of local relationships and support and social structures through which people find ways of coping with crisis and seek to avoid disrupting them. There is evidence from the field of numerous acts of individual kindness and bravery in search, rescue, and rebuilding. Furthermore, communities and community-based organization (CBOs) are the conduit around which the preparedness and early warning happens. There are user groups involved, especially in mitigation-especially where PWP user groups organize digging out sand remaining in flooded areas that make them unusable for agriculture and others that are involved in preparedness through the organization of flood defenses.

Local NGOs and local chapters of national NGOs, especially the NRC play a substantial role in preparedness (especially early warning) and early response. They sit on the district DMC and are frequently the first responders, alongside the army and police, to rapid onset shocks. Staff of the Red Cross are formally assigned in teams with local officials and the police to make assessments of impact and need in the immediate aftermath of a crisis. 
For communities, disasters can be moments at which they come together or flashpoints for division and disagreement. When disasters are covariant, the experience and damage is widespread, and resources are limited, mechanisms to target the most in need become very sensitive issues and are a point of contention for members of communities, especially those who did not receive support but feel they were among the needy. Some SSA recipients who did not receive disaster relief believed they were being discriminated against for receiving government payments, especially in Humla after a devastating hailstorm. Others were critical of elected representatives who they felt failed to represent them during disasters. Relief distribution was identified as an opportunity for local political activity with politicians taking advantage of the disaster situations in a bid to further their political popularity. In Saptari in particular, high levels of dissatisfaction with the relief distribution came out strongly in FGDs. People were angry about the distributions and there were some tense discussions. The mechanisms and outcomes for targeting were poorly communicated, leaving victims of disaster in confusion about transparency and accurate collection of data. Respondents from all three districts provided accounts of expecting to be on the beneficiary lists, but when it came to distribution, their names were not found on the list, and thus they were not able to receive support. When asked if it was communicated to them as to why they were not on the list, responses were largely speculative, and fed local tensions.

Respondents also reported difficulties in reporting grievances. Where respondents felt that targeting was unfair and discriminatory, people either did not raise a grievance because they did not believe it would have any effect, or they found themselves with conflicting emotions of grievance and gratitude toward actors in the flood response. People regarded the very people against who they held a grievance about disaster relief as the same people that had saved their lives in the immediate aftermath of the flood, and this influenced the extent they were willing to raise grievances.

\subsection{Conclusions: implications for linking SP and disasters}

Notwithstanding the challenges (and interruptions) to managing shocks that have occurred during the decentralization transition, there are good reasons to be positive about the potential role of SP in many of the areas of DRM. There is a strong appetite for exploring options among central and local government officials and other actors including NGOs and donor agencies, and support at the local level among disaster-affected households. The DRRM Act provides an opportunity to establish mechanisms for ensuring greater coordination between the agencies delivering DRM and SP. Before moving on to discussing some of the options for this in Chapter 6, some specific case studies are presented. Because different shocks present different sorts of challenges for linking SP and disasters, in the next section five case studies of shocks - the 2015 earthquake, the 2017 floods, drought in Karnali, and landslides and fires-are presented. Each explores the impact of the shocks, lessons about responses to the shock, and what this implies for prospects for ASP. 
Case Study: Flooding in Bardiya and Saptari, 2017

In August 2017, excessively heavy monsoon rains left Nepal experiencing the largest floods in living memory on many parts of the Terai.
Figure 10: Flood affected districts in Nepal

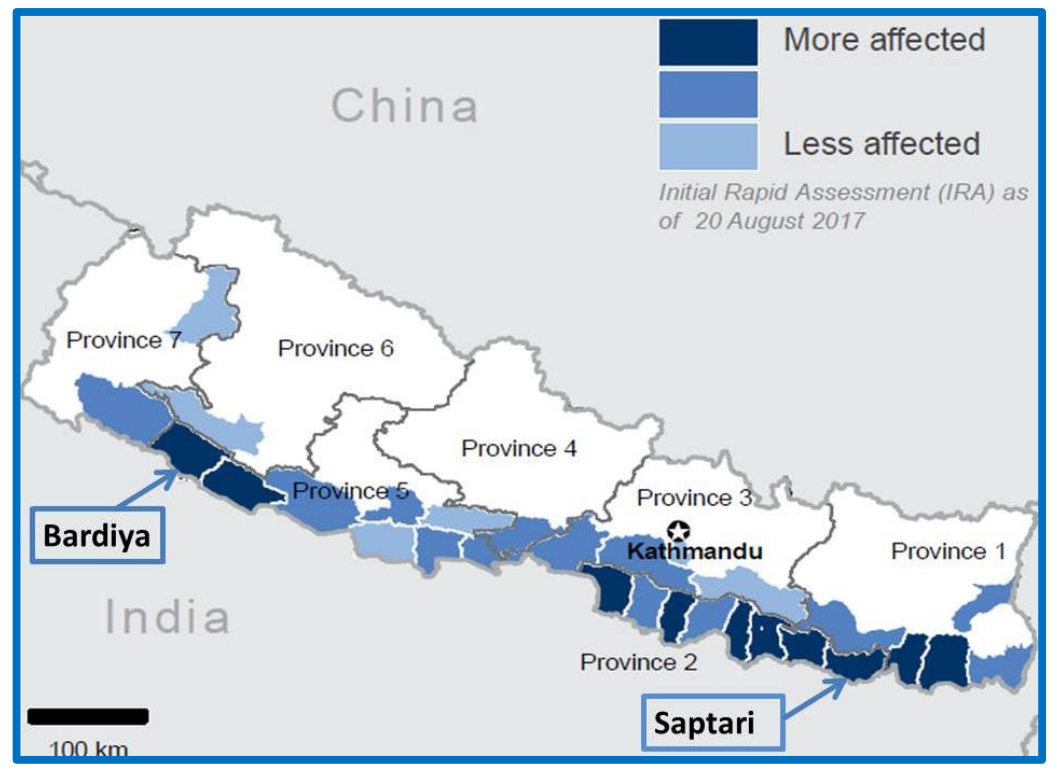

Source: United Nations Office of the Resident Coordinator, 2017.

By late August, 1.7 million people were affected and almost half a million people were displaced from their homes, more than 100 were dead, and scores missing or injured (United Nations Office of the Resident Coordinator, 2017). A total of 19 districts were affected with homes damaged in 181,000 households across the Terai. Homes built by squatters were especially vulnerable to flood damage. Flooding also destroyed road, bridges, culverts, and many communities, including in Bardiya and Saptari where interviews took place. Nearly 1,500 schools were damaged or destroyed and 93 schools were used for temporary shelter by displaced households who were not sheltering beneath tarpaulins on roadsides. Global Acute Malnutrition (GAM) rates among children screened reached 23.6 percent across the affected districts. Nearly 1 million farming households found their land inundated by flood water and almost 80,000 ha of crops were damaged. The Ministry of Agriculture and Livestock Development ${ }^{5}$ reported economic and asset losses of US\$8.12 million, US\$10.18 million, and US\$15.5 million, respectively.

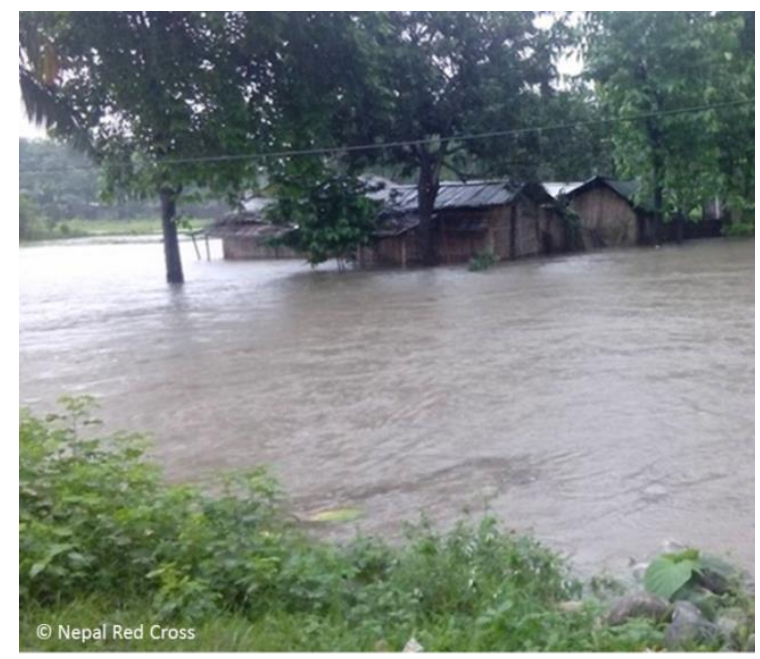

Besides these impacts measured by the Initial Rapid Assessment, our field study shows loss of infrastructure that supported agricultural production and other livelhoods, destruction of water and sanitation systems, sickness and loss of livestock, and dropout of children from education for labor work as some of the other impacts that will have bearings in the future. In the first two weeks of the response, 37,000 tarpaulins from government warehouses were provided to displaced families with a further 30,000 ready for distribution. About 18,000 households were

\footnotetext{
${ }^{5}$ Then called the Ministry of Agricultural Development, Livestock, and Irrigation
} 
provided with non-food item (NFI) kits. Households also received hygiene kits, blankets and mattresses, food, water purifiers, and jerry cans. Health camps were established and staffed by 1,595 health workers providing, among other services, hygiene messaging given the risk of cholera and other waterborne diseases.

\section{Assessment of the response}

Delalay et al. (2018) find that, in addition to climate change and socioeconomic developments, multiple and complex factors contribute to growing vulnerability to floods in Nepal. They include the lack of flood risk preparedness (for example, lack of flood risk assessments and an acute shortage of adequate flood early warning systems [FEWSs]), as well as inadequate efforts in flood disaster response and flood disaster recovery. Together, these factors point to limited flood disaster governance. In Bardiya and Saptari, it was clear that improvements had been made following the floods in 2014 and the mechanisms

'Our important things should be kept in an emergency bag'

FGD, Saptari District, April 2018

In Bardiya and Saptari improvements to preparedness appeared, in large part, to be supported by district-level single women's officers or leaders or chairpersons of user groups. As part of their work they were supporting flood preparedness by holding meetings informing women about the need to have key documents with them in plastic bags and telling them where and how to store food.

for early warning had substantially improved by 2017. This included the identification of safe spaces, alternate water and sanitation systems, and stockpiling of relief materials being in place in most of the districts.

An overall assessment of the 2017 response also reflects the transition stage that the government is going through. There was some confusion between districts and municipalities/rural municipalities about the roles of new local government structures. District line agencies of the government carried out recovery activities from their core program. In the absence of the DDC structure, former DDC staff were often involved on an informal basis. In terms of the identification of needs and beneficiaries, the District DMC completed two rounds of assessments, the Initial Rapid Assessment and the Multi Cluster Initial Rapid Assessment or Cluster Specific Detailed Assessments in the floodaffected districts. In both Bardiya and Saptari, DMCs found themselves under-resourced. In Saptari,

\section{'This is like we need a sari,}

but we have got a

handkerchief'

Deputy Mayor, Gulariya,

April 2018 for example, the Emergency Operations Center had only has one police officer as staff, no separate rooms, and daily communication charges being borne by NGOs. During the 2017 flood, this lack or resources made it difficult for the DAO to continuously update its data system and give accurate information to stakeholders and carry out its own response.

The criteria for the identification of beneficiaries for flood response and recovery was not technically adequate to effectively understand people's needs. Flood-affected households were assessed based on whether housing was fully destroyed $(63,000$ households) or partially damaged $(118,000$ households). There was no assessment, however, of food stocks, or the impacts on livelihoods, especially sources of income.

As a result, targeting and relief distribution was hugely controversial. In several instances, it led to riots, and the government had to halt relief distribution. On the one hand, evidence emerges from both Saptari and Bardiya, of beneficiary lists and relief distribution being manipulated to the 
advantage of people who had good political networks. On the other hand, lack of clear communications about targeting mechanisms meant that people felt excluded and cheated even when decisions were made according to established procedures. For example, the reconfiguration of boundaries and consolidation of VDCs across municipalities and wards, left villagers not understanding why neighboring villages were included in their lists and believing

\section{'Among 135 victims in total, the poorest} were left out and other people had access to the relief.'

FGD, Saptari District

April 2018

In both Saptari and Bardiya, there were reports of households, particularly female headed households and other disadvantaged groups, being routinely excluded from relief after their names are removed from lists because the resources are inadequate for the caseload.

that resources had been misused and misallocated. Other boundaries were also at the forefront of the discussion about the floods, with many respondents at village, local government, and district level perceiving that residents in India just across the border had been protected by the closing of barrages, with the result that Nepali households suffered the brunt of the flooding.

\section{Implications for adaptive social protection}

The potential for using SP across different parts of the disaster cycle is shown in Annex 2, Figure 1, but three key messages are drawn out here. First, given that recurrent floods are anticipated to worsen due to climate change, with an increasing number of households vulnerable to flooding on Nepal's Terai each year, there is an important role for SP in mitigation and preparedness. However, given the scale and cross-border nature of the water management challenge, this will only be effective alongside investments in large infrastructures and high-level bilateral negotiation with neighboring countries.

Second, floods in Saptari and Bardiya did not affect only people who are deemed vulnerable due to age or identity (such as the elderly, single women or marginalized caste groups), although these groups experience problems accessing humanitarian responses beyond the immediate emergency universal transfers for all those displaced to the roadside or higher ground.

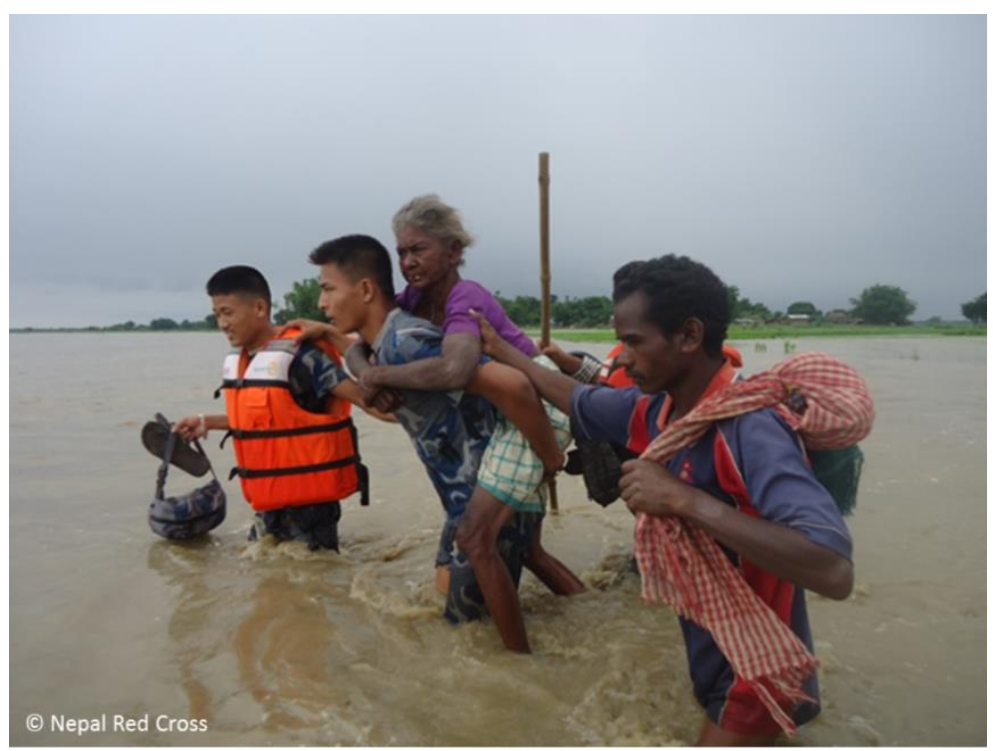

Third, for supporting flood response, it is unlikely that existing SP coverage in flood-affected communities overlaps with a large share of flood-affected households on the Terai, but it could form part of a coordinated response alongside other humanitarian activities. Hence, the ASP pathway should be used as an appendage to the emergency response and not as the sole route for relief distribution and targeting. 


\section{Earthquake in Sindhupalchok 2015}

Nepal's 2015 earthquakes affected about 8 million people, killed nearly 9000 people, and injured more than 22,000 . It left almost 3 million people in need of humanitarian assistance, many of them outside the Kathmandu valley

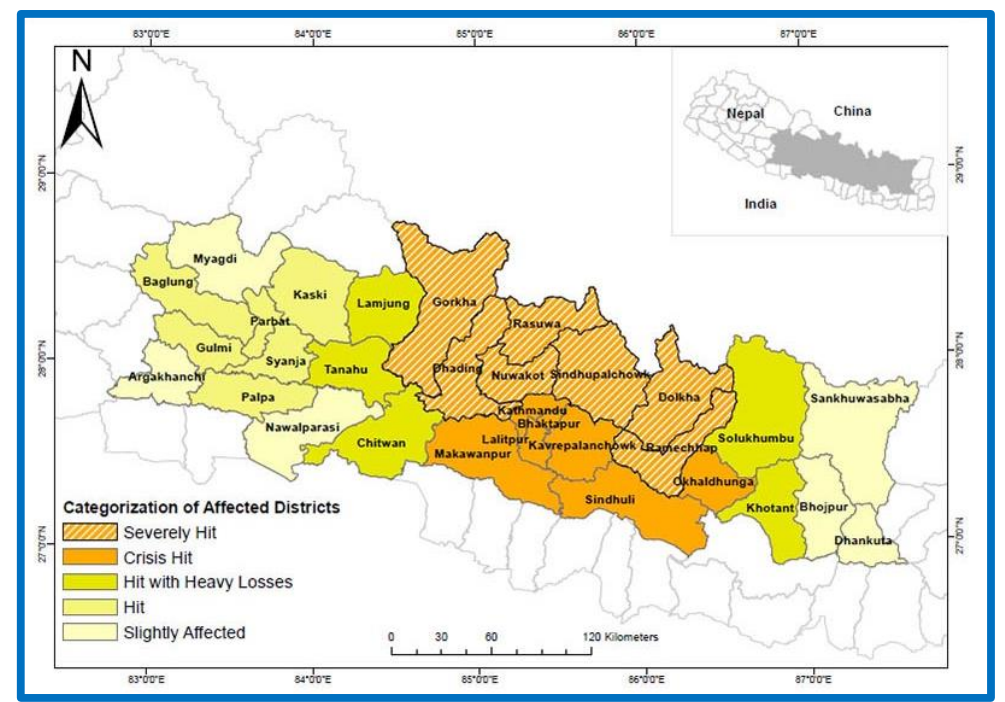

Source: GoN/MoHA 2015. cut off, as the earthquake destroyed transport infrastructure, energy supplies, and communications services.

Figure 12: Earthquake damage in Sindhupalchok (red $=$ most severe)

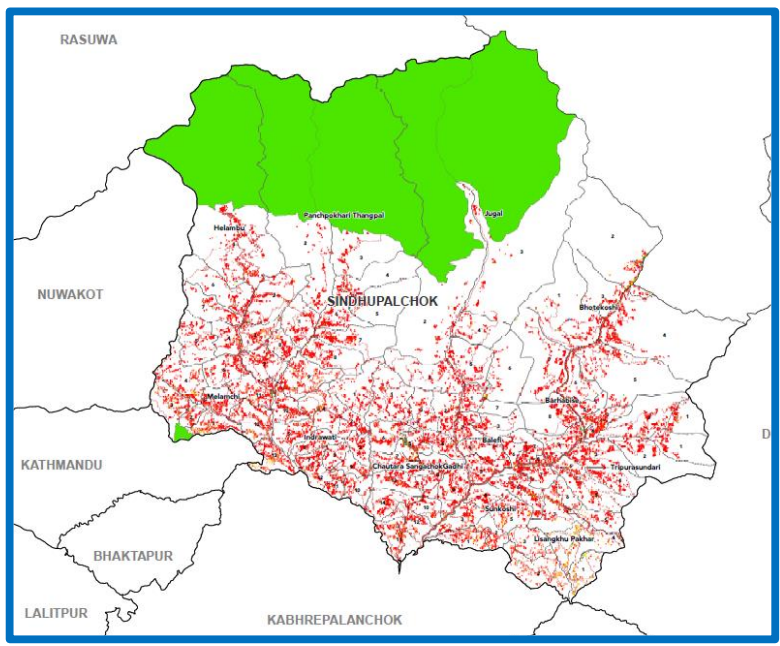

Source: Housing Recovery and Reconstruction Platform.
More than one-third $(3,425)$ of lives lost were in Sindhupalchok (Data from MoHA, May 2017). More than 63,000 houses were destroyed. Households in the district, classified as 'severely hit', were already in a precarious situation, having experienced severe flooding and landslides in 2014. Some households were still living in tents in warehouse buildings in 2018. Delalay et al. $(2018,356)$ stress the precariousness of wellbeing and livelihoods in Sindhupalchok District: 18 percent of households lack access to an improved source of drinking water; 11 percent do not have electricity for lighting; and toilet facilities are absent for 36 percent of households.

The response to the earthquake was vast, with the engagement of many actors and substantial sums of money and is too great to describe in any detail here. Instead we specifically focus on where SP was used as part of the response. SP was a key part of the earthquake response with the establishment of the ETCTP. The aim of the top up was to meet immediate household consumption needs and to help households avoid negative coping strategies and behaviors. NPR 3,000 (about US\$30) was provided as a top up to usual regular payments for existing beneficiaries of the old age allowance, widows/single women's allowance beneficiaries ages 60 or above, people with disabilities, households with Dalit children under five, and marginalized indigenous groups. This reached about 434,690 people in 19 districts. A second payment, to Dalit households with children under five followed later. 


\section{Assessment of the response}

There are numerous assessments of government, international agencies', and local NGO responses (see for example ALNAP 2015). These highlight the importance of working with and through national and local actors, tailoring coordination to local contexts, and using assessment as the foundation for an appropriate response. Geography and remoteness make these lessons all the more pertinent. Given the challenges of access, lack of transportation facilities, and blockades caused by debris, it was difficult to deliver material assistance in many places. Respondents, especially in the rural areas of Sindhupalchowk, complained of relief materials being distributed only in market areas and a large number of needy populations in remote areas being left out for days without food, water, and shelter. Respondents also noted that the response to flooding and landslides were largely subsumed by the earthquake response which occurred eight months later-this made it difficult to deal with the different needs that resulted from the different types of shocks.

In our fieldwork in Sindhupalchok, surprisingly there was little mention of the ETCTP. However, the United Nations Children's Fund (UNICEF) evaluation of the ETCTP found that about 93 percent of intended beneficiaries received the top-up transfer in the districts where it has been rolled out and that cash was most commonly used to meet basic daily needs such as food and medicine, plus clothing and other household essentials (Gurung et al. 2015). A small share of households used the money for shelter. There were limited impacts on livelihoods though Gurung et al. 2015 suggest that because cash was used to support household food security this would make them less likely to resort to negative coping strategies. There were many reports of trafficking increasing following the earthquake, but it is not clear how much the ETCTP protected SSA beneficiary households from these situations.

The ETCTP faced a number of administrative and implementation challenges, including the difficult access for beneficiaries to payment sites, static beneficiary lists (that, at that time, were only updated annually), and delays approving payments. VDC staff reported struggling to meet the burden of this additional responsibility at a particularly difficult time. In spite of these shortcomings, the ETCTP was viewed as a success and represents a highly informative experience that Nepal can learn from, particularly for shocks that are rapid onset and shared across a wide number of people in specific geographical locations.

A key element of the ETCTP was the inclusion of behavior change messaging, in particular to try and discourage negative coping strategies. It is not clear how effective this process is-awareness of the messages was low because there were delays getting pamphlets and leaflets out to VDCs. Grants have been widely provided to households to subsidize the costs of reconstruction and these also include an element of mitigation as the grants are subject to following building design and construction guidelines that make households more resistant in the case of earthquakes.

For longer term rehabilitation and recovery, the GoN used a cash transfer mechanism after establishing the NRA in late 2015. After surveys of damage and developing of several policies and guidelines such as those for housing grant distribution, reconstruction regulation, and around working with NGOs, the Post-disaster Recovery Framework decided to route recovery and reconstruction support to households through cash transfers. 


\section{Implications for adaptive social protection}

The potential for using SP across different parts of the disaster cycle is shown in Annex 2, Figure 2. Two lessons from ALNAP (2015) are especially pertinent to ASP: the importance of supporting preexisting goods and service delivery systems; and paying special attention to marginalized, hidden, and vulnerable populations.

These lessons suggest that disaster response to rapid onset shocks for which there is little warning can work through pre-existing service delivery systems, particularly SP. Indeed, given that SP in Nepal is heavily focused on various forms of vulnerability, expanding transfers to vulnerable groups (for example, the elderly, single women, the disabled, and Dalit households) may prove an effective mechanism to reach those who would otherwise be left out. The findings also highlight the importance of other investments, particularly pre-positioning of food stocks through the Nepal PFDS to ensure that when cash transfers are delivered, there is food available in markets at affordable prices.

Lack of banks in rural areas and the difficulties and costs for those who are travelling to collect transfers present a real obstacle for flexible and rapid emergency responses. In cases where banks are not present, alternative ways to get transfers to beneficiaries need planning in advance. This might be branchless banking or use of local savings and credit groups and community cooperatives. Disaster recovery can also be a trigger for the expansion of bank accounts-for example, the NRA was successful in opening around 600,000 new bank accounts for house owners in 32 districts.

Although the response to the 2015 earthquake highlights that the country was poorly prepared for disaster response, including limited planning for using cash transfers, several approaches were tried and there are important lessons to draw for disaster management and ASP. In particular, forward planning and the development of roadmaps and guidance for emergency top ups will allow a far more rapid response in the future. The inclusion of behavior change messaging activities in the ETCTP highlights that SP can play an important role in mitigation, preparedness, and recovery, that is, beyond disaster response alone. 


\section{Case}

Study:

Drought

in Karnali,

2015-

2016

In 2015, a combination of limited winter snowfall, and poor monsoon rains led to a sharp decline in the summer and winter

\section{Agricultural drought conditions in Mid and Far West}

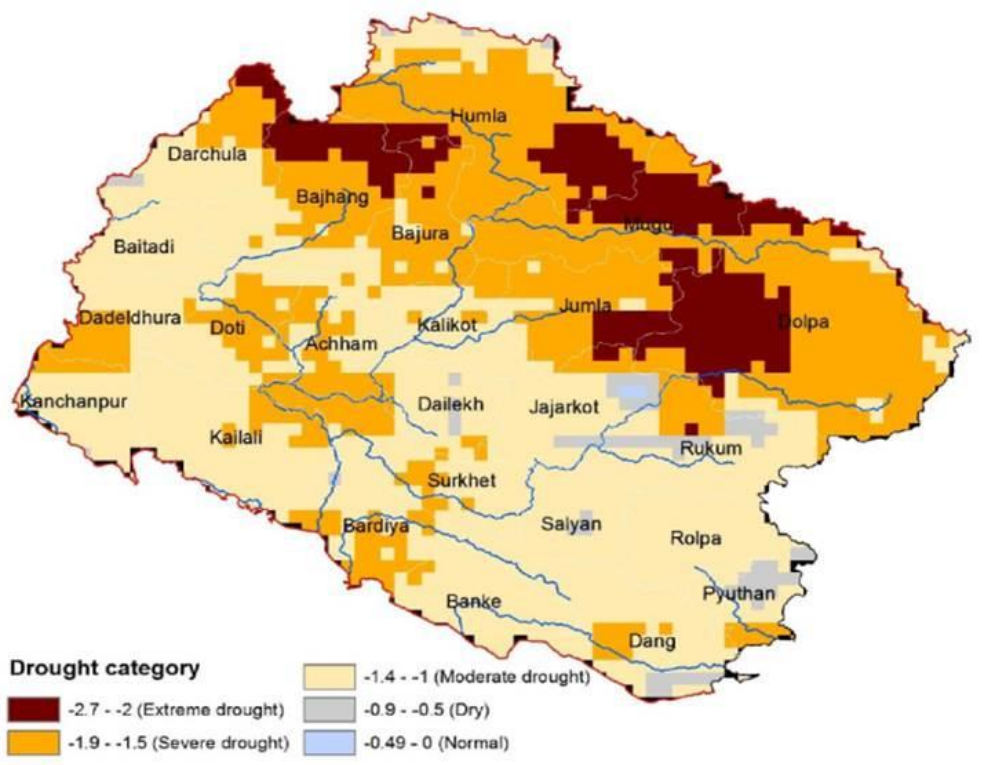

Source: MoA Food Security Cluster Meeting, 2016

crops. Between November 2015 and March 2016, around 87 percent of Karnali's population were estimated to be highly or moderately food insecure.

The NeKSAP found evidence of households selling productive assets to get access to food and health care costs, and individuals in remote areas walking for many days to towns such as Simikot to find sources of affordable food. Migration out of Karnali increased substantially, especially to the areas around Nepalgunj and across the border into India, and notably among Dalit households.

Our interviews in Humla, specifically in Simikot and nearby villages, found evidence of food shortages, livestock loss, livelihood insecurity, and severe deprivation poverty and famine. While drought directly affects those with agricultural land, others without land are also affected because there are fewer casual work opportunities in agriculture and because the reduced supply of food into local markets pushes up prices.

\section{'If there is no rain then we have a} drought. The political party leaders do not give us any rice. $25 \mathrm{~kg}$ of rice is costing NPR 5,500. It is 3-4 years since the last big drought, we had to chop the heads off all the wheat, barley, and millet and give it to the cattle.' Focus Group, Simikot, April 2018

Geographical factors including remoteness increased the vulnerability of victims to drought due to limited road access and higher transportation costs for food supplies. Karnali has notably fewer road networks than other parts of Nepal making food distribution and market access more difficult and costly. This was compounded by the economic blockade which pushed up costs of transportation further still. The average retail price of coarse rice was three times higher in Humla (NPR 120 per $\mathrm{kg}$ ) compared to Darchula (NPR 39 per kg). For wheat flour the price was NPR 120 per kg in Humla compared to NPR 45.9 per kg in Darchula (WFP 2017). 
NeKSAP food security indicators for Bajura, Dolpa, Humla, Jumla, Kalikot \& Mugu

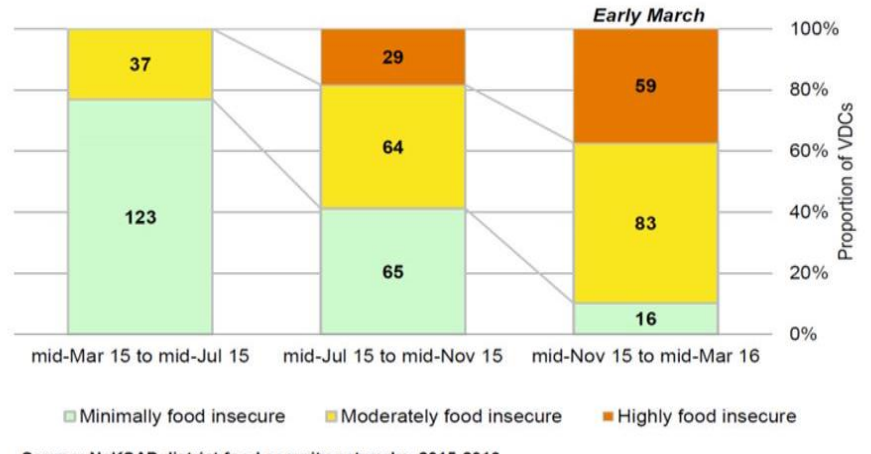

Source: NeKSAP district food security networks, 2015-2016

\section{Assessment of the response}

The response in Karnali, including Humla, was tricky to assess. The primary reason is that drought is not viewed in the same way as other disasters such as floods or earthquakes-indeed the focus of many agencies was still on the most earthquake-affected districts east of Karnali. There was far less urgency regarding response to the drought in 2016, perhaps because the impacts of drought emerge slowlyfollowing snow or rainfall failures, it is only later at harvest time that drought begins to have an impact. A second reason is that defining or declaring a drought disaster is far more complex than cases of earthquakes, landslides, fires, or floods. There are debates over definitions. The thresholds at which, food security indicators trigger an emergency response are not agreed, especially because high levels of GAM are common in Nepal irrespective of whether a natural disaster has occurred.

Respondents reported that WFP provided supplementary feeding in some parts of Humla although WFP's Emergency Operation (EMOP) reports support only in Jumla and Mugu. More than 500 MT of super-fortified cereals were provided across Karnali. Stocks in food depots were increased. There were some examples of wards/VDCs seeking to increase public works wage rates or allocation days to beneficiaries, but these are largely anecdotal.

Despite strong views that the climate is changing in Humla and that drought was becoming more frequent, there is was little evidence that drought mitigation and preparedness efforts were being stepped up commensurately. Respondents spoke of vegetables (potatoes, onions, garlic, radish, carrots, and cauliflower) and fruits (apples) which were not previously cultivable in Humla but were now thriving. Focus group participants reported that in the past there have been external interventions led by the Department of Agriculture and NGOs that addressed diversification of crops in light of changing climates but, in the shift to local government, it was not clear how this would be maintained. The CDO argued that more needed to be done on the education and growing of awareness on the nutritional value of diverse diets to counteract the stress of limited crops during the lean season. 


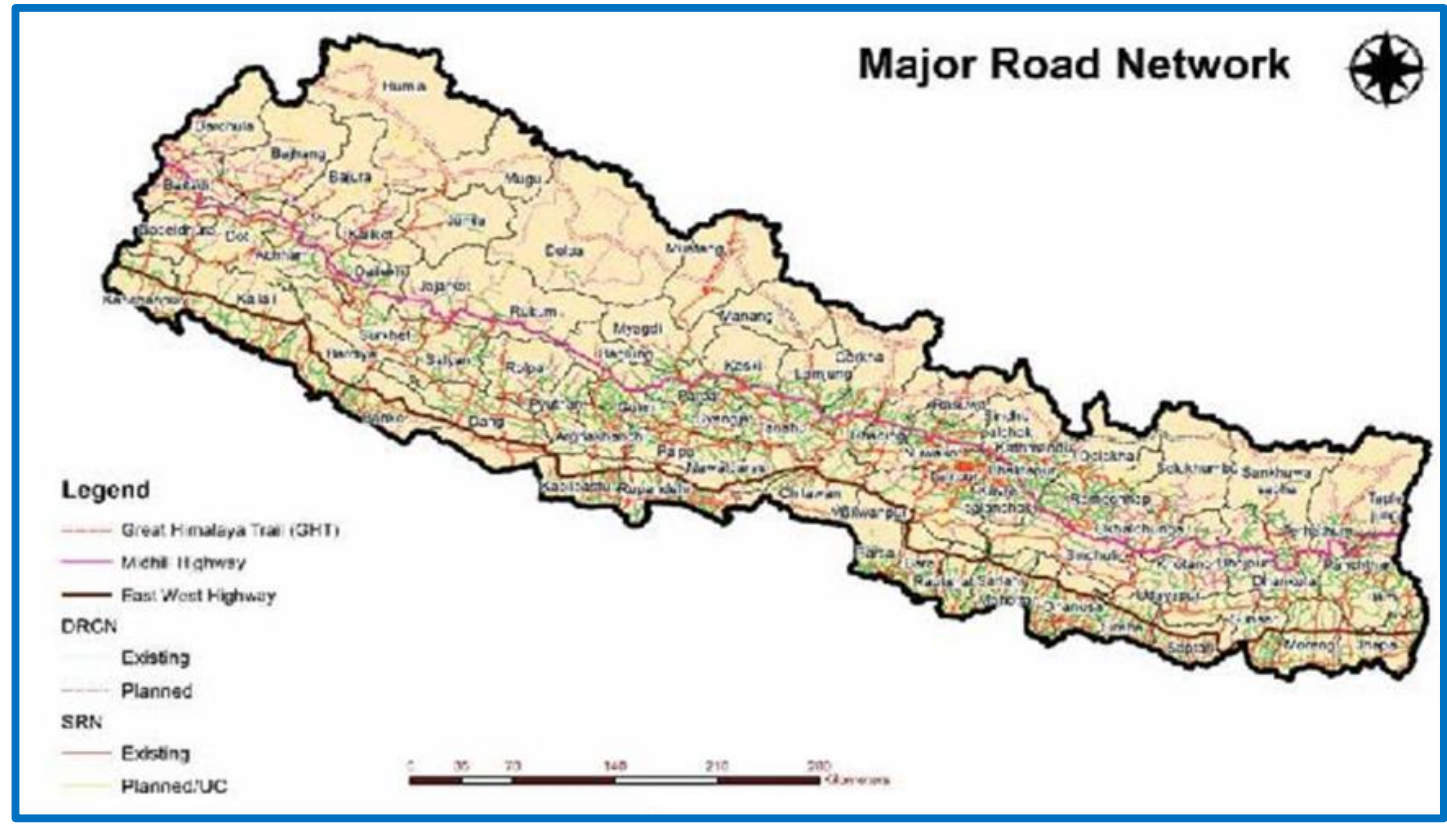

Source: Ministry of Federal Affairs and Local Development Department of Local Infrastructure Development and Agricultural Roads (DoLIDAR) (2016) 'Statistics of Local Road Network (SLRN) 2016', Kathmandu, Nepal

\section{Implications for adaptive social protection}

The potential for using SP across different parts of the disaster cycle is shown in Annex 2, Figure 3. The slow onset nature of drought provides good opportunities for disaster mitigation and preparedness through SP. There is particular potential for the works carried out through programs such as the KEP and RCIW to contribute to mitigating drought. Rather than focus solely on road construction, public works could include the construction of check dams and small-scale irrigation infrastructure, maintenance of terracing and afforestation to reduce degradation, and improving soil structure and water-retention capacities.

ASP systems can allow the introduction of mechanisms and interventions that look to reduce the impact of droughts on

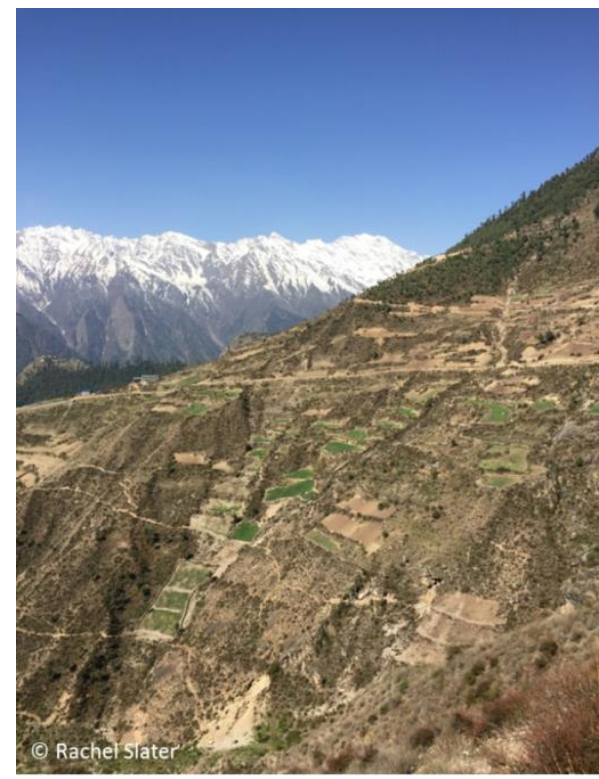
households. Scaling up to increase coverage of PWPs - such as the KEP and RCIW-can reach more drought-affected households. Given the oversubscription for public works activities in Humla, ward offices already have ranked community lists that allow them to quickly identify an additional caseload if emergency funds are routed through PWPs.

This appears particularly important given the significant structure of economic and social changes underway in Humla. Respondents said that an increase of access to education and changing employment opportunities outside were making it difficult to sustain traditional livelihood activities. Although labor migration might bring remittance income in the future, many felt that it exacerbated the hardship experienced by households: because rearing or tending to livestock, was formerly done by children and young people, but was foregone due to education and migration. The impact of less livestock meant less dung for fertilizing the soils and less spare cash from sales of livestock/meat. 
Case Study:

Fires and

Landslides

During the monsoon, Nepal's newspapers and other media are replete with news of landslides, while in February, March, and April, the focus switches to incidents of fires. However, most fires and landslides in affecting whole villages, or more are far less common. This has major implications for the extent and ways in which ASP will be useful for managing fire and landslides risks.

The extent to which trends, events, and impacts can be rigorously analyzed is severely limited by the idiosyncratic nature of fire incidences. Data on fire incidents is mainly collected from news reports. This creates two potential biases in the data: (a) they capture reports on bigger incidents and are less likely to pick up on incidents that affect small areas/number of households or those in remote rural areas; and (b) news reports are rarely based on rigorous and verified measures of either incidence or impact. There is often little data demonstrating extent of damage or cost of damage.

Figure 17: Prevalence of forest fires, 1971-2011

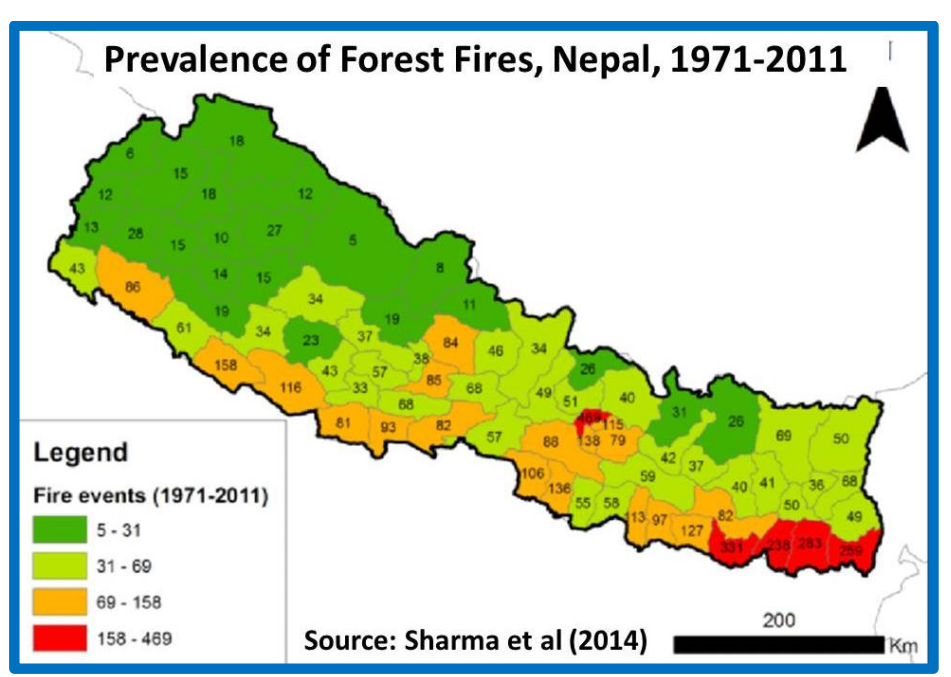

Larger fires are seasonal, especially on the Terai. For example, in Humla, it was reported that pastoralists set fire to land to encourage new growth of grass. So, setting fires was a key livelihood strategy in some areas. April in Humla is renowned for guchi mushrooms harvesting, fetching from NPR 8,000 to 10,000 per kilogram. Mushroom harvesters sometimes set fires to encourage the mushrooms to sprout better.

Two kinds of landslides frequently

occur in Nepal: seismic landslides which are triggered by earthquakes and monsoon landslides triggered by high intensity rainfalls. Aftershocks of the 2015 earthquake alone produced 25,000 landslides (Roback et al. 2017). The monsoon causes landslides every year. However, unless it causes massive loss of lives and infrastructure, it does not get reported. 


\section{Assessment of the response}

Despite clarity on paper there is confusion in practice: officials are unclear if responsibility for compensation payments will stay with the district or shift to the local government and respondents reported varying amounts-from NPR 5,000-500,000. Compensation rates are generally viewed as inadequate by victims. The mechanisms for responding to individual fires, specifically payments to affected households, appear
53 families displaced in Darchula

As many as 53 families have been displaced due to floods and landslides in Naugad Rural

Municipality, Darchula, in the past one week. Floods and landslides have destroyed at least six homes and rendered many others uninhabitable, said Prem Singh Dhami, the chairman of the rural municipality. Kathmandu Post 19th July 2018

clear at the local level, despite disruptions due to the transition from district to local government administrative structures. At the district level, funds are distributed to fire and landslide victims. Standard guidelines for provision of compensation is provided by the 2017 Rescue and Relief Standard for Disaster Affected (6th amendment, 2074). This amounts to NPR 1 lakh per person for death, up to NPR 10,000 for destruction of houses, food, crops, and business premises. Up to NPR 5,000 can be provided for housing and clothing if the affected households remain displaced based on assessment by the district DMC. A further NPR 50,000 per family can be given by the center based on district recommendations. Refunds for government hospital treatment and NPR 1,000 per person plus travel costs are given in case of injury during a disaster.

Preparedness for fires was focused on during awareness raising. In Saptari, this was dealt with collectively by a range of agencies and NGOs. Local radio stations and TV channels also broadcast messages to raise awareness. Pamphlets are handed out. The main messages broadcasted included telling people not to light open fires in their homes and not to leave fires unattended. It was expressed that people heeded to the messages and the general consensus among respondents was that fires were less frequent than in previous years. In Bardiya, awareness raising sessions were targeted at schools. In Humla, community forestry user groups were raising awareness about fires to prevent fenced forest lands being set alight. For landslides, there were no reported activities for raising awareness. Tree planting had not taken place for some time in Humla. There was inconclusive evidence to demonstrate whether food items and NFIs were given to fire and landslide victims. People often depended on the support of neighbors following fire incidents.

\section{Implications for ASP}

There is little scope for SP to systematically respond to idiosyncratic shocks from fires and landslides (as can be seen in Annex 2, Figures 5 and 4 respectively): SP is not targeted specifically to these events; SP beneficiaries are no more or less likely to experience landslides and fires than nonbeneficiaries; and systems are in place to compensate individual households that are victims of landslides and fires. Given the relatively rarity of covariant fire and landslide shocks, any policy decisions regarding them might best follow any future systems established for floods or earthquakes. There is a significant opportunity for PWPs to support fire and landslide mitigation, preparedness, and recovery. While programs currently focus primarily on road construction, other works activities - such as the construction of water storage facilities at the village level to tackle fire, or afforestation programs to support the soil structure and prevent land slippage-might be considered to simultaneously support the incomes of poor households and reduce the incidence of fires and landslides. 


\section{Chapter 5: International Experiences with Adaptive Social Protection}

\subsection{Introduction}

This chapter draws on lessons from other countries to provide insights into the options that the GoN and its development partners might choose to adopt to more usefully utilize SP to support DRM in Nepal. The focus is on 'best fit' rather than 'best practice' experiences to ensure that the lessons are feasible in the Nepal context. We draw in particular on (a) countries with similar levels of human development indicators and with similar financial and administrative capacity rather than on SP systems that will require more resources than Nepal has at its disposal; and (b) what might be feasible with further resourcing-particularly from international and donor agencies-by drawing examples from countries where there have been strong partnerships between governments and donors. We also draw out lessons from countries that have federal systems of government (for example, Ethiopia), especially those that have recently made the transition to federalism (for example, Kenya)

The existing evidence on international experiences is disproportionately focused on (a) responses to the 2008 economic crises, when food prices and fuel prices skyrocketed and when elements of global financial systems collapsed and (b) the role of SP in shock response compared to other elements of DRM. We seek to explicitly bring out what is known about other elements of response (mitigation, preparedness, and recovery), and focus as much as possible on shocks beyond food, fuel and financial (3-Fs) crisis.

The chapter is divided into three sections. The first explores what is known about the roles of SP in contributing across the different pillars of DRM (mitigation, preparedness, response, and recovery). The second examines the key features of ASP programs that have been identified in reviews and evaluations. Selected examples focus primarily on countries with federal systems-and the opportunities and challenges that this affords. In the first two sections we note the implications of international experiences for Nepal and then, in the third section, suggest specific priority areas and actions across the administrative, financial, and program design and implementation domains for Nepal.

\subsection{Disaster management through SP}

\subsubsection{Disaster mitigation}

Disaster mitigation through SP happens in two ways. First, SP programs can reduce the underlying structural vulnerability that exposes households and individual to hazards. Second, specific features of SP programs, especially the assets created through public works, can contribute to reducing both the prevalence and the severity of hazards.

\section{Reducing the underlying vulnerability to hazards}

SP reduces poverty, vulnerability, and exclusion in numerous ways. Bastagli et al. (2016) use a systematic review to consider six outcomes of cash transfers-monetary poverty, education, health and nutrition, savings/investment/production, employment, and empowerment. All of these are 
outcomes that can be related to people's exposure to shocks and their capacity to buffer themselves against their worst effects.

For monetary poverty, the evidence sourced for the review consistently shows an increase in total and food expenditure and reduction in poverty measures. There are impacts on household expenditure, in particular food expenditure, though the effect is not always big enough to have a subsequent effect on aggregate poverty levels.

In education, there is a clear link between cash transfer receipt and increased school attendance but less evidence of a clear-cut pattern of impact for learning and cognitive development outcomes. For health and nutrition, cash transfers are found to support improvements in use of health services, dietary diversity, and anthropometric measures. This finding suggests that cash transfers alone may support the first two of these improvements, making a difference to anthropometric measures requires complementary interventions.

In the case of employment-participation in and intensity of-cash transfers result in an increase, but one that is not statistically significant. Where reductions in employment are reported they are usually among the elderly, with child care responsibilities, and in casual rather than secure work. In other areas related to livelihoods, positive effects of cash transfers are also found for impacts on savings, livestock ownership or purchase, and use or purchase of agricultural inputs-suggesting that cash transfers can not only improve livelihoods and income-generating opportunities but also allow households to build up savings that can provide a critical buffer during a disaster.

For empowerment, transfers are found to reduce physical abuse of women by men, and possibly to increase non-physical abuse, such as emotional abuse or controlling behaviour. Bastagli et al.'s 2016 review supports the theory that increased income lowers stress-related abuse, and the theory that increased income enables the woman to bargain out of abuse. Cash transfers are also found to reduce risky sexual behavior and early marriage and reduce the incidence of transactional relationships. Evidence also suggests that they reduce fertility rates (despite the frequent assertion that cash transfers will lead to people having more children).

The lesson from all the literature is that these positive effects occur when programs are well implemented, that is, they target beneficiaries well and deliver transfers on time, for a reasonable duration, and in adequate amounts. The quality of basic implementation thus matters for disaster mitigation but, as we will see in subsequent sections, it matters for preparedness, response, and recovery too.

\section{Reducing the prevalence and severity of hazards through SP}

Several natural disasters can be reduced through SP. The science around landslides is complex but overall suggests that afforestation can reduce landslide risk (Forbes and Broadhead 2011). The FAO notes that "Public works programmes are desirable in that they can be used to mobilize community participation in environmental projects, and they provide local employment, build community infrastructure, enhance skills, protect against shocks and increase resilience." Thus, the roles of afforestation in tackling drought are also widely acknowledged (UNISDR 2016) and the secondary impacts on other disasters, notably floods, are also recognized. 
There are numerous PWPs that include afforestation activities. In Uganda, the SAFE programme is implemented as part of the Karamoja Productive Assets Programme, which provides food and cash for work in Karamoja. Karamoja is one of Uganda's poorest, marginalized, and conflict-affected areas and has experienced severe environmental degradation and recurrent droughts. Activities include cash or food transfers to food insecure pastoralists and agro-pastoralists in exchange for work on land and soil conversation measures, livestock watering points, and reforestation. About 14,000 trees were estimated to be planted during the program's lifetime. In drought-prone Mauritania, 300,000 trees were planted as a part of a WFP project. The program sought to build resilience by providing food transfers in exchange for planting trees, building dams, and planting of forests for the supply of community firewood (Tirivayi 2017).

Other key activities in PWPs include the construction of terracing, check dams, small-scale irrigation systems, and other soil and water conversation measures with impacts on prevalence of not only landslides but also floods and drought. There is potential for better water resource management through public works to also reduce the risks of fire.

\section{Links with other programs for disaster mitigation}

Sometimes it is possible for the two pathways above to be integrated. In these cases, SP needs to be linked to other programs to have strong disaster mitigating effects. Cash transfers alone may have relatively modest impacts but combined with other interventions can have stronger impacts. Evaluations in Ethiopia find that households participating in the Productive Safety Net Program (PSNP, more on this program below) alongside other food security programs saw a greater positive effect on food intake and income diversification. Households were more likely to be food secure, to borrow for productive purposes, use improved agricultural technologies, and operate their own nonfarm business activities. The latter is particularly important as it allows participants in Ethiopiawhere livelihoods are heavily focused on agriculture and highly susceptible to drought - to diversify their activities and have other income sources should drought occur (Gilligan, Hoddinott, and Taffesse 2009). Similarly, Andersson, Mekonnen, and Stage (2011) found that among PSNP participants, improved credit access (part of the suite of other food security programs) is associated with increased livestock holdings, suggesting that PSNP participation can lead to increased asset holdings that households can use, rather like savings, to buffer themselves against the impact of drought.

Other important links are with microfinance and microcredit programs. For example, Vakis (2006) notes that microfinance schemes can also help ex ante income diversification which can mitigate against widespread natural disasters. Bangladesh, where numerous SP programs are provided in parallel with microfinance, provides a good example: both floods in 1998 had a serious deleterious impact on primarily peak season economic activities but microfinance programs allowed households to diversify their income-earning activities across seasons and so the impact of peak season disasters was reduced (Pitt 2000).

\subsubsection{Disaster Preparedness}

There are rather few examples of how SP can contribute to preparedness but there are some insights from examples of messaging and add-on elements to programs. In Bangladesh, the Chars Livelihoods Program includes activities such as plinth-raising to protect households on the Chars (riverine islands) when the monsoon brings an annual rise in the water level. Other instruments, 
especially those that are frequently delivered in parallel to SP can also be important. Microfinance instruments contribute to preparedness as they can be used to establish local groups that then participate in civic and political organizations investing in preventive measures such as drainage, emergency warning systems, and food storage (Vakis 2006).

In the scaled-up SSA delivered as part of the 2015 earthquake response in Nepal, UNICEF attached behavioral change communications to cash transfer payments to support disaster mitigation, preparedness, response, and recovery. The international experience using SP to support preparedness messaging is limited but there are many parallels that can be drawn from SP that have used messaging to support, for example, improved health (Bradley, McFarland, and Clarke 2014; Hoddinott et al. 2017; Roy et al. 2017).

\subsubsection{Disaster Response}

Using SP to support shock response is the area that has received most attention in the literature, and most of the lessons about the implementation capacities to scale up are to be found here. A number of different types of programs have been scaled up during crises, especially school feeding programs, cash transfers, and public work programs. Scaling up can be either vertical (increasing the support given to existing beneficiaries) or horizontal (reaching new/temporary beneficiaries).

Countries that have scaled up school feeding programs include Haiti, Liberia, Senegal, and Togo. In addition to providing food for school-going children there are further benefits-they encourage parents to continue sending children to school and, where take-home rations are included, also allow other household members to eat. Targeting errors include households without children of school-going age or those so poor that even the incentive of food transfers does not outweigh the other costs, including opportunity costs, of sending children to school. The Kenyan Government has used the Expanded School Feeding Programme to offset negative effects of drought on education (Government of Kenya 2012) and WFP found that the program reduced dropout rates during drought periods (WFP 2011).

In terms of PWPs, the exemplary example is the PSNP in Ethiopia (Box 4). The PSNP reflects a serious attempt by the Ethiopian Government and both humanitarian and development agencies to shift from annual appeals for emergency assistance (usually to cope to with seasonal drought) to a more predictable and long-term response to chronic food insecurity. In this way it is insightful for seasonal disasters in Nepal, including floods and drought. For unconditional cash transfers, Kenya's Hunger Safety Net Program (HSNP) provides a useful example (Box 5).

Some programs add a specific additional component during a shock to address a specific element of vulnerability or exposure. The Mi Familia Progresa program in Guatamala, began in 2008 and by 2011 reached more than 900,000 households or about 25 percent of the population. The increase in beneficiaries was planned but not at the pace that it occurred at. The food, fuel, and financial crisis of 2008 forced a faster rollout than initially planned. What is important about the Mi Familia Progresa program is that although it covers many of the usual features of a conditional cash transfer program, in the context of a food price crisis an additional focus on nutrition was added with activities to strengthen community-based nutrition services and provide extra micronutrient supplements (Grosh et al. 2011). 
The Productive Safety Net Programme (PSNP) covers around 8 million beneficiaries each year, usually providing six months of food, or cash, or a combination of the two. Transfers are provided in return for the delivery of labor intensive public works to around 80 percent of beneficiaries with the remaining labor-constrained households not required to work. The program has a number of different mechanisms to support scale up. Contingency funds account for 20 percent of the budget annually and is held at the federal, state, and woreda (district) levels allowing decisions to be made for both large-scale shocks and those that are geographically more limited. There is also a Risk Financing Mechanism (RFM) that pre-positions resources at the national level. The release of the RFM was triggered in 2011 to nearly 10 million people. About 6.5 million were existing participants in the PSNP and received top-up support. The other 3.1 million were people in PSNP districts, who in a normal year did not need additional assistance, but in 2011 received up to three months of support to secure their food consumption needs until the harvest. The PSNP RFM provides an example of how drought, or other seasonal disasters that can be forecasted, offer particular opportunities to scale up SP.

Institutional arrangements. Scaling up the PSNP requires strong interagency, interministerial, and intergovernment coordination between those with concurrent mandates for delivering SP and humanitarian responses. Figure 18 shows the roles of different ministries and development partners and how programming regulations are filtered through the various levels of government. Compared to other countries, because the PSNP is housed, along with other programs aimed at tackling food security, in the MoA, coordinating and managing contingency is somewhat easier than in other countries where SP is housed in different ministries to disaster management and humanitarian response.

Figure 18: Institutional arrangements for Ethiopia's PSNP

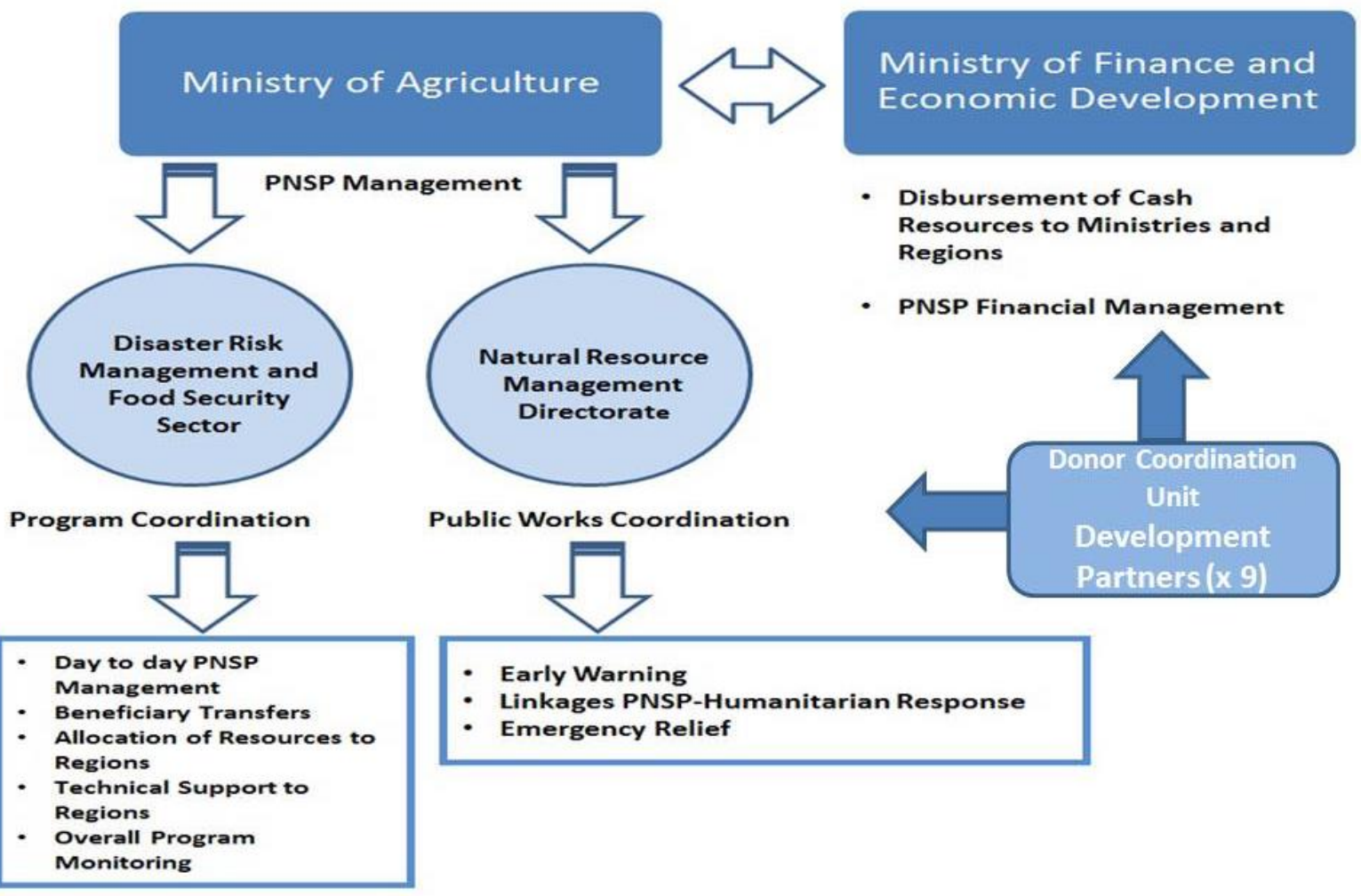

Source: Adapted from World Bank 2013b. 
In Kenya, scale up is possible in merely a number of weeks, owing to mobile point-of-sale (POS) devices through which payments can be made to pre-registered temporary beneficiaries. The HSNP was designed with the capacity to anticipate shocks from its outset. Its operational procedures are shock sensitive-for example the payment of transfers through POS devices allows people to access their payments despite very low population densities and few banks in the northern areas of Kenya and makes getting money to people a faster process. In April 2015, the HSNP was able to make payments to an additional 90,648 households as northern parts of the country began to suffer the worst of an extreme drought. Fitzgibbon (2016) notes that this scale up was faster "than any other previous humanitarian mechanisms on the continent." The scale up in Kenya depended on four key design features. First, the program pre-registered both regular beneficiaries and a set of households that were not regular recipients but would receive transfers when food security and other wellbeing indicators were threatened. Second, the HSNP depends on satellite mapping to produce a vegetation condition index $(\mathrm{VCl})$ to trigger additional payments. Since most of its beneficiaries are pastoralists or agro-pastoralists, vegetation cover is a key indicator of forage for livestock and so a proxy for wellbeing for communities. Finally, the HSNP staff made huge efforts to ensure that all those registered were supported to get bank accounts (78 percent of households in 2015), allowing payments to be made anywhere with a POS device.

Although the type of payment system and the pre-registration of potential beneficiaries are the key elements of the HSNP design that allow scale-up, the institutional arrangements for the HSNP are also important. While other unconditional cash transfers in Kenya (cash transfer for orphans and vulnerable children, older persons, and people living with disabilities) are housed in the Ministry of Labour and Social Protection, the HSNP is executed through a program implementation unit (PIU) of the National Disaster Management Authority (NDMA) which has responsibility for all drought response and management activities in the country. This allows direct coordination between the HSNP implementation and wider disaster management activities.

There are also programs that are useful alongside social transfers. Subsidies are a common intervention in response to economic shocks and this was notably the case during the 2008-2009 food and fuel price crisis. In 2008, a survey by the International Monetary Fund of country responses in 2008 saw 33 countries reducing taxes on fuel and 29 countries increasing subsidies (Grosh et al. 2011). They note that this is a possible alternative to SP where administrative systems are lacking, because it is easier to resort to widespread market interventions. Subsidies are often regressive rather than progressive in their impact ("when they delivered some relief did so irrespective of need," Grosh et al. 2011, 17) but not always. During 2008, Bangladesh, for example, began an open market sales program-a self-targeted program to buy small amounts of rice at subsidized prices. There are existing targeted subsidies for food in Nepal, notably the PFDS, that warrant further investigation, especially if administrative capacity to deliver an ASP at the local level becomes difficult among the new and fledgling local institutions, or if no other contingency measures are in place.

It is important to note that, while withdrawing subsidies is challenging, so too is scaling back after the horizontal expansion of a cash transfer program. In many countries, especially in Latin America, the food, fuel, and financial crisis saw very rapid expansion of numerous programs (Brazil, Colombia, Costa Rica, Equador, Guatamala, Mexico, Paraguay, and Peru) and very few have scaled back subsequently. For example, OPM (2017) note that for the Solidaridad program in the Dominican Republic an intended scale up was delivered far faster than planned from 1.2 to 2.1 million households in 2008 and has retained the same number of beneficiaries since then. 


\subsubsection{Disaster recovery}

Just as PWPs can mitigate disaster risks, so can the assets that they create: they also support rehabilitation of natural resources which, in turn, can mitigate against future hazards. FAO $(2013,1)$ notes that "the rationale for choosing a public works programme over other cash transfer (CT) modalities is based on the assumption that the creation and rehabilitation of vital community assets provides beneficiaries with better protection against future shocks which can negatively affect livelihoods in rural settings." Examples include making simple repairs to roads, clearing irrigation channels, repairing agricultural land (for example by clearing alluvial deposits from flood events), and replanting trees.

Bowen (2015) notes that, in the Philippines, guidelines for the National Community Driven Development Program include provision for the use of local grants for public works for rehabilitation activities, including repair of rural and local roads; collection and removal of debris ; backfill, reshaping, and landscaping of areas affected by erosion; repair of public buildings and infrastructure (for example, traffic signs and bus stops); repair of riverbank protection systems and earth-fill dykes up to $5 \mathrm{~m}$ height (if supervised by a qualified engineer); repair/reconstruction of small bridges (span up to $15 \mathrm{~m}$ ); construction of temporary bypass roads; and repair/reconstruction of communal irrigation and water supply facilities.

There is also evidence that households in receipt of regular cash transfers are better able to access microcredit-and at notably lower interest rates-when they are in regular receipt of SP. They can then use that credit to rebuild housing and replace domestic productive assets that have been lost to get life back on track. In the Philippines, following Typhoon Yolanda/Haiyan, the Pantawid Pamiliya Pilipino Program (4Ps) was scaled up not only to support disaster response but to support recovery (Reyes, Albert, and Reyes 2018). Reyes, Albert, and Reyes (2018) note strong impacts on household capacity to either fully or partially recover, while Bowen (2015) notes stress placed in the Philippines on SP as part of disaster recovery (Figure 19), especially through a program aiming to build/recover assets through cash transfers.

Figure 19: SP programs during DRM stages, Pantawid Pamiliya Pilipino Program, Philippines

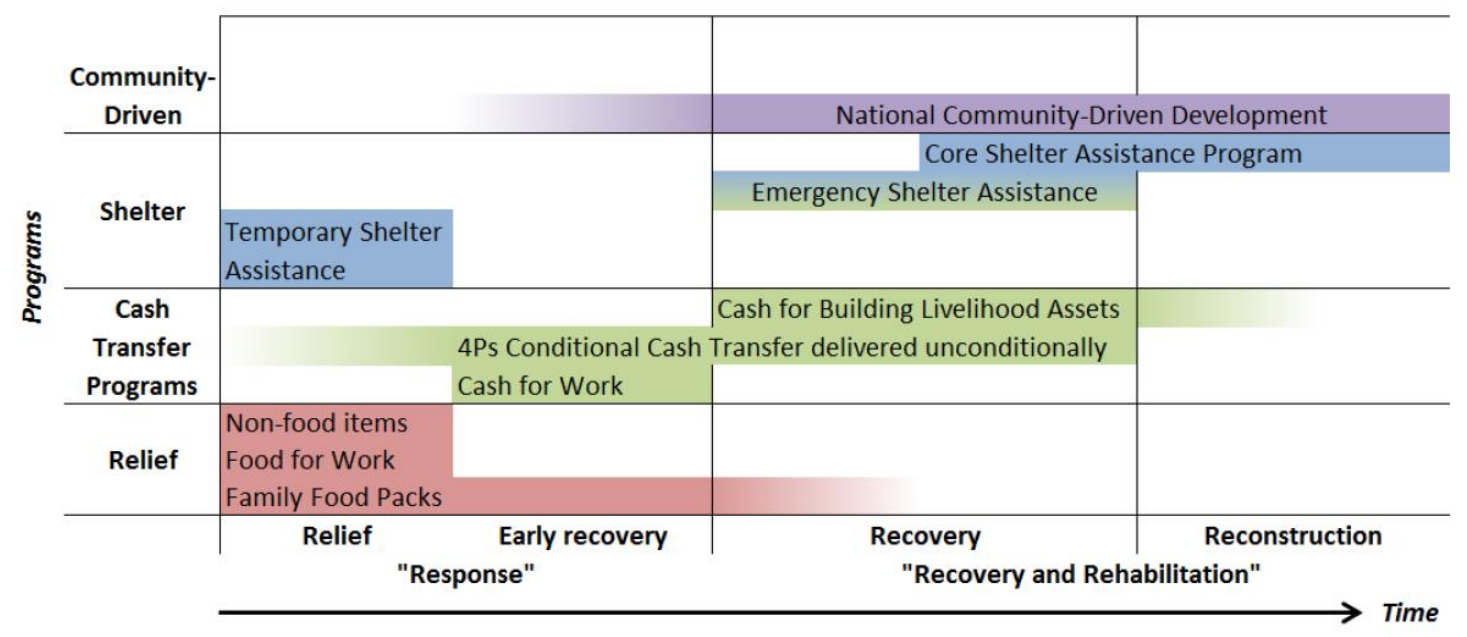

Source: Bowen 2015. 
From the program experiences listed above and a multitude of others (see in particular OPM 2017), we identify the main factors and program features and attributes that are important for making SP more adaptive and relevant to Nepal.

Levels of experience in program delivery and the longevity of programs matter. It takes time, and capacity, to build a shock responsive system. It is no accident that the vast majority of scale ups during the 2008 crises were in Latin America which hosts the majority of the developing world's established SP programs. In low-income countries, the example of Ethiopia's PSNP shows that it takes time for implementation capacity to be built up and enable flexibility to scale up and incorporate more disaster and climate management efforts. Ulrichs and Slater (2017) highlight three distinct phases of the PSNP (2005-10, 2010-2015, and 2015-2020) that demonstrate a steady increase in the capacity of the PSNP to contribute to resilience building. In the first phase the program design included the contingency funds at each level, the second phase introduced the RFMs, and in the most recent phase the PSNP was cited as a key pillar of the government's DRM strategy, and donors increasingly articulated the rationale for and objective of the PSNP in the language of climate action and adaption and climate funding was increasingly used to resource the PSNP.

Reflections on that first phase in Ethiopia point to the challenges of attempting to do too much too soon, the fact that people can slide back into food insecurity as easily as they move out of it, and the importance of getting the transfer system, especially the institutional and financial mechanisms, working well to deliver transfers predictably, regularly, and reliably (Ulrichs and Slater 2017). For Nepal this means prioritizing improvements to the existing implementation processes for SP before seeking to branch out too far into complex arrangements and thinking about being ambitious only in the medium to long term.

The presence of poverty-targeted programs is widely recognized as a key ingredient for ASP. Grosh et al. (2011) find that shock response is achieved far more easily if there are poverty-targeted programs already in place and where these cover a good share of poor people. Slater et al. $(2006,5)$ concur, reporting to the High Level Panel on Cash Transfers in Emergencies that "Social protection programmes that target specific groups, such as older people and orphans, will not be particularly useful to draw on in terms of reaching the desired caseload in a humanitarian response, where the crisis is felt by all, regardless of age or social category."

This is challenging for Nepal as many of its SP programs do not explicitly and overtly target those living in poverty. Rather, they provide a signal of the presence of the state and its respect for particular groups, especially senior citizens. Some of the programs, through their focus on vulnerable and excluded groups, may contribute to tackling structural exclusion and inequality, but will require concurrent and complementary interventions alongside them. Furthermore, much of the international experience and evidence is based on responses to economic shocks-where the disproportionate impact on poor people is clear-rather than natural disasters where the losses are often greater for less poor households (Walker, Khadka, and Pandey 2017). This, combined with the fact that SSAs in Nepal target some groups that are often among the most disadvantaged, and the fact that poverty is widely spread across the population in Nepal, suggests that there are good reasons to continue to explore the potential for and of adaptive SSAs. 
Furthermore, there are examples of using scaled up categorically-targeted SP programs in parallel with an emergency response for non-beneficiaries. Smith (2015) and Bowen (2015) both reflect on lessons from the scale up of the Pantawid Pamilyang Pilipino Program ' $4 \mathrm{P}^{\prime}$ '-targeted at extremely poor families with children-in the Philippines, following Typhoon Haiyan. A reasonable share of disaster-affected households was reached rapidly through the 4P beneficiary list, but many other households were affected. By coordinating the 4P scale up with the broader response, it was possible to cover a greater share of those affected through parallel but coordinated routes.

High levels of coverage are critical. There is strong agreement that low SP coverage prior to the occurrence of a shock limits both mitigation and response. The tables showing the likely coverage of those affected by shocks in our risk profile paper show that most of Nepal's current SP programs will reach only a small share of those who are shock affected. This is, in part, because exposure to shocks is very weakly related to eligibility for programs but is mainly about the limited coverage of many of Nepal's programs. There are very similar situations elsewhere (McCord, Harris and KC 2013) with Grosh et al. (2011) noting that social safety nets in Bangladesh reach less than 10 percent of the poorest quintile. As in Nepal, particularly with the KEP and RCIW, many households in other countries meet official eligibility criteria for selection but the resources to cover them all are absent. The implication for Nepal is that the contribution of SP to shock mitigation and response will be limited without the expansion of programs to cover a greater number of beneficiaries.

In many low-income settings there are not currently the resources allocated to SP programs to allow high levels of coverage nationwide. However, given that geographical targeting is a near universal feature of humanitarian response (Kuriakose et al. 2012), there may be a case for prioritising the expansion of SP coverage to areas that are especially disaster prone. In Ethiopia, the PSNP is focused on districts that have been classified as food insecure which, given that the predominant covariant shock in Nepal is drought, provides a useful link between PSNP targeting and likely shocks. In Nepal this would be challenging because of the widespread geographical distribution of shocks-there are few districts not affected by some sort of disaster, so prioritization may be easier said than done. However, geographical targeting is already a feature of SP in Nepal and would not only support a more effective use of SP for disaster response but also mitigate disasters given the role that SP can play in reducing household vulnerability to shocks by enhancing human, physical, and financial capital assets.

The regularity of enrolment/verification is also important. Where it is either slow or 'static' (that is, where new registrations happen only annually or where validation of the targeted group happens only in longer cycles) there is less chance of it supporting a shock response because the beneficiaries lists do not reflect those currently in need who have not been able to join programs. Castel (2010) notes that in Vietnam the lists of poor households were only validated each time a new poverty line was issued, and this usually took place only every five years, presenting an obstacle to supporting those whose circumstances have changed-including those whose livelihoods have been disrupted by disasters.

Drawing on a study of 13 countries, Grosh et al. (2011) found that "a number of countries do not allow households to register year long as they are formed or feel hardship; in these countries registration is confined to defined periods and/or the number of recipients is capped to fit a certain budget envelope. These factors limit shock responsiveness." Grosh et al. (2011) go on to note that for shocks that exacerbate existing poverty (such as food price shocks) the issue of static targeting is 
less problematic but for countries where many 'near poor' are pulled into poverty by a shock it can be a serious challenge. It is not entirely clear how much of a problem this would be in Nepal. On the one hand, Nepal uses mainly social categorical targeting for its SP system so this has little bearing on poverty. On the other hand, as Walker, Khadka, and Pandey (2017) note, there are many 'near poor' in Nepal and protecting them during any shock and supporting their early recovery is a pressing challenge.

A further ingredient is the adequacy of the response. Even without the presence of shocks, delivering $\mathrm{SP}$ at high enough transfer levels to make a meaningful difference to people's basic consumption and opportunities to invest in livelihoods is difficult. And poorest households are most at risk; estimates by the World Bank show that per capita transfers received by households in the bottom quintile are lower than those received by the other four quintiles: "In Malawi, the poorest quintile receives on average 0.5 cents per day, while the richest 20 percent receives more than 17 cents. In Vietnam, transfers are respectively 9 cents and US\$1.6, in Colombia, the poorest receive 23 cents per day and the richest more than 4.6 cents per day" (Hallegate et al. 2016, 150, citing the World Bank ASPIRE database). When shocks occur, this is even more challenging, particularly because local or widespread inflation in the prices of basic consumption goods that follows a shock reduces the purchasing power of cash transfers. Del Ninno et al. (2001) found that in Bangladesh in 1998, transfer amounts covered only 4 percent of monthly expenditures among poor households.

Devereux (2012) notes that in Kenya, the cash transfer rate for the HSNP that was established in 2007 based on the cost of a WFP food basket, within 18 months could purchase only one-third the amount of food. In this case the shock that drove prices up was a combination of regular seasonal drought and the global 3Fs crisis-showing that managing food price fluctuations is a major impediment to the efficacy of SP programs being uised for shock response, particularly when market prices are beyond the control of national governments.

It isn't feasible to implement SP programs for disaster response from scratch.

In Pakistan, there were numerous delays - financial, administrative, and targeting - to the delivery of the cash transfer response package following the 2005 earthquake. Pelham, Clay, and Braunholz 2011 found that targeting assessment processes were lengthy, that it was not possible to directly assess needs and compensation claims of every one of more than a quarter of a million households, and that instead village meetings were conducted using oral evidence to assess needs. In Pakistan, Save the Children estimates that the preparation phase for community-based targeting in general can take up to 14 weeks and concluded that while this may be possible if scaling up a safety net and targeting process that is already in place, "it is infeasible if trying to implement a safety net rapidly from scratch" (Pelham, Clay, and Braunholz 2011 cited in Bastagli et al. 2014).

Targeting challenges (inclusion and exclusion errors) can be addressed, at least partially, through better grievance mechanisms and communication

It is important to recognize that there are trade-offs between the extent of overlap of shock-affected and SP beneficiary households, and the need for a timely response. While minimizing inclusion and exclusion errors is a priority in SP programs, in humanitarian or emergency contexts there is a risk that taking time to address errors delays getting resources to households when they desperately need them. As Hallegate et al. $(2016,141)$ note "to be effective, safety nets must be rapidly scalable, even if speed of delivery may come at the cost of targeting." One of the ways to help manage the 
trade-off is to invest, ex ante, in grievance systems that address challenges rapidly (Hallegate et al. 2016).

Timely responses require not only established lists of existing beneficiaries, but also a social registry of a wider group of households and individuals among the population

OPM (2017) find that data availability is a critical prerequisite and consider registries that collect information on vulnerable groups beyond existing SP beneficiaries are a powerful tool for effective and rapid shock responses. Similarly, Bastagli $(2014,19)$ finds "if administrative records are restricted to collecting information on existing SP beneficiaries, their use in identifying potential new ones in the aftermath of a shock is limited. In contrast, registries that regularly collect information for a broader segment of the population, including the 'near poor' and other vulnerable groups in addition to program beneficiaries, are a powerful tool for SP shock response."

Evidence for these assertions is found widely across varied countries. In Brazil, the Cadastro Unico includes households with a per capita income below half the national minimum wage. This threshold is higher than in most SP programs in the country and so allows rapid horizontal scale up of beneficiaries for the Bolsa Familia conditional cash transfer program. In the Philippines, Reyes, Albert, and Reyes (2018) stress the importance of generating local level data on household and individual characteristics, and keeping it regularly updated, to improve the potential for shock response. In Mauritania and Senegal, registries include a 'buffer' caseload whereby around half of names on the registry are safety net beneficiaries and the other half are not beneficiaries but are vulnerable to shocks. In Mauritania, the buffer is greater for regions that are more exposed to climate-related shocks.

The exemplary example of this for a country with Nepal's resources is Kenya's HSNPs. The HSNP has a cohort of households that are not the regular caseload but receive transfers only when their living situations worsen, usually because of drought. Establishment of the list before a shock occurs is critical. In Kenya, all households in the four locations of the country in which the program operates were ranked according to poverty. This provided the basis for scaling up subsequently. It is important for the HSNP that, while it is viewed as a key program in Nepal's SP framework, it is implemented rather differently to Kenya's other cash transfer programs (which are targeted to poor households with orphans and vulnerable children, the elderly, people with disabilities, and the urban food subsidy cash transfer program). The HSNP is administered from the NDMA, with substantial technical and financial support from international donors and NGOs and works through offices at the county level with strong links to the new, devolved government structures. The other cash transfer programs, in contrast, are operating by local arms of the national government.

Financial arrangements and payment systems need to be established before shocks occur

Making SP systems more adaptive, as opposed to seeking to link SP and disaster response in more ad hoc ways, represents a financial commitment on the part of the government. Hallegate et al. (2016) suggest that this has implications for the sorts of financial instruments that may be required to deliver a more systematized approach-from reserve funds, contingent finance, reinsurance products, and support from international donors.

The lessons about contingency funds are pertinent for Nepal. The international experience shows that pre-positioned funds and trigger criteria are critical (Ethiopia, the Philippines, and Mexico), that 
separate funds for different types of shocks and separate funds for ex ante and ex post actions are required (Mexico and Kenya), and that there are benefits for holding contingencies at different levels of the government (Ethiopia).

Evidence from other countries suggests that a single DMF is unlikely to work and that a range of funds (or at least earmarked fund components) is required. The National Drought and Disaster and Contingency Fund in Kenya has two components to disburse funds for an ex ante response to slow onset shocks (notably drought but in a Nepal equivalent case this could also support more predictable/seasonal shocks such as cold waves and monsoon flooding at a small scale) and for ex post responses for quick action (for more unpredictable and rapid onset disasters) (Tilsone 2012).

In Mexico, there are different funds in the financial instrument for disaster response, FONDEN, that differentiate between financing for prevention, reconstruction, and emergencies (Espinosa 2017). While response and recovery activities continue to dominate expenditures (as they do in Nepal), a review of FONDEN (World Bank 2012) finds an increasing focus on ex ante responses (that is, mitigation and preparedness activities) (Figure 20). The amounts of funds available are also secured, for example, Federal Budget Law requiring that no less than 0.4 percent of the annual federal budget (net of the uncommitted funds in the FONDEN Trust at the end of each year) should be available to FONDEN and a number of other DMFs. In 2011 this was around US\$800 million (World Bank 2012).

Figure 20: Funds and resource allocation for FONDEN

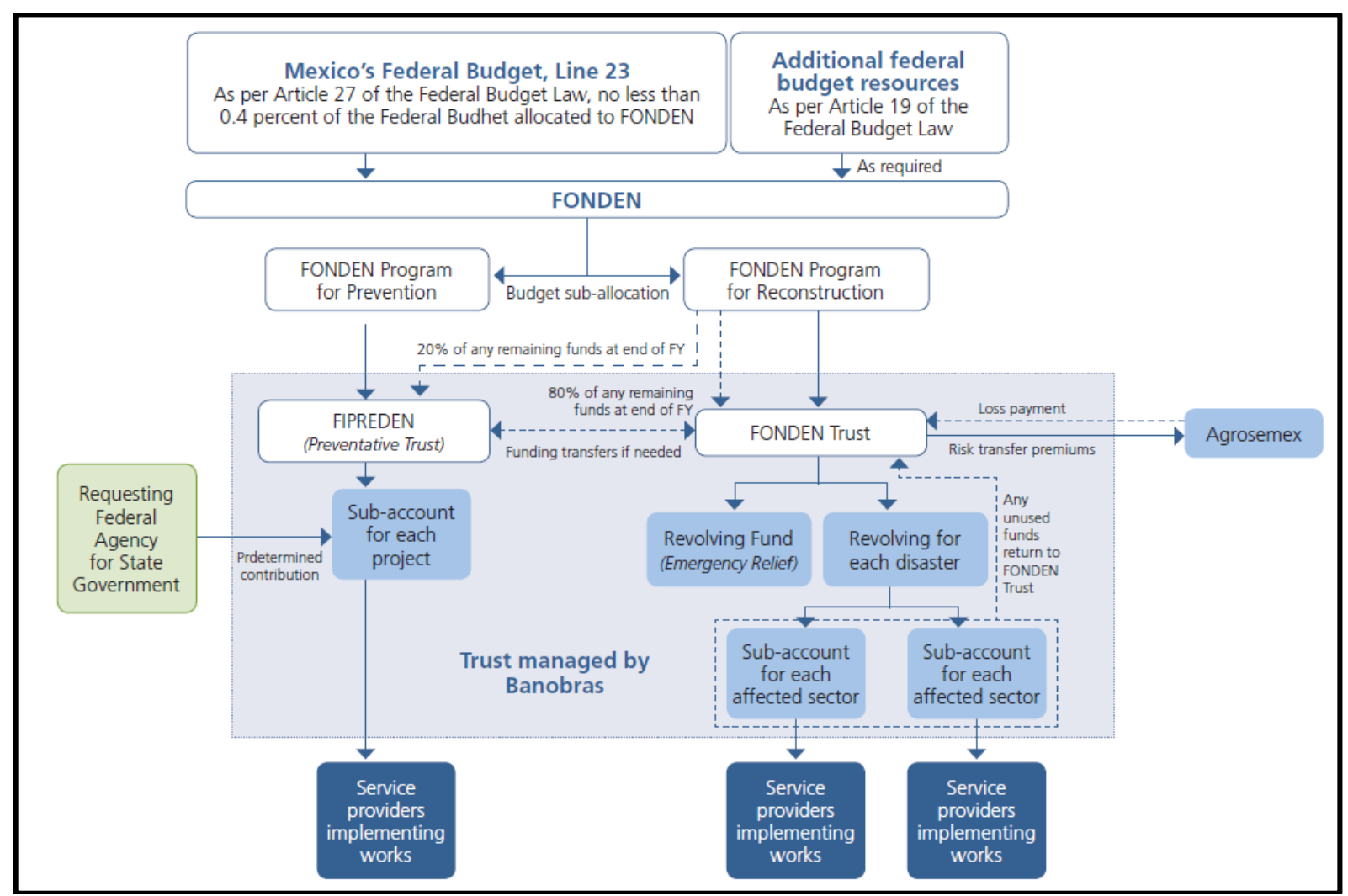

Source: World Bank 2012. 
While in Mexico, funds are held at the central level, the Ethiopia PSNP holds contingency at federal, state, and district levels giving, in theory, greater autonomy to the local level to respond in ways most appropriate to their specific context (Slater et al. 2006).

In terms of payment systems, there are other lessons from Africa about payments systems, most notably the branchless banking system used by the HSNP to deliver cash transfers and the speed that having beneficiary bank accounts brings to shock response. Furthermore, the challenges of setting up payments systems following an earthquake in Pakistan are noted in Pelham, Clay, and Braunholz 2011.

\section{EWSs combined with pre-positioning of resources can ensure a timely response}

Hobson and Campbell (2012) highlight the importance for slow onset shocks such as drought of having EWSs in place to indicate the need for a response as early as possible. At present much of the emphasis on early warning in Nepal is on warning people that a shock is imminent. The Hobson and Campbell case in Ethiopia is different and is about early warning for a slow onset shock to ensure that resources are prepositioned. Contingency planning is underway in Nepal but, at this particular time, is rather constrained by the slowly emerging guidance on roles and responsibilities for both DRM and for SP at the provincial and local levels. Contingencies in Nepal appear to be funded and held mainly at the central level, though some local governments are considering trying to build contingency funds. More guidance will be needed on where contingencies can be held, how they will be financed and by who, and whether the central government will seek to recover unspent prepositioned resources at the end of each year or whether they can and should be maintained at the local level.

\section{Institutional arrangements}

There are multiple institutional arrangements and coordination mechanisms for ensuring strong links between SP and DRM but from international experience there are lessons to learn. Two patterns are discernible. First, as shown in the examples from Kenya and Ethiopia above, in lowincome countries the integration of SP and DRM appears to be strongest where SP is embedded in ministries that also deliver natural resource management and disaster response. Indeed, in Kenya, of four cash transfer programs, it is only the one that is housed in the NDMA that is able to scale up rapidly in response to shocks. Second, elsewhere, the leadership of disaster management by institutions responsible for SP is paramount. The primary example here is from the Philippines. Bowen argues that the capacity to use SP in disaster response and recovery and rehabilitation has depended on the central role played by the government's Department of Social Welfare and Development (DSWD). "DSWD is prominently integrated into the national disaster risk management (DRM) framework, taking the lead coordinating role in disaster response activities. DSWD is the lead agency for 'disaster response' within the Government of Philippines's National Disaster Risk Reduction and Management Plan (NDRRMP). The department also has responsibilities across the national prevention and mitigation, preparedness, recovery, and rehabilitation pillars of the NDRRMP" (Bowen 2015, 1).

\section{Capacities and roles should be clearly defined and realistic}

SP programs frequently depend on statutory and voluntary roles at the local level. Kardan et al. (2017) note the importance of implementation roles at the local level, especially in targeting, but also note that, in the case of Zambia and Kenya at least, there is often limited institutional clarity at 
the national level and that this worsens as guidance about roles, responsibilities, and mandates are cascaded down to the local level. This is also the case in Nepal at this time, because of the very recent transition to decentralized government systems and the pending emergency of specific guidance. It is also noted that material and financial support, and adequate training, are often lacking at the local level with implications for the effectiveness and sustainability of program delivery. This stresses the importance of functioning systems for delivering basic systems of SP, even before the addition of adaptive and flexible elements of program design and delivery.

Individual roles at the local level are also in flux. While the shift to local governments in Nepal may provide an opportunity for more integrated working at the local level and technical staff working together on a number of programs rather than in silos, it also brings challenges. In particular, it may require staff to expand their existing skill set and adopt a broader range of capabilities. As Karden et al. (2017) note, "while the level of range of qualifications is quite high amongst professional staff, the nature of their work has substantially changed from their traditional social welfare role, requiring higher levels of project management skills and leadership skills." While it appears critical for staff at the local level in Nepal to deliver a broader portfolio, and to work in an integrated way on DRM, we should also be cautious of what Pritchett Woolcock, and Andrews (2010) have called 'premature loadbearing' at the local level. By asking staff to combine roles in SP and in DRR we may be asking "too much of too little, too soon, too often" (p. 37).

\subsection{Conclusion}

In a review of shock response and SP following the 2008 food, fuel, and financial crisis, the countries that are least prepared for using SP (that is, those with the least ASP systems) were those where "the existing base of safety nets is characterized by fragmentation, small programs and poor systems development" (Grosh et al. 2011). All were fragile countries that had either recently emerged from violent conflict or were still in conflict and all had a proliferation of small programs, against a background of fragmented policy. There are lessons here for Nepal, about needing to be modest about what it might achieve in ASP and the need to continue to build on bringing together currently fragmented SP programs into an overarching framework. Nepal has already begun this work-with substantial investments in administrative and MIS systems at the central level, and with the development of a national SP framework. 


\section{Chapter 6: Analyzing What Might Work in Nepal}

In this section we integrate lessons from Nepal's risk profile, SP sector and programs, DRM system, and international experience in ASP to explore what might work best for Nepal. We structure our assessment according to the four different elements of DRM that SP might play a role in: mitigation, preparedness, response, and recovery, and in relation to the overarching SP system.

\subsection{What might work for making SP systems more adaptive in Nepal?}

SP systems are, in this context taken to comprise three elements: administrative, institutional, and financial.

\subsubsection{Aligning SP and disaster management systems}

The lessons from international experience suggest strong arguments for aligning SP and disaster management systems. An integrated social registry of households, including those already in receipt of SP would provide a valuable resource for the identification of households that might benefit from support for disaster mitigation, preparedness, response, and recovery.

In terms of payments, however, alignment is not entirely straightforward for Nepal because of the specific evolution of its SP programs in rather fragmented ways. In terms of alignment between disaster management/humanitarian programming and SP systems, OPM (2017) define shadow alignment as running a parallel humanitarian system that aligns as best as possible with a current or possible future SP program. The main obstacle is the fragmentation, particularly of transfer levels, between the existing programs. While senior citizens receive NPR 2,000 per month, the under-five child grant pays NRP 400 per month and single women/widows receive NPR 1,000 per month. This creates a rather intractable challenge of aligning emergency payments to shock-affected households who are not in receipt of SP, to existing payment levels. Without consistency across payments within the SP system, it is difficult, perhaps impossible, for humanitarian response to align with it, thought it might piggyback on the payment system. The implication for Nepal is that for the SP system to be more adaptive, the fragmentation and lack of coherence in program coverage needs to be addressed.

Overall, while the opportunities for alignment are somewhat limited, there are some exceptions. First, there is substantial scope within Nepal's food distribution system to pre-position food stocks in food depots to ensure that the delivery of cash transfer payments do not create inflationary effects in food prices. Second, at the local level, it is possible that local government officials with new responsibilities for registering and enrolling SP beneficiaries, might use their local level knowledge and systems to support the identification of shock-affected households and thereby support emergency response targeting.

\subsubsection{Strengthening institutional coordination}

International experience highlights the importance of strong integration of and coordination between SP agencies and ministries and those responsible for DRM. In Nepal, there is provision for 
this through the DRRM Act and the composition of the committee governing the operations of the DMA. However, it might be more specific about which parts of MoFAGA, that is, those responsible for SP, should be represented on the high-level committees. The prospects for improved alignment might be furthered by ensuring that the involvement in the committee of the Department of Civil Registration and those parts of MoFAGA or the Ministry of Labour, Employment and Social Security (MoLESS) is detailed and exploring having specific SP expertise within the DMA staffing composition.

\subsubsection{Making SP financing more adaptive}

From international experience, there is recognition of the critical importance of having prepositioned resources and agreed criteria for triggering expansions in SP during times of shocks and disasters. At present, because the largest share of SP programs are targeted not to poverty but to specific demographic and social categories, there are no arrangements for contingency in the SP system nor contingency budgets held at central ministry, central department, or local government levels. Furthermore, among stakeholders at the central, district, and local government, it is not well understood or agreed whether disaster response funds can be routed through existing SP financial payment systems. A core element of a more ASP system would be the establishment of contingency funds that are held at different levels of government and can be flexibly deployed.

There would be additional benefits to clarifying these systems. At present, there are concerns among donors that government disaster funds (such as the PMDRF, and the DMF that is provided for in the DRRM Act are not currently able to account for expenditures in a manner that allows international agencies to contribute to them and then provided a clear account of where and how money was spent back to their home governments. This accountability challenge creates obstacles to close engagement and partnership between the GoN and international partners in disaster response and, by extension, contributes to a rather fragmented humanitarian response overall. Routing funding through the SP system-provides a clear paper trail of which households have received and where-increases accountability and transparency and reduces concerns among international agencies about fiduciary risks. Clarifying the options for routing funds through SP could, therefore, increase confidence among donor agencies and allow a more coordinated disaster response.

\subsection{What might work for disaster mitigation through SP in Nepal?}

Chapter 5 demonstrates that SP can play a key role in mitigating disasters in two main ways: by making households more resilient in the face of shocks and stresses; and by reducing the incidence of disasters themselves by contributing to better environmental management. There are prospects for enhancing the mitigating role of SP in Nepal in both these ways. Two possible mechanisms are envisaged-the introduction of a poverty-targeted program into Nepal's suite of SP programs; and a re-envisioning and redesign of PWPs so that they are more oriented toward disaster mitigation.

\subsubsection{Poverty-targeted SP for mitigation}

Poverty-targeted SP plays a key role in mitigating disasters by making households more resilient when exposed to droughts, floods, earthquakes, fires, and landslides. Given that it is frequently the poorest and most vulnerable households that are most exposed to shocks-particularly those dependent on agricultural and other casual labor-a longer-term program targeting the poorest could potentially help reduce their exposure to shocks and help them buffer themselves against 
disasters. Experiences in Ethiopia, Kenya, and Uganda, as outlined in Ulrichs and Slater (2017) suggest that in the relationship between SP and resilience note that it is that core, foundational element of all SPi.e. - the transfer itself-that is what helps people absorb shocks.

Yet, Nepal's existing suite of SP programs are not currently well targeted to the poor (the lower coverage PWPs being an exception to this) (Box 6) and so the opportunity to build household resilience is missed. Elements providing the foundation for more poverty-targeted SP include building a social/poverty registry and establishing lists or community rankings at the local level. Moving toward more poverty-targeted SP would increase the fiscal burden on the government and is likely to require the support of international donor agencies.

\title{
Box 6 Coverage of different types of vulnerability in Nepal's SP system
}

\begin{abstract}
Sijapati's (2017) differentiation of types of vulnerability demonstrates substantial gaps in SP programs. The main focus of Nepal's programs is on lifecycle vulnerabilities with the biggest programs in terms of coverage (senior citizens, widows/single women, and the child grant) defining eligibility in terms of lifecycle risks. On paper, the current suite of SP programs go some way to addressing historical and structural exclusion, albeit tackling symptoms rather than the causes of historical and structural exclusion where it will take complementary programming and substantial social change to achieve anything really transformational. Previous assessments of this element of SP have commented that a lack of results or impacts on levels of inequality between ethnic groups or genders can also be attributed, in part, to the low levels of transfers made to households, although there have been substantial increases in payments to senior citizens in particular. There is some programming that seeks to address the legacies of violent conflict (for example cash transfers to the families of those killed, injured, disappeared, and displaced due to conflict) operated by the Ministry of Peace and Reconstruction. However, overall, programs that define eligibility in terms of income poverty and natural disasters have far less coverage.
\end{abstract}

Prospects for improving the poverty-targeting of existing programs, or establishing a new povertytargeted SP program in Nepal

The importance of poverty-targeted SP programs for ASP is not disputed in Nepal. However, given that they would be substantially different from the existing suite of programs, there are questions about institutional and financial capacity to deliver them, and the extent to which there is widespread political support for them.

In terms of capacity, although Bastagli $(2014,17)$ note that "Effectiveness in the aftermath of a shock depends to a large extent on whether mechanisms were in place and institutionalized prior to the crisis or set up in the crisis context." Nepal would not be starting completely from scratch. In a number of municipalities and rural municipalities, efforts are underway to create lists at the local level that rank the most vulnerable households, and include data about existing sources of support, including participation in PWPs or receipt of SSAs. The Ministry of Land Management, Cooperatives and Poverty Alleviation continues to work toward the establishment of a poverty identification card system and further progress in this regard could provide an enrolment mechanism for households to receive regular cash transfers. This work is not without its own challenges-in particular technical challenges of data collection and maintenance, but the pilot initiatives in 25 districts does provide indication of the government's aim to tackle poverty.

The current urgency of responding to natural disasters has highlighted the lack of poverty-targeted SP in Nepal. This urgency may provide an entry point for further analysis and dialogue-especially between the government and donors-about how a long-term program, with the capacity to scale up, might work. Pilots, supported by donors, could be developed relatively quickly at provincial and 
local government level, given the concurrent responsibilities for SP held, particularly at the local level. However, this will depend on political support. It is not clear whether the urgency to strengthen disaster management-and to tackle the poverty that underpins people's exposure to shocks-will be sustained over time. In our interviews, a number of respondents noted how quickly we forget about large-scale disasters and how quickly they slide off the policy agenda. Enthusiasm, especially for disaster mitigation and preparedness, can often dissipate among politicians and policy makers rather quickly. Exploring whether an explicitly poverty-targeted mechanism will be politically acceptable depends on a stronger understanding of the shifting priorities of local-, provincial-, and central-level actors and a wider consultation on this by political economy experts or political scientists.

Exploring the use of these emerging lists to identify cash transfer beneficiaries, either for a permanent program or for an emergency top up, may provide the missing element for an ASP system in Nepal.

The challenge with a bottom-up approach of this kind would be twofold. First, as Carraro and Lakhey $(2018,8)$ note, although it is likely there will be different requirements for SP among distinct populations in certain localities, "it is also realistic to expect that this could create divergent levels of protection within the country...not based on actual different needs of the local population, but the different level of capacity of the local government or financial/economic opportunities." The redistributive element of equalization grants goes some way to balancing need and resources but will not account for technical capacity requirements. Second, while the establishment of elected officials at the local level will make local decision makers more accountable to all their constituents, it is unlikely to dissolve the dynamics of exclusion completely, nor do away with elite capture. A final element of difficulty associated with localized approaches to poverty reduction would be to establish the right balance between the need for national or standardized methodologies for identifying the poor that ensure equality on the one hand and some flexibility in approaches to ensure equity across different provinces and municipalities.

\subsubsection{Re-envisioning PWPs for DRM}

As seen in many other countries, PWPs have the potential to contribute not only to shock responses, but also to disaster mitigation, preparedness, and recovery. At present there have been significant investments in PWPs in Nepal for more than a decade-indeed the RCIW was first established in 1995-96. At the same time, there is widespread disappointment about the extent to which public works have been able to create assets that support livelihoods and economic growth in the long term and make meaningful and sustainable differences to the lives of participants and their households. Based on evaluations and reviews of PWPs in Nepal, and elsewhere (GoN 2012b; KEPTA 2014; McCord, Harris, and KC 2012), we suggest that a combination of challenges with finances and administration, and the overwhelming focus on road building and only labor-intensive works, present a missed opportunity.

Broadening the range of public works activities would allow public works to contribute across the whole spectrum of DRM-from mitigation, through preparedness and response, to recovery. Examples of possible works include tree planting to allow afforestation of land that is subject to slippage, or the construction of check dams and basic irrigation systems to both improve water control and ensure its availability for agriculture. For preparedness, the monitoring of river, dam, 
and snow pack levels could become a public works activity and formalized and systematized at the community level (for example, households could be paid for monitoring activity). For response, existing beneficiaries might receive wages irrespective of whether work has taken place (see above) to provide them with life-saving support at critical times. During recovery workers might clear roads or (when appropriate and legal) remove sand deposits from agricultural land that has been flooded.

At the central level, an appropriate approach might be to integrate PWPs more directly and explicitly with the NAPA for Climate Change (GoN 2010), with the Local Adaptation Plans of Action (LAPAs) and with emerging agricultural strategies. Incorporating public works more fully into DRM would require a refocus of current national-level priorities to give greater attention to mitigation and preparedness. Clarifying the roles of the various central-level committees in respect of the four phases of DRM would be an important step toward achieving this.

At the local level there are many implications, and new ways of working would be required. In some cases, this will require greater capital, as opposed to labor, inputs into the work, and this will involve a change of mentality from only doing road building and only using labor to develop physical infrastructure and assets. It will also require more attention from engineers, agricultural technicians, and others, but there may be opportunities in the new local government setups to have technical staff working in a more integrated way across programs - this in turn would require revisiting job roles and descriptions to ensure an appropriate distribution of tasks and responsibilities and an assessment of capacities at the local level. However, better integration of sectors and programs at the local level-for example, in disaster management, agriculture, climate change, small scale infrastructure development, and public works-is one of the potential benefits of the new ways of working at the local level.

This is a highly ambitious option and it would require strong political will-at central, provincial, and local government levels, and among local participants, NGOs, and international agencies. It will be challenging and require a reframing of public works in Nepal. It has a number of shortcomings, for example, efforts to address climate change are highly focused on rural areas at this time. In the absence of more climate change programming in urban areas, there is a risk of excluding, for example, those in urban areas that are susceptible to food price shocks caused by blockades, and so on.

Whether or not there is appetite to tackle disasters in this way is less clear. We found enormous support for a more integrated approach at the local level. However, as Jones (2012) notes, what has driven progress with SP in the last decade or so has been alliance of political will with something that is relatively simple to implement institutionally. An integrated public works, DRM, climate response, and agricultural development program would not offer simple implementation. However, it may be possible that the wave of energy and enthusiasm created by the transition to the federal system and the interests of elected officials at provincial and local government level to do something different and visionary will allow a more ambitious approach.

There are other reasons to be optimistic about a rethinking of public works-notably the announcement in the 2018-2019 budget of a new employment program based in the MoLESS. It is anticipated that a large part of the program will be focused on public works and there is strong potential to incorporate a planning process for the creation of infrastructure through public works that support disaster mitigation. 


\subsection{What might work for disaster preparedness through SP in Nepal?}

The sorts of public works activities identified above for disaster mitigation, could also apply to disaster preparedness. Examples include payments for monitoring of soil and forest resources or of river levels and avalanches that might trigger glacial lake outflows. Beyond this, there are some noteworthy and relatively simple opportunities to piggyback on existing administrative and implementation systems in SP to support disaster preparedness in Nepal. The experiences found in the international experience are limited in Nepal, notably because the greater share of Nepal's SP programs is demographically targeted, rather than being targeted based on poverty. This means that options for using existing beneficiary lists, registration and enrolment systems, and payment systems to deliver humanitarian responses are limited. Yet, there is one specific opportunity for DRM to piggyback on SP communication systems.

In the scaled-up SSA delivered as part of the 2015 earthquake response, UNICEF attached behavioral change communications to cash transfer payments to support disaster mitigation, preparedness, response, and recovery. Although the results were mixed (Box 7), as SP payments and communication become increasingly automated, they have the potential to provide a simple, low cost way to deliver information about managing shocks.

From international experiences, examples of messages extend across a range of shocks-from messages about hand washing (to mitigate health shocks), to advice to keep women and girls as safe as possible after disasters-especially given the high risk of violence and trafficking they face during displacement (Standing, Parker, and Bista 2016), to messages about keeping documents (such as citizenship certificates) protected from water during floods.

The findings from wider research, especially in more developed countries (Bradley, McFarland, and Clarke 2014) suggest that cash transfers could provide an appropriate vehicle for disaster risk communications, allowing communities to be prepared. Communications methods used include posters at sites where people receive transfers, leaflets included in SP documentation or messaging on payment slips, and text messages when beneficiaries are alerted that payments have been made into their bank accounts or are ready for collection. In principal, the vehicle applies not only to preparedness but also to mitigation, response, and recovery.

Furthermore, there is a growing body of evidence in support of attaching messaging for behavioral change (for examples from Bangladesh see Hoddinott et al. 2017) that suggests that messaging often reaches beyond program recipients to non-beneficiary households. Lessons from the experience of the 2015 earthquake in Nepal and from other countries suggest that the messaging needs to be simple and timely (requiring it to be prepared in advance), that succinct messages work better, and that the process needs to be sustained over time.

\section{Box 7 Behaviour change communications during the 2015 earthquake in Nepal}

The scale up of SP following the 2015 earthquake in Nepal included behavioral change messages. These were targeted to specific vulnerable groups and sectors and were aimed to support specific relief and recovery outcomes. They included simple shelter guidance, household preparedness measures, and checklists to protect water sources from contamination. There was also potential to expand messaging to provide key health and other messages relevant to the rainy season or further earthquakes and other natural disasters in the future.

Communications took two forms as booklet and leaflets. An evaluation found that only 6.5 percent of sampled beneficiaries of the scaled-up response received the communications booklet-mainly widows and single 
women, non-Dalit senior citizens, and households with Dalit children, in Gorkha, Rasuwa, and Okhaldhunga. Leaflets did not appear to make it from the district level into communities. It was logistically challenging to transport leaflets and booklets to the VDC level and hard to mobilize human resources to deliver information campaigns in a very short timescale.

Source: Gurung et al. 2015.

\subsection{What might work for disaster response through SP in Nepal?}

There are a large number of potential ways in which SP might contribute to disaster response in Nepal. These are discussed with reference to the typologies of Bastagli $(2014)$ and OPM $(2017,2018)$ (Table 9).

Table 9: Typologies of mechanisms by which SP can support shock response

\begin{tabular}{|l|l|}
\hline Bastagli (2014) & OPM (2017, 2018) \\
\hline $\begin{array}{l}\text { Increase payments/make } \\
\text { extraordinary payments }\end{array}$ & Vertical expansion - topping up support to (existing) beneficiaries \\
\hline $\begin{array}{l}\text { Expand coverage to reach } \\
\text { additional beneficiaries }\end{array}$ & $\begin{array}{l}\text { Horizontal expansion - temporarily extending support to new } \\
\text { households }\end{array}$ \\
\hline & $\begin{array}{l}\text { Piggybacking - borrowing elements of an existing program or system } \\
\text { while delivering a separate emergency response }\end{array}$ \\
\hline $\begin{array}{l}\text { Relax/change requirements to } \\
\text { make more households eligible }\end{array}$ & $\begin{array}{l}\text { Alignment - humanitarian response mimicking elements of an existing } \\
\text { program (payment levels, payment frequency) but without integrating it } \\
\text { tweaks }\end{array}$ \\
\hline New programs & \\
\hline
\end{tabular}

Note: * This element was part of OPM's analysis in 2017 but in 2018 reassessed as part of a resourcing strategy in a constrained environment rather than as a mechanism for achieving shock response.

\subsubsection{Increase payments / make extra-ordinary payments}

International experience suggests that one option for shock response is to increase the size of existing transfers for a limited period or to make extraordinary payments to existing beneficiaries. There are good reasons to explore how effective and achievable this mechanism would be in Nepal. First, experiences with the ETCTP in 2015 provide a good sense of what is feasible in the Nepal context (Gurung et al. 2015) and what the GoN and its development partners might work toward. Second, for a different type of SP program altogether, analysis of the HRVS data suggests that PWPS have potential for supporting shock responses. Walker, Khadka, and Pandey (2017) find that "earthquake-affected households that participated in temporary public works programs were no more food insecure than unaffected households, while those that experienced the shock and did not participate in public works were significantly more food insecure" (p.52).

We assess increasing SP transfers payments in two ways-first, by looking at whether support would reach the right people (that is, assessing how far exposure to shocks is related to receipt of SP, and what the inclusion and exclusion errors would be); and, second, by considering the readiness of SP systems and the acceptability of such an approach to key stakeholders. 


\section{Would scaling up existing SP payments reach the right people?}

It is not only households that receive SP who are exposed to shocks, especially given that most SP in Nepal is not targeted on the basis of poverty or food insecurity. The relationships between receipt of SP and exposure to shocks are not especially strong; the HRVS data shows that 65 percent of households in receipt of SP were exposed to at least one shock in the 24 months before their interview. This is lower than the average for all households across Nepal. When we disaggregate by program, in the very few cases where the relationship is statistically significant, beneficiaries of SP programs are less likely to report being exposed to shocks compared to non-beneficiaries. Disaggregating this overarching finding further by differentiating between different shocks also provides limited results (Table 10). The key message is that the HRVS data does not immediately suggest a strong rationale for scaling up SP for shock response.

Table 10: Households affected by shocks: differences between SP beneficiary and non-beneficiary households

\begin{tabular}{|c|c|c|c|c|c|c|}
\hline & \multicolumn{6}{|c|}{ Shock } \\
\hline & Any shock & Earthquake $^{2}$ & Landslide & Flood & Drought & Fire \\
\hline $\begin{array}{l}\text { Total number of } \\
\text { households affected by } \\
\text { shock }\end{array}$ & $\begin{array}{r}3289 \\
\left(4731^{1}\right)\end{array}$ & 809 & 151 & 190 & 1134 & 23 \\
\hline $\begin{array}{l}\text { Number and \% of } \\
\text { affected households } \\
\text { receiving } \mathrm{SP}^{3}\end{array}$ & $\begin{array}{r}1259 \\
(38.3 \%) \\
\left(26.6 \%^{1}\right)\end{array}$ & $\begin{array}{r}541 \\
(66.9 \%)\end{array}$ & $\begin{array}{r}54 \\
(35.8 \%)\end{array}$ & $\begin{array}{r}53 \\
(27.9 \%)\end{array}$ & $\begin{array}{r}372 \\
(32.8 \%)\end{array}$ & $\begin{array}{r}6 \\
(26.1 \%)\end{array}$ \\
\hline $\begin{array}{l}\text { Affected households not } \\
\text { receiving SP }\end{array}$ & $\begin{array}{r}2030 \\
(61.7 \%) \\
\left(73.4^{1}\right) \\
\end{array}$ & $\begin{array}{r}268 \\
(33.1 \%)\end{array}$ & $\begin{array}{r}97 \\
(64.2 \%)\end{array}$ & $\begin{array}{r}137 \\
(72.1 \%)\end{array}$ & $\begin{array}{r}762 \\
(67.2 \%)\end{array}$ & $\begin{array}{r}17 \\
(73.9 \%)\end{array}$ \\
\hline $\begin{array}{l}\text { Mann-Whitney test (P- } \\
\text { value }\end{array}$ & $0.00 * * *$ & $0.00 * * *$ & 0.34 & 0.20 & 0.62 & 0.53 \\
\hline
\end{tabular}

Note: 'Any shock' in this table includes the only shocks listed in this table-earthquake, landslide, flood, drought, and fire.

${ }^{1}$ The numbers in italics show results for a combination of natural disasters and some specifically selected health, economic, and political shocks as per Annex Table 1. This reduces the percentage of shock affected households receiving SP falling to about 27 percent. Walker, Khadka, and Pandey (2017) refer to the full list of shocks in the HRVS survey instrument.

${ }^{2}$ Earthquake is based on earthquake-affected districts in the sample (7 districts out of the 50 in the HRVS: Gorkha, Dhading, Nuwakot, Kavrepalanchok, Sindhupalchok, Dolakha, and Makwanpur).

${ }^{3}$ SP programs included: old age allowance, single women/widow's allowance, disability allowance, under 5's child allowance, RCIW, KEP, and scholarships.

These estimates suggest large gaps in coverage and substantial exclusion and inclusion errors if shock-responsive SP is targeted using the same lists as regular SP programs. However, the estimates are based on 50 districts in the HRVS and so, for more robust estimates we explore in more detail on a district-by-district, shock-by-shock, and program-by-program basis whether delivering shock response through SP, as well as supporting disaster-affected people, might tackle the structural vulnerabilities that underpin poverty in an effective way.

Table 11 uses the HRVS data to estimate how many households that are affected by particular shocks would be included and how many shock-affected households would be excluded if shock response was routed through existing SP programs (exclusion error). It also shows how many current $\mathrm{SP}$ beneficiaries are not affected by particular shocks (and would represent inclusion errors if they received SP top ups intended as a shock response). 
These estimates suggest large gaps in coverage and substantial exclusion and inclusion errors if shock-responsive SP is targeted using the same lists as regular SP programs. However, the estimates are based on 50 districts in the HRVS and so, for more robust estimates we explore in more detail on a district-by-district, shock-by-shock, and program-by-program basis whether delivering shock response through SP, as well as supporting disaster-affected people, might tackle the structural vulnerabilities that underpin poverty in an effective way.

Table 11: Coverage of shock response using selected SP programs

\begin{tabular}{|c|c|c|c|c|c|}
\hline & & $\begin{array}{l}\text { Landslide } \\
\text { (\%) }\end{array}$ & $\begin{array}{c}\text { Flood } \\
(\%)\end{array}$ & $\begin{array}{l}\text { Drought } \\
(\%)\end{array}$ & $\begin{array}{r}\text { Fire } \\
(\%)\end{array}$ \\
\hline \multirow{3}{*}{ 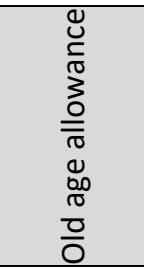 } & $\begin{array}{l}\text { Shock-affected households receiving old age } \\
\text { allowance (and therefore included) }\end{array}$ & 12.6 & 11.1 & 13.4 & 8.7 \\
\hline & $\begin{array}{l}\text { Shock-affected households not receiving old age } \\
\text { allowance (and therefore excluded) }\end{array}$ & 87.4 & 88.9 & 86.6 & 91.3 \\
\hline & $\begin{array}{l}\text { Share of old age allowance beneficiaries that are } \\
\text { not shock affected but still included }\end{array}$ & 97.3 & 97.0 & 78.4 & 99.7 \\
\hline \multirow{3}{*}{ 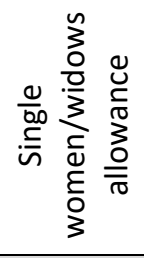 } & $\begin{array}{l}\text { Shock-affected households receiving single } \\
\text { women's allowance (and therefore included) }\end{array}$ & 7.9 & 10.5 & 10.9 & 4.3 \\
\hline & $\begin{array}{l}\text { Shock-affected households not receiving single } \\
\text { women's allowance (and therefore excluded) }\end{array}$ & 92.1 & 89.5 & 89.1 & 95.7 \\
\hline & $\begin{array}{l}\text { Share of single women's beneficiaries that are not } \\
\text { shock affected but still included }\end{array}$ & 97.7 & 96.2 & 76.6 & 99.8 \\
\hline \multirow{3}{*}{ 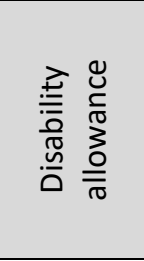 } & $\begin{array}{l}\text { Shock-affected households receiving disability } \\
\text { allowance (and therefore included) }\end{array}$ & 6.0 & 5.8 & 2.5 & 8.7 \\
\hline & $\begin{array}{l}\text { Shock-affected households not receiving disability } \\
\text { allowance (and therefore excluded) }\end{array}$ & 94 & 94.2 & 97.5 & 91.3 \\
\hline & $\begin{array}{l}\text { Share of disability beneficiaries that are not shock } \\
\text { affected but still included }\end{array}$ & 94.1 & 92.8 & 81.7 & 98.7 \\
\hline \multirow{3}{*}{ 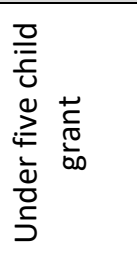 } & $\begin{array}{l}\text { Shock-affected households receiving under } 5 \text { grant } \\
\text { (and therefore included) }\end{array}$ & 5.3 & 1.1 & 2.2 & 0 \\
\hline & $\begin{array}{l}\text { Shock-affected households not receiving under } 5 \\
\text { grant (and therefore excluded) }\end{array}$ & 94.7 & 98.9 & 97.8 & 100 \\
\hline & $\begin{array}{l}\text { Share of under } 5 \text { beneficiaries that are not shock } \\
\text { affected but still included }\end{array}$ & 97.1 & 98.0 & 74.7 & 100 \\
\hline \multirow{3}{*}{$\begin{array}{l}\frac{\tilde{N}}{\tilde{N}} \\
\frac{\bar{\alpha}}{\sigma}\end{array}$} & $\begin{array}{l}\text { Shock-affected households receiving any SSA (and } \\
\text { therefore included) }\end{array}$ & 27.8 & 24.7 & 27.7 & 17.4 \\
\hline & $\begin{array}{l}\text { Shock-affected households not receiving any SSA } \\
\text { (and therefore excluded) }\end{array}$ & 72.2 & 75.3 & 72.3 & 82.6 \\
\hline & $\begin{array}{l}\text { Share of SSA beneficiaries that are not shock } \\
\text { affected but still included }\end{array}$ & 97.5 & 97.2 & 81.6 & 99.8 \\
\hline \multirow{3}{*}{ 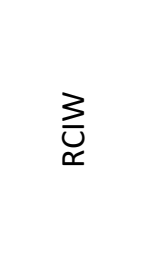 } & $\begin{array}{l}\text { Shock-affected households receiving RCIW (and } \\
\text { therefore included) }\end{array}$ & 6.6 & 0 & 3.8 & 4.3 \\
\hline & $\begin{array}{l}\text { Shock-affected households not receiving RCIW } \\
\text { (and therefore excluded) }\end{array}$ & 93.4 & 100 & 96.2 & 95.7 \\
\hline & $\begin{array}{l}\text { Share of RCIW beneficiaries that are not shock } \\
\text { affected but still included }\end{array}$ & 93 & 100 & 69.7 & 99.3 \\
\hline \multirow{3}{*}{ 岀 } & $\begin{array}{l}\text { Shock-affected households receiving KEP (and } \\
\text { therefore included) }\end{array}$ & 2 & 1.6 & 0.8 & 4.3 \\
\hline & $\begin{array}{l}\text { Shock-affected households not receiving KEP (and } \\
\text { therefore excluded) }\end{array}$ & 98 & 98.4 & 99.2 & 95.7 \\
\hline & $\begin{array}{l}\text { Share of KEP beneficiaries that are not shock } \\
\text { affected but still included }\end{array}$ & 91.9 & 91.9 & 75.7 & 97.3 \\
\hline \multirow{2}{*}{ 莒 } & $\begin{array}{l}\text { Shock-affected households with access to PFDS } \\
\text { (and therefore included) }\end{array}$ & 4.6 & 1.6 & 2.3 & 0 \\
\hline & Shock-affected households without access to PFDS & 95.4 & 98.4 & 97.7 & 100 \\
\hline
\end{tabular}




\begin{tabular}{|l|l|c|c|c|c|}
\hline & (and therefore excluded) & & & & \\
\cline { 2 - 5 } & $\begin{array}{l}\text { Share of households with access to PFDS that are } \\
\text { not shock affected but still included }\end{array}$ & 95.8 & 98.2 & 84.3 & 100 \\
\hline
\end{tabular}

Focusing solely on earthquake-affected districts sampled in the HRVS and assessing the coverage rate and inclusion and exclusion errors of providing an additional payment through the SSAs produces a more positive picture (Figure 21). The HRVS survey covers 7 of the most severely affected districts (Gorkha, Dhading, Nuwakot, Kavrepalanchok, Sindhupalchok, Dolakha, and Makwanpur) and finds 809 respondents there reporting experiencing the earthquake. Of these, 56.2 percent are covered by the SSA and would be reached by an additional payment, but 43.8 percent of households who reported being earthquake-affected would not be covered by an additional SSA payment.

For flood events, we assess coverage and inclusion and exclusion errors for a top up to the SSAs in the HRVS district with the highest share of respondents reporting that they experienced flooding. The number of respondents is small but provides a more useful analysis than a nationwide one. Of the 30 households in Banke in HRVS Wave 1 that reported experiencing flooding, one-third are covered by the SSA and would be reached by an additional payment but two-thirds of households who reported being flood affected would not be covered by an additional SSA payment. In Banke, 47 households in the sample receive one or more regular SSA payment but 78.7 percent did not report being affected by the earthquake (Figure 22). In this case, the inclusion error cost would be high, though it is important to note that the reporting period (2015-2016) did not cover a large, covariant flood in Nepal.

For future drought events, we assess coverage and inclusion and exclusion errors for a top up to the SSAs and RCIW in the HRVS district with the highest share of respondents reporting that they experienced drought. Of the 48 households in Kalilot in HRVS Wave 1 that reported experiencing drought, more than half are covered by the SSA and would be reached by an additional payment, but just under half of the drought-affected households would not be covered by an additional SSA payment. This greater coverage is probably the result of the under 5 child grant being universal in Karnali. Of those receiving SSAs, 16.7 percent were not affected by drought (Figure 23). Just 14.6 percent of drought-affected households are covered by the RCIW and 30 percent of households in the RCIW are not affected by drought. Overall, in Kalikot, the RCIW appears too small to make a significant contribution to drought response at current coverage levels. In a later section, we will explore whether expanding the coverage of programs could work for Nepal's SP programs to be more adaptive. 


\section{SSA and earthquake response}

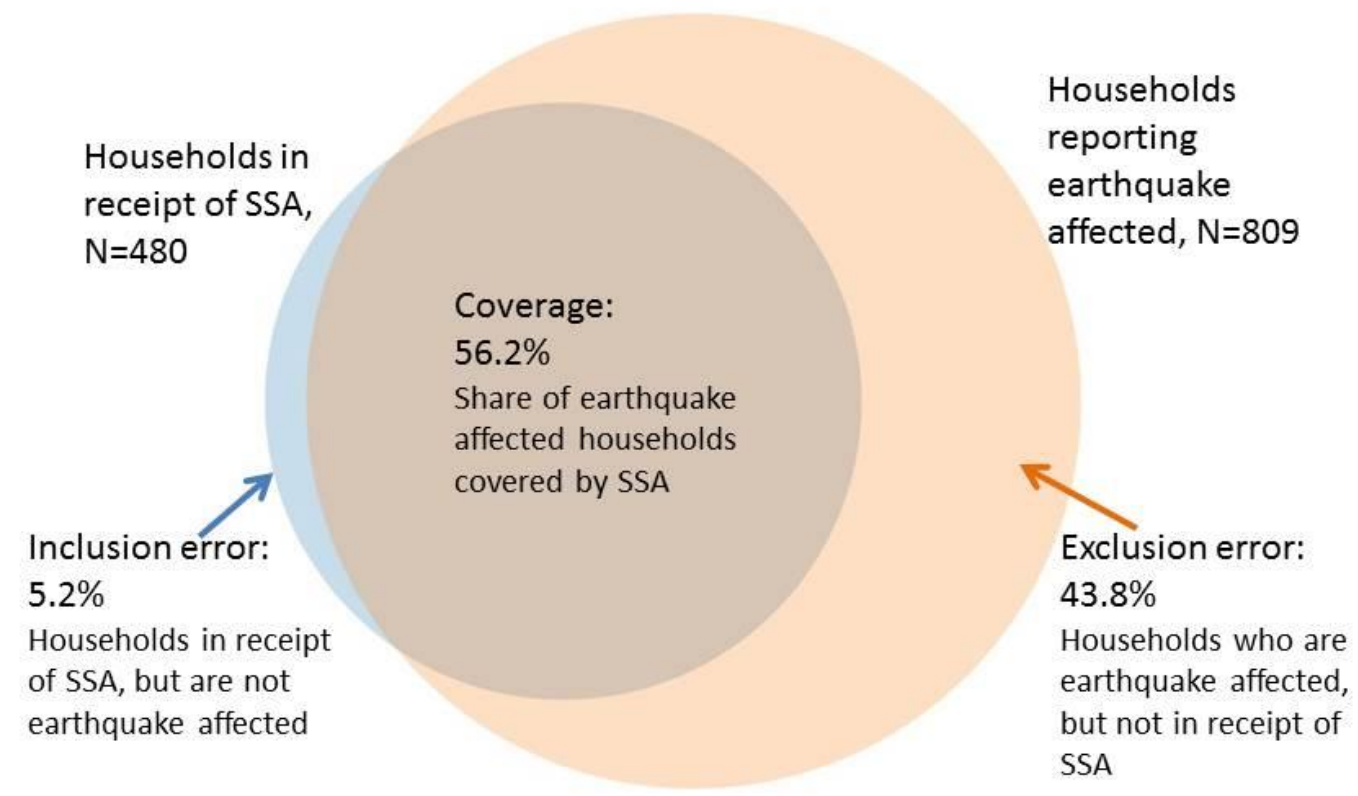

Figure 22: Coverage and inclusion and exclusion errors for district-level flood response

\section{SSA and Flood response at district level (Banke)}

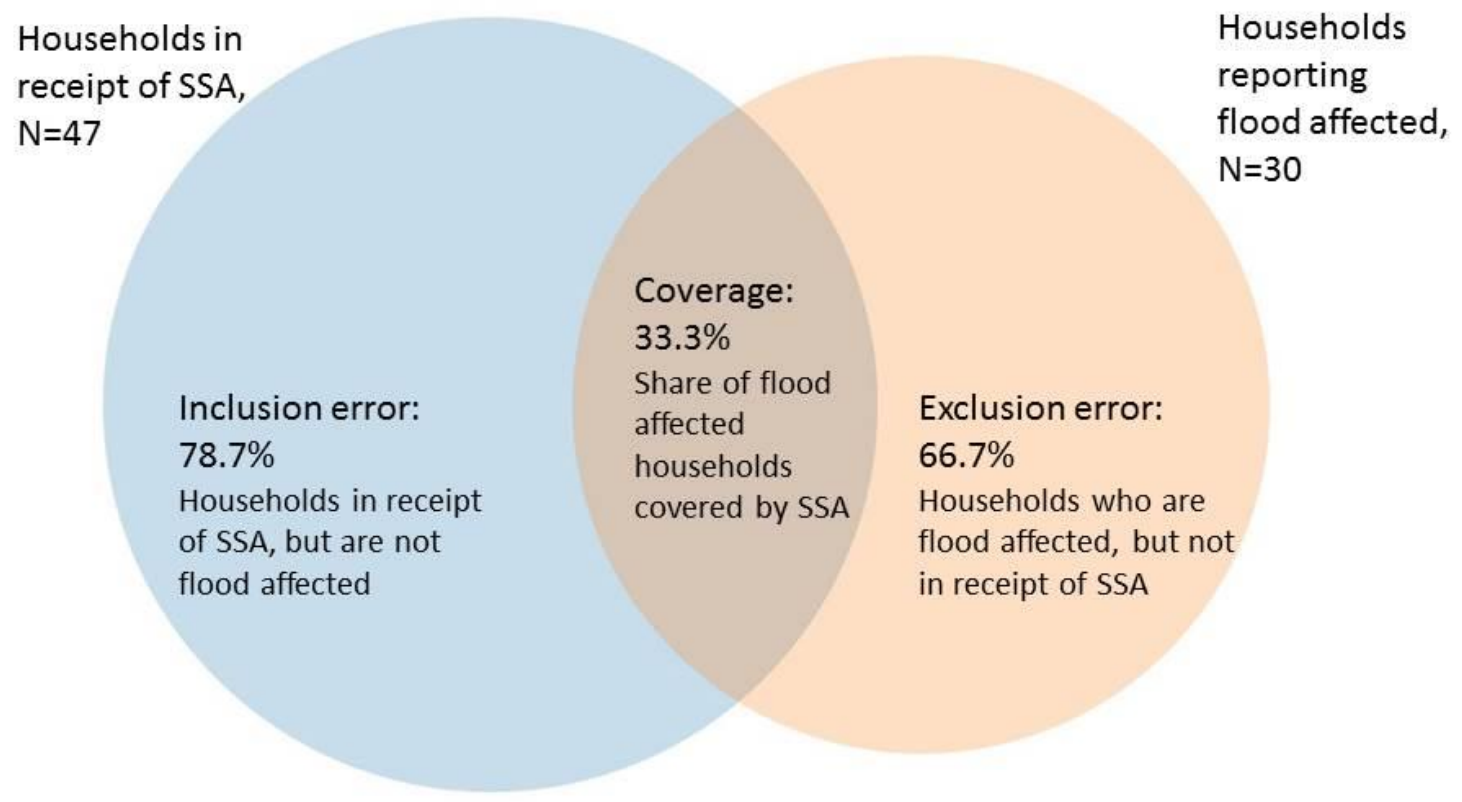


Figure 23: Coverage, exclusion, and inclusion for district-level drought response

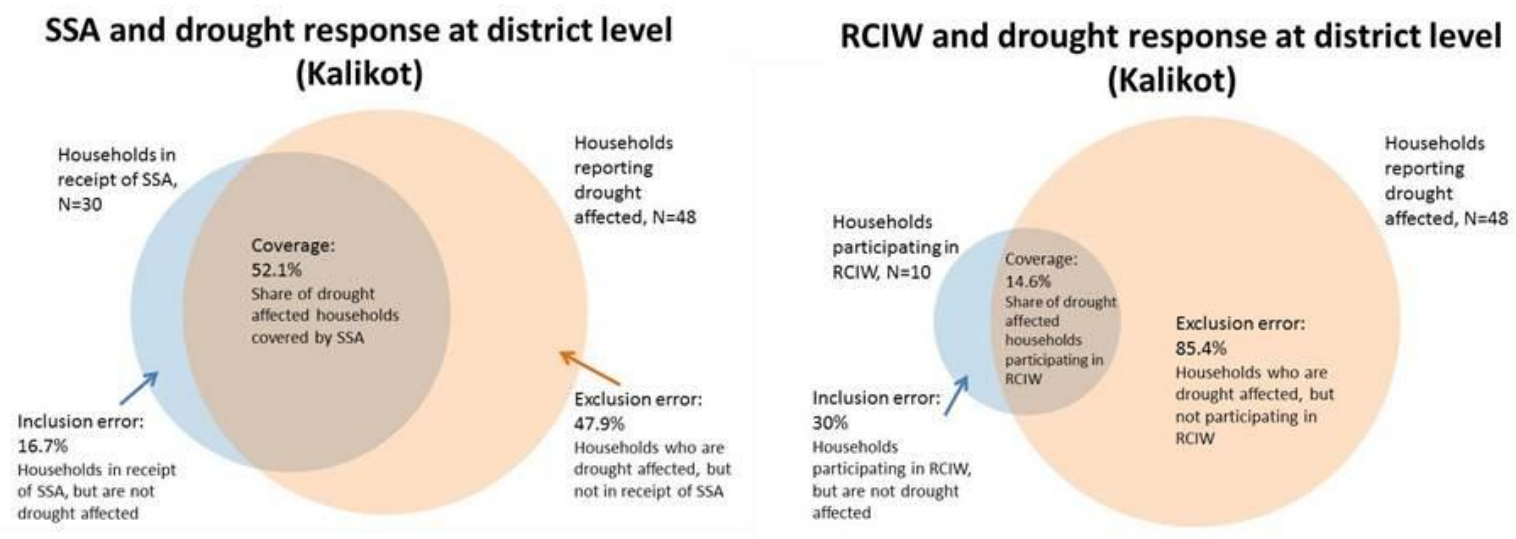

There is potential for scaling up programs, but it depends heavily on both the shock affecting a very large share of the population and high coverage of SP programs among those affected by shocks. Overall though, the estimates based on the HRVS data suggest that SP can support disaster responses alongside other humanitarian interventions but not as a substitute for them.

\section{Could scaling up payments happen in practice?}

The experiences of the ETCTP show that, in terms of institutional capacity, it is possible to deliver extraordinary payments to beneficiaries of SP. There is interest in government departments in establishing roadmaps for decision making and criteria for the situations when an extraordinary payment might be triggered.

Providing disaster response through SP would require some substantial improvements to delivery systems. The delays that are seen at present would have to be eliminated and the timings of payments realigned with major shocks. In terms of payments, in many areas, the switching to payments through bank accounts is creating problems for people accessing their payments, especially senior citizens, people with disability, and single women. More and rapid progress in getting mobile banking to rural municipalities and wards would be required.

In terms of support for scaling up payments, a number of concerns are found the central, district, local, and community levels. Respondents in interviews at the central level raised concerns about scaling payments down again. For example, one respondent in the MoF suggested that "as per historical experience, once [SP] is increased, you can never take it away, so we cannot ever increase during a disaster." At the community level, respondents expressed concerns about both shockaffected people being left out, because they are not SP beneficiaries, and about SP beneficiaries getting support even though they are not shock affected. At all levels there were concerns about 'double-dipping', that is the disproportionate allocation of support to households with more than one individual recipient of SP. Based on the HRVS data, about 17 percent of households that receive SP get more than one transfer/allowance, with the majority of multiple-beneficiary households being more than one person receiving the old age allowance-usually a husband and wife.

The implications are that, in terms of public, political, and bureaucratic support, programs are more likely to be acceptable if they 
(a) Make only temporary increases in payment rates over a limited number of months, or as extraordinary payments;

(b) Do not limit shock response only to existing SP beneficiaries; and

(c) Include a mechanism that recognizes which households receive more than one SP transfer to stop them from receiving a disproportionate share.

This will require an effective mechanism for communicating about increases to beneficiaries and local communities, in particular, and more coordination with humanitarian responses in the future.

\subsubsection{Expand coverage}

Given that Nepal's SP programs are fledgling but expanding, and the lesson from international experience that high levels of coverage are required for SP programs to support disaster mitigation, preparedness, response, and recovery, it is useful to consider how far expanded versions of Nepal's existing programs might provide ASP.

There are various options for doing so across the main SP programs. In 
Table 12 we calculate coverage for expanded versions of Nepal's existing programs. For example, we assume that the old and disability allowances have perfect coverage (everyone age 70 and over, even those without citizenship documents, and everyone with a red or blue card receives benefits). We estimate coverage for scenarios in which all households with children under five, not just those in Dalit or Karnali households, receive allowances. And we estimate the coverage in that program is extended to all households with children under ten. Finally, we extend the single women/widows allowance to all female-headed households, and the disability allowance to anyone reporting a disability (irrespective of which card they hold).

At a national level, inclusion and exclusion errors remain high in the estimates. We suggest further work running this analysis on a district-by-district basis to provide more accurate estimates. This could provide, in the future, a useful decision-making tool for policy makers, given that it is highly unlikely that a shock will ever affect every single district in Nepal. Overall, the lesson is that, by itself, having a high level of coverage of SP programs is not enough to maximize the role of SP in disaster response. Because of the relationship between exposure to shocks and poverty, having an element of poverty-targeting seems to be critical.

\subsubsection{Refocusing and revising programs for effective response}

In their respective frameworks OPM (2017) describe 'refocusing' as the tightening of targeting or concentration of support among a smaller group or number of households. Bastagli (2014) focus on changing or relaxing program requirements and design to better support households facing shocks. To this we add 're-envisioning' programs-essentially a different kind of refocusing process but one that widens rather than narrows the vision of programs and the ways in which they work. 
Table 12: Coverage and exclusion and inclusion errors for shock response routed through expanded SP programs

\begin{tabular}{|c|c|c|c|c|c|c|}
\hline Program & & $\begin{array}{l}\text { Earthquake } \\
\text { (\%) }\end{array}$ & $\begin{array}{l}\text { Landslide } \\
(\%)\end{array}$ & $\begin{array}{c}\text { Flood } \\
(\%)\end{array}$ & $\begin{array}{l}\text { Drought } \\
(\%)\end{array}$ & $\begin{array}{l}\text { Fire } \\
(\%)\end{array}$ \\
\hline \multirow{3}{*}{ 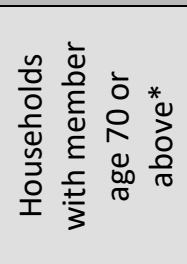 } & Shock-affected households included & 16.1 & 15.2 & 11.1 & 14.0 & 4.3 \\
\hline & Shock-affected households excluded & 83.9 & 84.8 & 88.9 & 86.0 & 95.7 \\
\hline & $\begin{array}{l}\text { Share of households with member } \\
\text { age } 70+\text { that are not shock affected }\end{array}$ & 8.5 & 97.2 & 97.5 & 80.8 & 99.9 \\
\hline \multirow{3}{*}{ 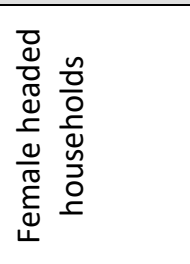 } & Shock-affected households included & 18.8 & 17.2 & 21.6 & 20.6 & 13.0 \\
\hline & Shock-affected households excluded & 81.2 & 82.8 & 78.4 & 79.4 & 87.0 \\
\hline & $\begin{array}{l}\text { Share of female-headed households } \\
\text { that are not shock affected }\end{array}$ & 13.1 & 97.8 & 96.5 & 80.2 & 99.7 \\
\hline \multirow{3}{*}{ 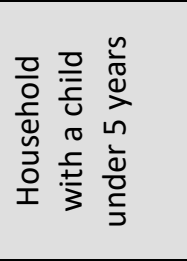 } & Shock-affected households included & 26.0 & 41.7 & 36.8 & 39.3 & 26.1 \\
\hline & Shock-affected households excluded & 74.0 & 58.3 & 63.2 & 60.7 & 73.9 \\
\hline & $\begin{array}{l}\text { Share of households with member } \\
\text { age under } 5 \text { and not shock affected }\end{array}$ & 13.2 & 96.9 & 96.5 & 77.8 & 99.7 \\
\hline \multirow{3}{*}{ 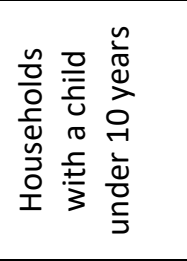 } & Shock-affected households included & 46.0 & 58.3 & 64.2 & 63.1 & 60.9 \\
\hline & Shock-affected households excluded & 54.0 & 41.7 & 35.8 & 36.9 & 39.1 \\
\hline & $\begin{array}{l}\text { Share of households with child } \\
\text { under } 10 \text { that are not shock affected }\end{array}$ & 13.1 & 97.5 & 96.5 & 79.5 & 99.6 \\
\hline \multirow{3}{*}{ 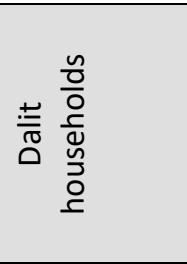 } & Shock-affected households included & 15.3 & 9.3 & 12.6 & 15.0 & 26.1 \\
\hline & Shock-affected households excluded & 84.7 & 90.7 & 87.4 & 85.0 & 73.9 \\
\hline & $\begin{array}{l}\text { Share of Dalit households that are } \\
\text { not shock affected }\end{array}$ & 9.5 & 98.6 & 97.6 & 82.7 & 99.4 \\
\hline \multirow{3}{*}{ 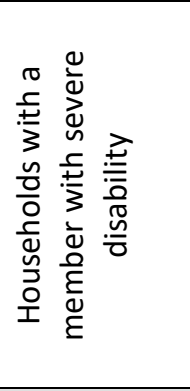 } & Shock-affected households included & 1.4 & 4.0 & 3.7 & 1.3 & 4.3 \\
\hline & Shock-affected households excluded & 98.6 & 96.0 & 96.3 & 98.7 & 95.7 \\
\hline & $\begin{array}{l}\text { Share of households with member } \\
\text { with severe disability and not shock } \\
\text { affected }\end{array}$ & 15.4 & 92.9 & 91.8 & 82.4 & 98.8 \\
\hline \multirow{3}{*}{ 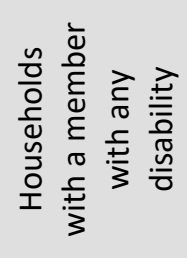 } & Shock-affected households included & 5.8 & 14.6 & 8.4 & 7.7 & 8.7 \\
\hline & Shock-affected households excluded & 94.2 & 85.4 & 91.6 & 92.3 & 91.3 \\
\hline & $\begin{array}{l}\text { Share of households with disabled } \\
\text { that are not shock affected }\end{array}$ & 6.0 & 93.9 & 95.6 & 76.0 & 99.4 \\
\hline
\end{tabular}

Note: * Differences in figures for households with a member under 70 here and those for old age allowance in These estimates suggest large gaps in coverage and substantial exclusion and inclusion errors if shockresponsive SP is targeted using the same lists as regular SP programs. However, the estimates are based on 50 districts in the HRVS and so, for more robust estimates we explore in more detail on a district-by-district, shock-by-shock, and program-by-program basis whether delivering shock 
response through SP, as well as supporting disaster-affected people, might tackle the structural vulnerabilities that underpin poverty in an effective way.

Table 11 reflect perfect coverage (while in reality not all age 70 or above receive old age allowance because they lack citizenship documents) and the fact that Karnali and Dalit households receive the allowance from 60.

Refocusing by tightening targeting to support the most vulnerable in the face of shocks. Our fieldwork at the local level in Nepal suggests that certain groups-particularly single women and the disabled-were being routinely excluded through current shock-response targeting processes. There were numerous occasions where they found themselves left off lists of beneficiaries and watched neighbors - usually those with stronger social networks-work the system far more effectively. For governments where there are attempts to narrow, rather than widen, the share of beneficiaries, routing through households that are viewed by the government as particularly vulnerable would be appropriate. However, interviews among government officials and others suggest that, notwithstanding attempts to ensure that shock responses reach Dalit communities, there is no emphasis in shock response on tightening targeting on particular demographic groups. In fact, more than concentrating resources on a particular group of (excluded) people during a shock, the priority of the government appears to be to reach those who are most shock affected, irrespective of whether they are from a particularly vulnerable demographic or social category.

\section{Relaxing program implementation}

There are numerous ways in which programs might be relaxed. In public works, it may be appropriate to temporarily pay 'wages' without requiring work, especially if 'works' are difficult to organize. This might be because of the impacts of the disaster on the immediate physical environment, because works require technical support that is not available during a disaster, or because shortfalls of food and injuries due to the disaster may mean that people are not in an appropriate physical condition to work. Although relaxing program requirements can raise concerns-for example about creating dependency or people becoming lazy-it is important to stress that these concerns are inappropriate during disasters when saving lives and ensuring that people's access to food, shelter, water, and health services must be the priority. It is also important to note that, in many other countries, works requirements have been relaxed during disasters without long-term negative implications.

It may also be appropriate to shift activities in PWPs-perhaps away from road construction, to more rehabilitation-focused activities. 'Tidy up' activities vary in scale with some requiring equipment and skilled workers but others with few such requirements. Examples of small-scale activities include the clearance of blockages to roads, rivers, and water supply and mending smallscale irrigation systems and terracing.

\subsection{What might work for disaster recovery through SP in Nepal?}

The opportunities for delivering disaster recovery through SP in Nepal are modest but noteworthy. On the whole they are linked to the options already outlined above. Messaging could be tailored to provide guidance on sources of information for agricultural rehabilitation or housing repair and reconstruction. Evidence from other countries shows that a regular poverty-targeted program would provide resources for households to invest in rebuilding livelihoods, encourage children back into 
school more quickly, and allow access to lower interest loans for recovery of lost assets. Top ups to support housing reconstruction could be routed through the SSAs. Public works could be deployed (as in the Philippines, see Bowen [2015]) on a whole range of reconstruction and rehabilitation projects in infrastructure and environmental management, to restore key assets.

In the aftermath of the 2015 earthquakes and the 2016-17 floods, the targeting of support for recovery has been very focused on individual households. Providing work through PWPs could also provide a cost-effective mechanism for the restoration of public infrastructure, buildings, and other public assets while simultaneously providing a wage to shock-affected households. Linking the new Prime Minister's Employment Program to the NRA might be worth exploring as a mechanism for achieving reconstruction of public assets that supports the wellbeing of individual households simultaneously. 


\section{Chapter 7: Toward Adaptive Social Protection in Nepal - Conclusions and Recommendations}

The recommendations presented here draw on findings from our desk and consultation-based analysis of existing policies, systems, and programs (and the institutional capacity therein) for both SP and DRM. It also draws on the experiences of shocks and disasters among SP beneficiaries and others at the community level in Bardiya, Humla, Saptari, and Sindhupalchok districts.

We have sought to be cognizant of the fact that this is a unique moment in Nepal's history, one in which substantial changes are emerging in both policy discourses and agendas and in implementation practices, and one in which it is important not to increase the burden on a currently disrupted and dislocated suite of government institutions. As a result, we stress both the importance of building on existing processes and modalities, that is, the endeavors and undertakings that are already established or underway, but also attempt (after being inspired by people's courage and forbearance at the local level) to be more aspirational and ambitious and explore options that will require a re-visioning of SP and DRM.

The chapter begins by assessing what the implications of lessons from the previous chapters are for ASP in Nepal. It then makes some recommendations for the GoN-in most cases directed to specific actors in specific ministries - and its development partners to explore further for making SP more adaptive and for using SP to help disaster mitigation, preparedness, response, and recovery. The recommendations are scaled-beginning with those that build on what is already in place and ending with longer-term approaches to ASP that could emerge over time.

\subsection{Implications and recommendations for ASP in Nepal}

Overall, the key implication for ASP in Nepal is that 'one size' will not fit all. There is no single SP program that offers a 'best bet' for ASP. Different programs have different useful features, for example, some are useful because they are targeted to the households that are most likely to experience shocks and have limited capacity to cope with the impact of shocks, while others are not targeted in such a way but reach many shock-affected households simply on account of their greater coverage. The distinctions between covariant and idiosyncratic shocks, the fact that some disasters are slower onset than others, the fact that Nepal's existing SP programs have very differentiated coverage in different parts of the country and are targeted very differently, and the ways in which different shocks (earthquake versus fire, drought versus flood) are experienced mean that it will be necessary to consider options for a range of different situations.

The recommendations here are underpinned by a number of principles. First, given that there are substantial financial and institutional constraints and Nepal's current exposure to shocks will only increase under accepted climate change scenarios, it is critical to start with existing policies, programs, and systems as much as possible. Second, recommendations are based on an assessment of what is realistic and feasible given existing human, institutional, and financial capacity in Nepal- 
notably in the context of the transition to a three-tier federal political system and decentralized institutions for defining and delivering government programs.

\subsection{Overarching recommendations}

Continue existing efforts to strengthen SP systems, particularly systems for identification, payment, targeting, and management processes. SP programs that perform well in response to shocks in other parts of the world are those that are able to deliver transfers reliably, with high levels of coverage, and at an adequate level (Bastagli et al. 2014; Grosh et al. 2011; Ulrichs and Slater 2017). So, there are strong arguments for continued investments - partly those being carried out in the Department of Civil Registration (DoCR) -in making the SP system itself work better in Nepal. Continuing the shift from annual to rolling enrolment for the SSAs is a core foundation of flexibility. Recipients of numerous programs such as the SSAs and PWPs reported that income from SP helped them to maintain consumption during both the floods and the 2015 earthquake-so ensuring that those payments are made reliably and perhaps tweaking payment times so that they take place just before seasonal shocks (such as floods and cold waves) are likely to hit, would be a useful way of building on existing systems strengthening efforts.

Clarify and make provisions in guidelines and regulations for SP representation in DRM decision making and allow for the routing of some disaster response through the emergency top ups in the SSAs and other SP programs. International experience demonstrates the importance of a formal regulatory framework to allow institutional coordination between SP and DRM agencies. These processes require specific arrangements to be in place (for example the provision for representation of MoFAGA and MoHA, the two main agencies responsible for SP programs) on the national DRM committee is, alone, not sufficient to ensure that SP is mainstreamed through DRM processes. Ensuring alignment will require direct involvement in the committee and DMA of the Department of Civil Registration and those parts of MoFAGA responsible for delivering public works. We also recommend that in the immediate term the working group developing the DMA regulations incorporates a specific SP role into the DMA, and that those responsible for revising SSA guidelines include mechanisms for incorporating both the goals of resilience building (for disaster mitigation) and flexibility (for response and recovery).

Make clear provisions in sector guidelines for the routing of some disaster response resources through SP programs. At present, it is not clear if and how resources and funds for disaster management might be routed through SP budgets and using SP bank accounts and payment systems. There is disagreement among stakeholders on the technical feasibility of routing funding through the SP systems. Clarification of these mechanisms as the DRM regulations and guidelines are developed is required rather urgently, not least because routing funding through SP systems does provide the transparency and accountability for the contributions made by international donors. Further clarification of the roles and responsibilities of the different levels of government in declaring a disaster or emergency and triggering a response is also required.

Continue the switch to making payments through electronic means and mobile banking with the concomitant implication that more banking would need to be available locally-to allow a more rapid payment of emergency support through local systems. This is a 'no regrets' option because even if, during a shock, a decision is made not to target through the SP or there is no shock, ensuring there is banking in every municipality and rural municipality, and perhaps even every ward, will 
provide substantial benefits such as the reduction of fiduciary risks in the SP sector and financial inclusion in the wider community.

\subsection{Recommendations for SP's role in mitigation and preparedness}

Increase attention and resources for mitigation and preparedness. The focus on recovery, particularly the reconstruction process for buildings and homes, leaves little attention paid to mitigation and preparedness. It is important to ensure that more focus and clarity is created at the central level-notably in the Executive Committee and DMA-on disaster mitigation and preparedness. This needs to filter down to the local level to allow a clear understanding of roles and responsibilities, and funding streams, in these areas. Two direct ways of doing this are presented below.

\section{Beginning a dialogue on potential policy and program options for poverty-targeted SP}

In Nepal, there are few SP programs providing transfers that explicit target poverty, although there is progress toward a poverty identification process. PWPs target using HDI indicators and/or seasonal food gaps, but the remainder of programs target based on social and demographic categories and this limits the extent to which the poorest and most vulnerable can be supported to build more resilience to shocks. Poverty-targeted SP programs are key to ASP. Given substantial progress toward establishing SP in Nepal over the last decade, and the pressing need to tackle vulnerability and impoverishment amidst increasing threats from natural disasters, this is an appropriate moment to start discussing how a poverty-targeted SP program might work to improve the resilience of the poorest households in Nepal. The dialogue would be a broad one-between the implementers of SP and development partners in particular-but the practicalities of the process would require direct coordination between MoFAGA (for SSAs) and the Ministry of Land Management, Cooperatives and Poverty Alleviation (MOLMCPA) (for the poverty identification card system).

\section{Consider integrating PWPs more with existing climate change adaptation, DRM, and agriculture/rural development programs}

There is substantial opportunity to link public works initiatives to wider actions seeking to adapt and protect livelihoods, especially agricultural livelihoods in the context of threats from climate change, and to broader infrastructure investments. Linking PWPs directly and explicitly with the NAPA for Climate Change (GoN 2010) and with LAPAs and with emerging agricultural strategies would provide mechanisms for public works to contribute across the full cycle of DRM. Afforestation activities in public works would mitigate landslides, flood, and drought. Monitoring of river, dam, and snow pack levels could become a public works activity and be formalized and systematized at the community level. During recovery, workers might contribute to the rehabilitation of damaged roads, community buildings, or agricultural land. Clarifying the roles of the various central-level committees in respect of the four phases of DRM would be an important step toward achieving this. Specific ways of achieving this broader utilization of PWPs would be through the following:

Incorporate disaster mitigation objectives and activities into the planning of the new Prime Minister's Employment Program. International evidence is awash with examples of public works activities that have supported soil and water conversation, constructed small-scale irrigation and water management schemes, or delivered afforestation activities. These sorts of activities would 
mitigate disasters associated with flood, drought, landslide, and fire. This would require a planning process for the new program with strong engagement of the line ministries associated with water, land, and forest management and with infrastructure and engineering to identify the most appropriate and effective activities across Nepal.

Pre-positioning resources for shock response. This could be in terms of monetary resources or food stocks and would reduce delays in in-kind or cash transfers once beneficiary needs have been identified. A specific example of pre-positioning resources would be the Nepal Food Corporation and its PFDS. The MoCTS would need to work with MoHA and other agencies such as NeKSAP to ensure food stocks are in place in remote areas where shocks are anticipated. This was a key part of the government's response to the 2015 earthquake. Food stocks can be sold (at varying rates of subsidy) during a shock, bought by the government and then distributed to shock-affected households. Maintaining food stocks where markets do not function properly is also critical to ensuring that other cash-based responses work: the first rule in emergency cash distribution is that local markets work. In the 2015 earthquake and in the following blockades, the PFDS was able to ensure the supply of food at reasonable prices in places where the private sector could not supply, except at very high prices.

In terms of financing, international experience suggests that there are benefits to holding contingency budgets or pre-positioning financial resources not just at the central level, but at all tiers of government. While the roles of provincial governments are yet to be clarified, at the local level there is confusion over financial flows for different elements of DRM and how preparedness can be supported without building local contingency budgets that needs to be addressed. Furthermore, it may be useful to explore contingency mechanisms held beyond the national level, including through Catastrophe Deferred Drawdown Options.

\section{Piggyback disaster preparedness messaging onto SP communications}

International experience, and Nepal's limited experiences attaching messaging to the ETCTP, demonstrate the potential for incorporating disaster management into cash transfer communications. Examples could include seasonally timed reminders about the risk of fire or information about potential aftershocks following an earthquake. It is recommended that the DoCR assesses how far it could provide an appropriate vehicle for disaster risk communications as part of its own information-such as DRM messaging on payment slips and text messages when beneficiaries are alerted that payments have been made into their bank accounts or are ready for collection. In principal, the vehicle applies not only to preparedness but also to mitigation, response, and recovery.

\subsection{Recommendations for response and recovery}

Rethink the assessment criteria for targeting response and recovery. The review found that damage to housing was the primary criteria driving the targeting of response and recovery. Given that this focus was leading to some unintended outcomes at the local level-particularly households with no mechanism to meet their basic needs or maintain their livelihoods receiving no support-a review of the assessment criteria used at the local level by MoHA is suggested, with inputs from across all clusters. In particular, it is essential to focus the resources on those households who are not able to cope with the impacts of shocks, rather than on all households affected by a shock (but who might be able to mitigate its impacts), to ensure efficiency of public spending. 


\section{Consider temporarily expanding SP payments to existing beneficiaries}

Although there are legitimate concerns about inclusion and exclusion errors, there are a number of reasons to further explore the expansion of SP payments. First, the evidence suggests that cash and in-kind benefits provided following the 2015 earthquake appear to have resulted in shock-affected beneficiaries being significantly less food insecure than those households that were affected by the earthquake but were not receiving any SP. Second, for those programs whose targeting is linked to poverty and food insecurity (for example, PWPs) temporarily setting the PWPs wage rate closer to the local casual labor rate (instead of the usual 20 percent reduction on the local rate) would be appropriate and reflect the fact that during a disaster there may be few opportunities in the local labor market. Third, evidence from both this study and others (for example, Schjødt 2017) suggests that people understand the targeting of the SSAs, whereas they found the various targeting systems for the flood and earthquake response difficult to understand. Fourth, expanding payments to existing beneficiaries would provide a mechanism for reaching households that otherwise struggle to access support following disasters. Our fieldwork demonstrates the importance of social networks and patronage in accessing support and that many vulnerable groups (most notably those in receipt of the single women/widow's allowance) do not make it onto lists at the community level. Providing payments through the SSAs would prevent the potential shortcoming of community-level targeting-that local networks, power relations, and discretion determine eligibility at the local level to the detriment of excluded groups. Having elected officials might make targeting decisions more accountable to residents in the long term (when they can choose not to reelect a mayor or chairperson whose resource allocation decisions they did not agree with) but this long-term incentive may help little in ensuring that the most needy people get the support that is desperately required in the immediate term. Fifth, when receiving SSAs during shocks, beneficiaries found that they were part of the solution to a household's troubles, rather than being seen as a burden on the household. Respondents felt that this had a substantial impact on their position in the community and reduced social exclusion.

A 'sub-recommendation' here is the importance of recognizing that increasing transfer levels could present a number of trade-offs and of being prepared to navigate these. Schjødt $(2017,42)$ notes that in selected districts affected by the earthquake "there were complaints about the earthquake support, which has less clear eligibility criteria, but none about the SP benefits." As much as the targeting of the SSAs appears to be widely accepted-at all levels of government and within communities themselves - there is however a serious risk that targeting a shock response through the SSAs could create serious resentment and, potentially, endanger already vulnerable recipients. As Koehler and Mathers $(2017,350)$ note, for Nepal "there are indications that this kind of positive discrimination may-inadvertently-deepen divisions and social exclusion. In Nepal, some communities are not happy with the additional benefits accorded to their Dalit co-citizens." Communication about a system routing funds through the SSAs would be critical. Tackling this will require far better communication than has been the case thus far. The trade-offs between acceptable targeting and speed of response are particularly acute in a post-conflict setting such as Nepal where grievances (in this case about access to emergency support) can endure for a long time and potentially undermine political stability (Slater and Mallett 2017).

Use SP as one of a complementary set of mechanisms for emergency response and not as an alternative to emergency response 
Overall, the recommendation is that routing benefits through SP should not be an alternative to a wider shock response but could work well alongside other complementary responses. Routing part of a shock response through existing SP would reduce the caseload of needs assessment and targeting that would be required at the local level during the response. Only households not in receipt of SP would require assessment with the potential to significantly speed up the assessment process.

\subsection{Conclusions}

The recommendations presented here are intended to support a dialogue about options for making SP more adaptive in Nepal and discussions about the roles that various stakeholders-government, donors, and NGOs-might play in that process. A number of options have been analyzed in Chapter 6 and woven into these recommendations. The recommendations cover actions that are proposed focused on policies, institutions, and coordination, and on programs themselves. They encompass different levels of ambition, with varied potential outcomes. The more ambitious the option, the greater the potential for supporting DRM across all four pillars (Table 13).

Finally, the four key messages from the review are as follows:

First, the variation in shocks - from those that come with little or no warning to those that are seasonal and those that have a slow onset; from those that affect very few people in specific locations to those that are generalized across the population; from those that cause death and injury to those that damage housing and to those that undermine livelihoods-means that there is no single best option for using SP to tackle the major shocks that Nepal faces. Multiple pathways for SP will need to be bear in mind these differences and adopt a best-fit approach across a range of circumstances.

Second, the tumultuous changes in Nepal's political and administrative systems mean programs will have to be flexible, not just to the specificities of individual disasters, but also to the constant transition and upheaval in government institutions, particularly at the local level. Assessing capabilities to deliver each of the options will be critical. However, the new arrangements at the local government level may also offer opportunities-in particular to work in a more integrated way.

Third, while delivering disaster management through SP in this rapidly changing context is difficultit also provides a unique window of opportunity to establish new ways of working that better link SP and responding to shocks, not just in terms of immediate disaster responses but also in relation to mitigation, preparedness, and recovery.

Lastly, the recommendations proposed here purposely encompass some relatively easy to achieve ways of better linking SP and DRM and some rather more ambitious ones. They are meant as the starting point for a dialogue between the government and other development and humanitarian agencies that might, in turn, be reflected in the guidelines that underpin SP and DRM systems, procedures, and programs. 
Table 13: Mitigation, preparedness, response, and recovery outcomes from recommended actions

\begin{tabular}{|c|c|c|c|c|}
\hline \multirow[t]{2}{*}{ Recommended Actions } & \multicolumn{4}{|c|}{ Outcomes } \\
\hline & Mitigation & Preparedness & Response & Recovery \\
\hline \multicolumn{5}{|l|}{ Policy, institutional, and systemic } \\
\hline $\begin{array}{l}\text { Strengthen SP systems - particularly systems } \\
\text { for identification, payment, targeting, and } \\
\text { management processes. }\end{array}$ & $x$ & $x$ & $\mathrm{x}$ & $\mathrm{x}$ \\
\hline $\begin{array}{l}\text { Make provision in guidelines for SP } \\
\text { representation in DRM decision making and } \\
\text { vice versa. }\end{array}$ & $x$ & $\mathrm{x}$ & $x$ & $x$ \\
\hline $\begin{array}{l}\text { Put in place a contingency and financing } \\
\text { strategy for the financing of responses to } \\
\text { shocks. }\end{array}$ & & & $x$ & \\
\hline $\begin{array}{l}\text { Clarify the procedures for expanding SP- } \\
\text { especially early warning criteria for triggering } \\
\text { expanded payments or other pre-determined } \\
\text { responses to shocks. }\end{array}$ & & $x$ & $x$ & \\
\hline $\begin{array}{l}\text { Expand electronic and mobile banking } \\
\text { services for SP payments. }\end{array}$ & $x$ & $x$ & $x$ & $\mathrm{x}$ \\
\hline \multicolumn{5}{|l|}{$\begin{array}{l}\text { Put in place a national social registry for the } \\
\text { identification of potential beneficiaries when } \\
\text { shocks occur. }\end{array}$} \\
\hline \multicolumn{5}{|l|}{ Programmatic } \\
\hline Attach DRM messages to SP payments. & $x$ & $x$ & $\mathrm{x}$ & $x$ \\
\hline $\begin{array}{l}\text { Ensure pre-positioning of food stocks using } \\
\text { Nepal's PFDS and manage food depot prices } \\
\text { flexibly. }\end{array}$ & $x$ & $\mathrm{x}$ & $\mathrm{x}$ & $x$ \\
\hline Expand temporarily SSA benefit levels. & $x$ & & $x$ & $x$ \\
\hline $\begin{array}{l}\text { Expand (temporarily) coverage of cash } \\
\text { transfers to shock-affected households. }\end{array}$ & $\mathrm{x}$ & & $\mathrm{x}$ & $\mathrm{x}$ \\
\hline Expand public works payments and coverage. & $\mathrm{x}$ & & $\mathrm{x}$ & $\mathrm{x}$ \\
\hline $\begin{array}{l}\text { Establish a national poverty-targeted SP } \\
\text { program to address chronic poverty and } \\
\text { increase the resilience of the poor to shocks. }\end{array}$ & $x$ & $\mathrm{x}$ & $\mathrm{x}$ & $\mathrm{x}$ \\
\hline $\begin{array}{l}\text { Use public works as part of integrated climate } \\
\text { change/rural development/disaster } \\
\text { management response. }\end{array}$ & $x$ & $\mathrm{x}$ & $x$ & $\mathrm{x}$ \\
\hline
\end{tabular}




\section{References}

Adhikari, T. P., F. B. Thapa, S. Tamrakar, P. Buda Magar, J. Hagen-Zanker, and B. Babajanian. 2014. How Does Social Protection Contribute to Social Inclusion in Nepal. Kathmandu: Nepal Participatory Action Network (NEPAN) and Overseas Development Institute (ODI).

ALNAP (Active Learning Network for Accountability and Performance). 2015. "Nepal Earthquake Response: Lessons for Operational Agencies." ALNAP Lessons Paper, ALNAP/ODI, London.

Andersson, C., A. Mekonnen, and J. Stage. 2011. "Impacts of the Productive Safety Net Program in Ethiopia on Livestock and Tree Holdings of Rural Households." Journal of Development Studies 94 (1): 119-126.

Aryal, K. R. 2007. "Mapping Disaster Vulnerability from Historical Data in Nepal." Northumbria University Disaster and Development Centre, Newcastle, UK.

Aryal, K. R. (2012) “The History of Disaster Incidents and Impacts in Nepal, 1900-2005" International Journal of Disaster Risk Science 3 (3): 147-154.

Asian Disaster Reduction Centre. 2000. “Natural Disasters Data Book 1901-2000." Accessed March 20, 2018. http://www.adrc.asia/publications/databook/DB2000_e.html.

Barca, V., and C. O’Brien. 2018. "What Role Can Social Protection Systems Play in Responding to Humanitarian Emergencies?' Shock-Responsive Social Protection Systems Research." Policy Brief, Oxford Policy Management, Oxford, UK.

Bastagli, F. 2014. "Responding to a Crisis: The Design and Delivery of Social Protection." Working Paper, Overseas Development Institute.

Bastagli, F., R. Holmes. 2014. "Delivering Social Protection in the Aftermath of a Shock: Lessons from Bangladesh, Kenya, Pakistan and Viet Nam." Working Paper, Overseas Development Institute, London.

Bastagli, F., J. Hagen-Zanker, L. Harman, V. Barca, G. Sturge, and T. Schmidt. 2016. "Cash Transfers: What Does the Evidence Say? A Rigorous Review of Programme Impact and of the Role of Design and Implementation Features." Overseas Development Institute, London.

Bowen, T. 2015. "Social Protection and Disaster Risk Management in the Philippines: The Case of Typhoon Yolanda (Haiyan)." Policy Research Working Paper 7482, Background paper for 'Shockwaves: Managing the Impacts of Climate Change on Poverty', World Bank, Washington, DC.

Bradley, D., M. McFarland, and M. Clarke. 2014. "The Effectiveness of Disaster Risk Communication: A Systematic Review of Intervention Studies." PLOS Currents Disasters, Edition 1. doi:10.1371/currents.dis.349062e0db1048bb9fc3a3fa67d8a4f8.

Bradshaw, S., and M. Fordham. 2013. "Women, Girls and Disasters: A Review for DFID.” Unpublished Review. https://assets.publishing.service.gov.uk/government/uploads/system/uploads/attachment_data/file/236656/ women-girls-disasters.pdf

Budhathoki, S., and H. Gelband. 2016. "Manmade Earthquake: The Hidden Health Effects of a Blockadeinduced Fuel Crisis in Nepal." BMJ GlobalHealth p. 1-2 1 doi:10.1136/bmjgh-2016-00011

Carraro, L., and S. Lakhey. 2018. "Service Delivery in a Decentralised Context: The Case of Social Security Allowances." UNICEF, Nepal.

Castel, P. 2010. "Fiscal Space Social Protection Policies in Vietnam." In Poverty and Sustainable Development in Asia, Impacts and Responses to the Global Economic Crisis, edited by A. Bauer and N. Thant. Philippines: Asian Development Bank.

Central Bureau of Statistics. 2010. “Nepal - Living Standards Survey 2010-2011, Third Round." National Planning Commission Secretariat, Government of Nepal, Kathmandu, Nepal.

Chew, L., and K. Ramdas. 2005. "Caught in the Storm: The Impact of Natural Disasters on Women." The Global Fund for Women. http://www.globalfundforwomen.org/impact-natural-disasters/. 
Costella, C., C. Jaime, J. Arrighi, E. Coughlan de Perez, P. Suarez, and M. van Aalst. 2018. "Resilient Solutions: Exploring Social Protection Linkages to Forecast-based Financing." BRACED Knowledge Manager Policy Brief, Overseas Development Institute, London.

Dahal, R. 2012. "Rainfall-induced Landslides in Nepal." International Journal of Erosion Control Engineering 5 (1): 1-8.

Davies, M., B. Guenther, J. Leavy, T. Mitchell, and T. Tanner. 2008. “Adaptive Social Protection: Synergies for Poverty Reduction." IDS Bulletin 39 (4): 105-112.

De Janvry, A., F. Finan, and E. Sadoulet. 2012. "Local Electoral Incentives and Decentralised Programme Performance." Review of Economics and Statistics 94 (3): 672-685.

Del Ninno, C., P. Dorosh, L. Smith, and D. Roy. 2001. The 1998 Floods in Bangladesh: Disaster Impacts, Household Coping Strategies, and Response. Research Report 122. Washington, DC: International Food Policy Research Institute.

Delalay, M., A. Zieglera, M. Singh Shresthab, R. Wassonc, K. Sudmeier-Rieux, B. McAdooe, and I. Kochharb. 2018. "Towards Improved Flood Disaster Governance in Nepal: A Case Study in Sindhupalchok District." International Journal of Disaster Risk Reduction 31: 354-366.

Devereux, S. 2012. "Social Protection for Enhanced Food Security in Sub-Saharan Africa." Working Paper 2010010, UNDP Regional Bureau for Africa, New York.

Dhungel, R., and R. Nath Ojha. 2012. "Women's Empowerment for Disaster Risk Reduction and Emergency Response in Nepal." Gender and Development 20 (2): 309-321. doi:10.1080/13552074.2012.687220

Dixit, A. 1996. "Disaster Management in Nepal." A Country Paper Prepared for UNCHS (HABITAT) and Presented to the Workshop Experiences in Disaster Management in Asia, November 1996, Kalutara, Sri Lanka.

- - . 2017. "Disastrous Unpreparedness" Nepali Times 18-24 th August Accessed July 16, 2018. http://archive.nepalitimes.com/regular-columns/guest-editorial/disastrous-response.

Drucza, B. 2016. "Social Inclusion and Social Protection in Nepal." A thesis submitted for the degree of Doctor of Philosophy. dro.deakin.edu.au/.../drucza-socialinclusion-2016A.pdf.

Epstein, K., J. DiCarlo, R. Marsh, B. Adhikari, D. Paudel, I. Ray, and I. E. Måren. 2018. "Recovery and Adaptation after the 2015 Nepal Earthquakes: A Smallholder Household Perspective." Ecology and Society 23 (1): 29. https://doi.org/10.5751/ES-09909-230129

Epstein, K., J. DiCarlo, R. Marsh, I. Ray, and I. Måren. 2017. "Coping Strategies of Smallholder Farming Communities after the 2015 Nepal Earthquake: Insights into Post-Disaster Resilience and Social-Ecological Change." Case Studies in the Environment 1 (1): 1-12. doi:doi.org/10.1525/cse.2017.000612

ESCAP. 2012. Reducing Vulnerability and Exposure to Disasters: The Asia-Pacific Disaster Report 2012. ESCAP, United Nations, Bangkok.

Espinosa, L. 2018. "National System for Civil Protection - Financial Instruments (FONDEN): Financial Tools and Approaches for Shock-responsive Safety Nets." Presentation to the South-South Learning Forum on Social Protection and Jobs, February 19-22, Frankfurt.

FAO (Food and Agriculture Organization of the UN). 2013. "Guidelines for Public Works Programmes: Cash-, Voucher-, and Food-for-Work." FAO, Rome.

Farrington, J., R. Slater, and R. Holmes. 2004. "Social Protection and Pro-poor Agricultural Growth: What Scope for Synergies." Natural Resource Perspectives No. 14, Overseas Development Institute, London.

Fenwick, T. B. 2009. “Avoiding Governors: The Success of Bolsa Família." Latin American Research Review 44 (1): 102-131.

- - - 2010. "The Institutional Feasibility of National-local Policy Collaboration: Insights from Brazil and Argentina." Journal of Politics in Latin America 2 (2): 155-183.

Fitzgibbon, C. 2016. "Shock-responsive Social Protection in Practice: Kenya's Experience in Scaling Up Cash Transfers." ODI HPN Blog, February 23. Accessed May 3, 2018. http://odihpn.org/blog/shock-responsivesocial-protection-in-practice-kenyas-experience-in-scaling-up-cash-transfers/. 
Forbes, K., and J. Broadhead. 2011. "Forests and Landslide: The Role of Trees and Forests in the Prevention of Landslides and Rehabilitation of Landslide-affected Areas in Asia." RAP Publication 2011/19, FAO, Bangkok.

Gaire, S., R. C. Delgado, and P. A. Gonzalez. 2015. “Disaster Risk Profile and Existing Legal Framework of Nepal: Floods and Landslides." Risk Management and Health Policy 8: 139-149. doi:10.2147/RMHP.S90238.

Gautam, D. 2017. "Assessment of Social Vulnerability to Natural Hazards in Nepal." Natural Hazards and Earth Systems Sciences 17: 2313-2320. https://doi.org/10.5194/nhess-17-2313-2017.

Gilligan, D., J. Hoddinott, and A. Taffesse. 2009. "The Impact of Ethiopia's Productive Safety Net Programme and its Linkages." Journal of Development Studies 45: 1684-1706.

Government of Kenya. 2012. "Kenya Social Protection Sector Review: Executive Report." Ministry of State for Planning, National Development and Vision 2030, Republic of Kenya.

GoN (Government of Nepal). 2010. "National Adaptation Programme of Action (NAPA) for Climate Change." Ministry of Environment, Kathmandu. https://unfccc.int/resource/docs/napa/npl01.pdf

- - - 2011. "National Framework on Local Adaptation Plans for Action." Government of Nepal, Ministry of Science Technology and Environment, Kathmandu.

- - - 2012a. "Assessment of Social Security Allowance Programme in Nepal." National Planning Commission, Kathmandu. https://www.npc.gov.np/images/category/Assessment-of-Social-Security-Allowance-Program-inNepal.pdf

- - . 2012b. "Assessment of Karnali Employment Program." National Planning Commission, Singh Durbar.

- - - 2016. 'Statistics of Local Road Network (SLRN) 2016', Ministry of Federal Affairs and Local Development, Department of Local Infrastructure Development and Agricultural Roads (DoLIDAR) Kathmandu, Nepal

GoN. 2017. “Disaster Risk Reduction and Management Act 2074". http://www.lawcommission.gov.np/

Grosh, M., C. Andrews, R. Quintana., and C. Rodriguez-Alas. 2011. “Assessing Safety Net Readiness in Response to Food Price Volatility." Social Protection and Labor Discussion Paper 1118, World Bank, Washington, DC.

Gurung, R., G. Tamang, F. Thapa, H. Sanner, and P. Magar. 2015. Assessment of the Emergency Top-up Cash Transfer Programme for Vulnerable Groups in Nepal. NEPAN report for UNICEF, Kathmandu.

GVA. 2015. Global Assessment Report on Disaster Risk Reduction 2015. Geneva: UNISDR.

Hagen-Zanker, J., R. Mallett, and A. Ghimire. 2015. How Does Nepal's Child Grant Work for Dalit Children and Their Families? A Mixed-methods Assessment of Programme Delivery and Impact in Bajura and Saptari. ODI Report. London: Overseas Development Institute.

He, L., J. Aitchinson, K. Hussey, Y. Wei, and A. Lo. 2018. "Accumulation of Vulnerabilities in the Aftermath of the 2015 Nepal Earthquake: Household Displacement, Livelihood Changes and Recovery Challenges." International Journal of Disaster Risk Reduction 31: 68-75.

HelpAge International. 2009. Global agewatch index 2013: A summary. Retrieved from http://www.helpage.org/global-agewatch/reports/global-agewatch-index-2013-insight-report-summary-andmethodology/

Hobson, M., and L. Campbell. 2012. “How Ethiopia's Productive Safety Net Programme (PSNP) Is Responding to the Current Humanitarian Crisis in the Horn." Humanitarian Exchange Magazine March 53. https://odihpn.org/magazine/how-ethiopia\%C2\%92s-productive-safety-net-programme-psnp-is-respondingto-the-current-humanitarian-crisis-in-the-horn/

Hoddinott, J., I. Ahmed, A. Ahmed, and S. Roy. 2017. “Behavior Change Communication Activities Improve Infant and Young Child Nutrition Knowledge and Practice of Neighboring Non-participants in a ClusterRandomized Trial in Rural Bangladesh." PLOS ONE 12 (6): e0179866. https://doi.org/10.1371/

Holmes, R., and S. Upadhya. 2009. The Role of Cash Transfers in Post-Conflict Nepal. London: ODI.

Holmes, R., F. Samuels, A. Ghimire, and S. Thewissen. 2018. Nepal's Cash Allowances for Children with Disabilities. ODI Report. London: Overseas Development Institute. 
Holzmann, R., and S. Jorgensen. 2001. "Social Risk Management: A New Conceptual Framework for Social Protection, and Beyond." International Tax and Public Finance 8: 529-556.

ICGTF (Inter Cluster Gender Task Force). 2015. "Gender Equality Update Number 1." https://reliefweb.int/report/nepal/gender-equality-bulletin-no-1-response-nepal-earthquake-

21052015INFORM. 2018. “Nepal: Country Risk Profile Version 2018." Accessed April 12, 2018. http://www.informindex.org/Portals/0/InfoRM/2015/Country Profiles/NPL.pdf $\quad$ http://www.informindex.org/countries/country-profiles

Jaquet, S., G. Shrestha, T. Kohler, and G. Schwilch. 2016. "The Effects of Migration on Livelihoods, Land Management, and Vulnerability to Natural Disasters in the Harpan Watershed in Western Nepal." Mountain Research and Development 36 (4): 494-505. http://www.bioone.org/doi/full/10.1659/MRD-JOURNAL-D-16$\underline{00034.1}$

Jones, S. 2012. "The Politics of Social Rights: Social Protection and Free Health Care in Nepal." Public Management Review Special Issue: The Politics and Governance of Public Services in Developing Countries 14 (2): 239-254. http://dx.doi.org/10.1080/14719037.2012.657920

Joshi, N., L. Piya, and K. Kaharjan. 2017. "Rural Household Poverty Dynamics in the Far-western Hills of Nepal: Empirical Evidence from Panel Data." International Social Science Journal 66 (219-200): 205-220 https://doiorg.ezproxy.wlv.ac.uk/10.1111/issj.12123

Kardan, A., A. Wyatt, R. Attah, and P. van Ufford. 2017. "Assessing the Capacity of Local Administration and Community Structures to Deliver Social Protection Programmes." OPM Working Paper, Oxford Policy Management, Oxford.

Karki, A. K. 2017. "Global Platform for Disaster Risk Reduction: Official Statement of Delegation of the Government of Nepal." May 22-26, Cancun, Mexico.

KC, S., B. Upreti, S. Paudel, G. Acharya, A. Tandukar, and B. Babajanian. 2014. "The Old Age Allowance and Perceptions of the State in Rolpa District." Nepal SLRC Working Paper 25, Secure Livelihoods Research Consortium, London.

KEPTA. 2014. "Social Protection through Public Works in Nepal: Improving the Karnali Employment Programme Briefing."

Khadka, R. 2017. "An Analytical Briefing on the Social Security Sector in Nepal." International Labour Organisation (ILO) and Ministry of Labour and Employment of Nepal, Kathmandu.

Khanal, S. 2014. "Social Protection in Nepal: An Overview." Development Advocate 2 (1): 4-7.

Khanal, N. R., M. Shrestha, and M. Ghimire. 2007. eds. Preparing for Flood Disaster: Mapping and Assessing Hazard in the Ratu Watershed, Nepal. Nepal: International Centre for Integrated Mountain Development (ICIMOD) and New Delhi: United Nations Educational Scientific and Cultural Organization (UNESCO).

Knight, K., and C. Welton-Mitchell. 2013. "Gender Identity and Disaster Response in Nepal." Forced Migration Review 42: 57-58

Knight, K., and R. Sollom. 2012. "Making Disaster Risk Reduction and Relief Programmes LGBTI Inclusive: Examples from Nepal." Humanitarian Exchange 55: 36-39.

Koehler, G. 2011. "Social Protection and Socioeconomic Security in Nepal." IDS Working Paper 370, Institute for Development Studies, Brighton.

- - . 2014. "Social Protection in Nepal: Challenges and Ideas." Development Advocate 2 (1): 8-15.

Koehler, G., and N. Mathers. 2017. "Dynamics of Social Protection in Fragile Contexts: Nepal and Myanmar." Global Social Policy 17 (3): 347-352. doi:10.1177/1468018117729914.

Koirala, P. 2014. Country Profile Nepal: Disaster Management Institution and System in Nepal. Kobe, Japan: Asian Disaster Reduction Centre.

Kuriakose, A., R. Heltberg, W. Wiseman, C. Costella, R. Cipryk, and S. Cornelius. 2012. "Climate Response Social Protection." Social Protection and Labor Discussion Paper 1210, World Bank, Washington, DC.

Lamichane, J. 2015. "Health Consequences of the Blockade in Nepal." The Lancet 386 (December): 2251. 
Laws, E. 2016. Decentralisation and Cash Transfers. GSDRC Helpdesk Research Report 1400. Birmingham, UK: GSDRC, University of Birmingham.

Lee, A. 2016. "Barriers to Evidence-based Disaster Management in Nepal: A Qualitative Study." Public Health 133: 99-106.

Lutz, A., H. ter Maat, H. Biemans, A. Shrestha, P. Wester, and W. Immerzeel. 2016. "Selecting Representative Climate Models for Climate Change Impact Studies: An Advanced Envelope-based Selection Approach." International Journal of Climatology 36 (12): 3988-4005.

Massey, D. S., W. G. Axinn, and D. J. Ghimire. 2010. "Environmental Change and Outmigration: Evidence from Nepal." Population and Environment 32 (2-3): 109-136.

McCord, A. 2013a. "ODI Shockwatch: Review of the Literature on Social Protection Shock Responses and Readiness." Overseas Development Institute, London.

- - - 2013b. "Shockwatch and Social Protection: Shock Response Readiness Appraisal Toolkit." Overseas Development Institute, London.

McCord, A., D. Harris, and S. KC. 2012. "Politics of a National Employment Guarantee Scheme in Nepal: An Initial Assessment of Feasibility." Working Paper, Overseas Development Institute, London.

Ministry of Agriculture and Cooperatives, World Food Programme, and Food and Agriculture Organization of the United Nations. 2009. 2008/2009 Winter Drought in Nepal Crop and Food Security Assessment. Joint Assessment Report, Kathmandu.

Mishra, B., K. Poudel, and D. Raj Mishra. 2016. "Effect of Change in Indian Rice Price on Nepalese Rice Market: A Partial Equilibrium Model." Agricultural Economics Research Review 29 (1): 127-133. doi:10.5958/09740279.2016.00025.2.

MoAC. 2009. "Statistical Information on Nepalese Agriculture 2008-09." Ministry of Agriculture and Cooperatives. Singhdurbar, Kathmandu

MoHA (Ministry of Home Affairs). 2018. "Government of Nepal. Nepal Disaster Risk Reduction Portal." Kathmandu, Nepal. Accessed April 15, 2018. http://drrportal.gov.np/risk-profile-of-nepal

MoPE (Ministry of Population and Environment). 2016. "Intended Nationally Determined Contributions: Communicated to the UNFCCC Secretariat in February 2016." Accessed April 18, 2018. https://www.climatewatchdata.org/ndcs/country/NPL/full

Muldoon, O., K. Acharya, S. Jay, K. Adhikari, J. Pettigrew, and R. Lowe. 2017. "Commnunity Identity and Collective Efficacy: A Social Cure for Traumatic Stress in Post-Earthquake Nepal." European Journal of Social Psychology 4: 904-915.

Neumayer, E., and T. Plumper. 2007. "The Gendered Nature of Natural Disasters: The Impact of Catastrophic Events on the Gender Gap in Life Expectancy, 1981-2002." Annals of the Association of American Geographers 97 (3): 551-566.

New Era. 2016. "Public Expenditure Tracking Survey \& Quantitative Service Delivery Survey of Social Security Entitlements: Research Findings on the Multi Donor Trust Fund's Demand-Side Initiative in Public Financial Management in VDCs of Eastern, Central, Mid and Far-Western Regions of Nepal, New Era, Kathmandu."

OPM. 2017. Shock-responsive Social Protection Systems Research: Literature Review. 2nd ed. Oxford: OPML.

Panthi, J., S. Aryal, P. Dahal, P. Bhandari, N. Krakauer, and V. Pandey. 2015. “Livelihood Vulnerability Approach to Assessing Climate Change Impacts on Mixed Agro-livestock Smallholders around the Gandaki River Basin in Nepal." Reg Environ Change 16: 1-12. doi:10.1007/s10113-015-0833-y

Paudel, J., and H. Ryu. 2018. "Natural Disasters and Human Capital: The Case of Nepal's Earthquake." World Development 111: 1-12

Pelham, L., E. Clay, and T. Braunholz. 2011. Natural Disasters: What is the Role for Social Safety Nets? Washington, DC: World Bank. 
Pitt, M. 2000. "The Effect of Non-agricultural Self-Employment Credit on Contractual Relations and Employment in Agriculture: The Case of Microcredit Programs in Bangladesh." Bangladesh Development Studies 26: 2 (3): 15-48.

Pritchett, L., M. Woolcock, and M. Andrews. 2010. “Capability Traps? The Mechanisms of Persistent Implementation Failure." Working Paper 234, Centre for Global Development, Washington, DC.

Rabi, A., G. Koehler, G. Fajth, A. Alim, T. Dhakal, and A. Spalton. 2015. "The Road to Recovery: Cash Transfers as an Emergency Response to Nepal's Earthquake of 2015 and a Catalyst for Consolidating Nepal's Social Protection Floor." UNICEF Nepal Working Paper Series WP/2015/003, Social Policy and Economic Analysis Section, UNICEF, Kathmandu. http://www.un.org/esa/socdev/csocd/2016/Kohler-paper-roadtorecovery.pdf.

Reyes, C., J. Albert, and C. Reyes. 2018. "Lessons on Providing Cash Transfers to Disaster Victims: A Case Study of UNICEF's Unconditional Cash Transfer Program for Super Typhoon Yolanda Victims." Discussion Paper Series 2018-04, Philippines Institute for Development Studies, Quezon City.

Roback, K., M.K. Clark, J. West, D. Zekkos, G. Li, S.F. Gallen, D. Chamlagain, J. Godt. 2017. "The Size, Distribution, and Mobility of Landslides caused by the 2015 Mw7.8 Gorkha Earthquake, Nepal." Geomorphology. 301: 121-138.

Roelen, K., and H. Chhetri. 2016. "Improving Social Protection's Response to Child Poverty and Vulnerability in Nepal." Institute for Development Studies, Brighton.

Roy, S., M. Hidrobo, J. Hoddinott, and A. Ahmed. 2017. "Transfers, Behaviour Change Communication, and Intimate Partner Violence: Post-program Evidence from rural Bangladesh." Unpublished paper, IFPRI, Washington, DC.

Schjødt, R. 2017. Social Accountability in the Delivery of Social Protection: Nepal Case Study. Orpington: Development Pathways.

Schneiderbauer, S., and D. Ehrlich. 2004. "Risk, Hazard and People's Vulnerability to Natural Hazards: A Review of Definitions, Concepts and Data." European Commission Director General Joint Research Centre, Brussels.

Shrestha, S. 2016. "Preparedness and Responses to the 2015 Earthquake Disaster in Nepal: Remittances and Differential Vulnerability by Caste System." Dissertation submitted in fulfilment of International Environment Studies, NORAGRIC, Oslo.

Sijapati, B. 2017. "The Quest for Achieving Universal Social Protection in Nepal: Challenges and Opportunities". Indian Journal of Human Development. 11 (1): 17-36.

Slater, R., S. Ashley, M. Tefera, M. Buta, and D. Esubalew. 2006. Ethiopia Productive Safety Net Programme (PSNP): PSNP Policy, Programme and Institutional Linkages Final Report. London: Overseas Development Institute. https://www.odi.org/sites/odi.org.uk/files/odi-assets/publications-opinion-files/3964.pdf.

Slater, R., and R. Mallett. 2017. "How to Support Statebuilding, Service Delivery and Recovery in Fragile and Conflict-Affected Situations: Lessons from Six years of SLRC research." Synthesis Briefing 2, Secure Livelihoods Research Consortium, London.

Smith, G. 2015. "Cash Coordination in the Philippines: A Review of Lessons Learned during the Response to Super Typhoon Haiyan." Cash Learning Partnership (CaLP), Oxford.

Standing, K., S. Parker, and S. Bista. 2016. “Grassroots Responses to Violence against Women and Girls in Postearthquake Nepal: Lessons from the Field." Gender and Development 24 (2): 187-204. https://doi.org/10.1080/13552074.2016.1194562

Sturge, G., R. Mallett, J. Hagen-Zanker, and R. Slater. 2017. "Tracking Livelihoods, Service Delivery and Governance: Panel Survey Findings from the Secure Livelihoods Research Consortium."

Sudmeier-Mieux, K., S. Jaquet, M. Derron, M. Jaboyedoff, and S. Devkota. 2012. "A Case Study of Coping Strategies and Landslides in Two Villages of Central-eastern Nepal." Applied Geography 21: 680-690.

Tilsone, V. 2012. "An Innovative Approach to Drought Management in Kenya: The Establishment of the National Drought Management Authority and National Drought and Disaster Contingency Fund." Disaster 
Reduction in Africa, UNISDR Informs: Special Issue on Drought Risk Reduction 2012, United Nations International Strategy for Disaster Reduction

Tirivayi, N. 2017. "Social Protection for Building the Resilience of Forest-Dependent People: Evidence, Linkages, Practices and Potential Applications." Social Protection and Forestry Working Paper 1, FAO, Rome.

Tombrink, G. 2017. "Flood Events and Their Effects in a Himalayan Mountain River: Geomorphological Examples from the Buri Gandaki Valley, Nepal." Journal of Mountain Science 14 (7): 1303-1316.

Ulrichs, M., and R. Slater. 2017. "How Can Social Protection Build Resilience? Insights from Ethiopia, Kenya and Uganda." BRACED Working Paper, ODI, London.

UNDP Nepal. 2009. "Nepal Human Development Report 2009: State Transformation and Human Development." UNDP, Kathmandu.

UNDP/UNCDF. 2014. Strengthening the Governance of Social Protection: The Role of Local Government. New York: Regional Bureau for Asia and the Pacific, United Nations. http://www.asia-

pacific.undp.org/content/rbap/en/home/library/democratic governance/strengthening-governance-of-socialprotection.html

UNFPA (United Nations Population Fund). 2017. "Population Situation Analysis of Nepal." Accessed April 21, 2018.

https://reliefweb.int/sites/reliefweb.int/files/resources/Nepal\%20Population\%20Situation\%20Analysis 0.pdf

UNICEF (United Nations Children's Fund). 2010. State of the world's children. UNICEF, New York

UNICEF. 2014. "A Matter of Magnitude: The Impact of the Economic Crisis on Women and Children in South Asia." UNICEF ROSA, Kathmandu.

UNISDR. 2015. “Global Assessment Report on Disaster Risk Reduction 2015: Making Development Sustainable, The Future of Disaster Risk Management". Geneva: United Nations Office for Disaster Risk Reduction.

UNISDR. 2016. “Drought Risk Management: A Strategic Approach." Geneva: United Nations Office for Disaster Risk Reduction.

UNISDR. 2018. “DesInventar Sendai Framework for Disaster Risk Reduction.”

https://www.desinventar.net/DesInventar/profiletab.jsp?countrycode=npl. [Accessed July 17, 2018.

https://www.desinventar.net/DesInventar/profiletab.jsp?countrycode=npl.

Upreti, B, S. KC, R. Mallett, B. Babajanian, K. Pyakuryal, S. Ghimire, A. Ghimire, and S. Sharma. 2012. "Livelihoods, Basic Services and Social Protection in Nepal." SLRC Working Paper 7, Secure Livelihoods Research Consortium, London.

USAID (U.S. Agency for International Development). 2018. "Nepal Country Profile: Agriculture and Food Security." Accessed July 1, 2018. https://www.usaid.gov/nepal/agriculture-and-food-security. Accessed 1 July 2018

Vaidya, K., with P. P. Regmi and B. Ghirime. 2010. "Appraisal of the Karnali Employment Programme as a Regional Social Protection Scheme." Ministry of Local Development, Government of Nepal and ILO Office in Nepal.

Vakis, R. 2006. "Complementing Natural Disasters Management: The Role of Social Protection." Social Protection and Labour Discussion Paper No 543, World Bank, Washington, DC.

Wagle, U. 2016. "The Caste/Ethnic Bases of Poverty Dynamics: A Longitudinal Analysis of Chronic and Structural Poverty in Nepal." Journal of Development Studies 53 (9): 1430-1451. https://doi.org/10.1080/00220388.2016.1224850

Walker, T., U. Khadka, and J. Pandey. 2017. Risk and Vulnerability in Nepal: Report on Wave 1 of the Household Risk and Vulnerability Survey. Kathmandu: World Bank.

WFP (World Food Programme). 2011. Summary Evaluation Report-Kenya Country Portfolio. Evaluation Reports, Agenda item 6. Rome: World Food Programme. 
- - 2018. "WFP Nepal Country Brief." Accessed May 3, 2018. https://docs.wfp.org/api/documents/e95cc5f06c8242eea08ff71631a8b898/download/

Wisner, I., P. Blaikie, T. Cannon, and I. Davis. 2003. At Risk: Natural Hazards, People's Vulnerability and Disasters. 2nd ed. London: Routledge.

World Bank. 2012. FONDEN: Mexico's Natural Disaster Fund-A Review. Report No 75322. Washington, DC: World Bank.

- - - 2013a. "Nepal Report on Human Development: Access, Equity, and Quality in the Education, Health and Social Protection Sectors." World Bank, Washington, DC.

- - . 2013b. "Ethiopia's Productive Safety Net Program (PSNP) Integrating Disaster and Climate Risk Management: Case Study." World Bank, Washington, DC.

- - - 2014. "Improving Social Protection for the Vulnerable in Nepal: A Review of Social Assistance Programs and Expenditures." World Bank, Washington, DC.

- - . 2016a. "Strengthening Systems for Social Protection and Civil Registration Project: Program Appraisal Document PAD 1639." World Bank, Kathmandu.

- - . 2016b. "Adaptive Social Protection Program: Addressing the Challenges of Climate Change and Disaster Risk for the Poor and Vulnerable." World Bank Brief, World Bank Group, Washington, DC.

- - - 2016c. "Closing the Gap: Building Resilience to Natural Disasters and Man-Made Shocks through Social Safety Nets."

- - - 2016d. "Project Appraisal Document for Strengthening Systems for Social Protection and Civil Registration Project" PAD 1639, World Bank, Washington DC.

- - . 2018. "Age Dependency Ratio: Older Dependents to Working-Age Population for Nepal." Accessed May 3, 2018. https://fred.stlouisfed.org/series/SPPOPDPNDOLNPL. 


\section{Annex 1: Statistical Analysis}

Annex Table 1: Exposure to shocks and gender of household head

\begin{tabular}{|l|c|c|c|c|c|c|c|}
\hline \multirow{2}{*}{ Type of shocks } & \multicolumn{2}{|c|}{ All households } & \multicolumn{2}{|c|}{$\begin{array}{c}\text { Female-headed } \\
\text { households }\end{array}$} & \multicolumn{2}{c|}{$\begin{array}{c}\text { Male headed } \\
\text { households }\end{array}$} & $\begin{array}{c}\text { Wilcoxon rank- } \\
\text { sum (Mann- } \\
\text { Whitney) test }\end{array}$ \\
\hline & Mean & Std. Dev. & Mean & Std. Dev. & Mean & Std. Dev. & P-value \\
\hline Any shock & 54.8 & 49.8 & 54.3 & 49.8 & 54.9 & 49.8 & 0.677 \\
\hline Earthquake & 89.9 & 30.2 & 86.9 & 33.9 & 90.6 & 29.2 & 0.139 \\
\hline Flood & 3.2 & 17.5 & 3.5 & 18.3 & 3.1 & 17.3 & 0.504 \\
\hline Landslide & 2.5 & 15.7 & 2.2 & 14.7 & 2.6 & 15.9 & 0.440 \\
\hline Drought & 18.9 & 39.2 & 19.8 & 39.9 & 18.7 & 39.0 & 0.371 \\
\hline Fire & 0.4 & 6.2 & 0.3 & 5.0 & 0.4 & 6.4 & 0.422 \\
\hline Forced displacement & 0.0 & 1.8 & 0.2 & 4.1 & 0.0 & 0.0 & - \\
\hline Riots/blockages & 20.7 & 40.5 & 18.5 & 38.8 & 21.2 & 40.9 & $0.037^{* *}$ \\
\hline Death of a family member & 1.8 & 13.4 & 3.6 & 18.5 & 1.4 & 11.7 & $0.000^{* * *}$ \\
\hline $\begin{array}{l}\text { Diseases or injury of family } \\
\text { member }\end{array}$ & 12.9 & 33.5 & 13.9 & 34.6 & 12.6 & 33.2 & 0.235 \\
\hline Breakup of family & 0.2 & 4.1 & 0.3 & 5.0 & 0.1 & 3.8 & 0.412 \\
\hline Fuel shortage & 2.1 & 14.4 & 2.8 & 16.5 & 2.0 & 13.8 & $0.071^{*}$ \\
\hline Unexpected higher prices & 18.0 & 38.4 & 22.8 & 42.0 & 16.9 & 37.5 & $0.000^{* * *}$ \\
\hline Livestock loss & 4.1 & 19.8 & 4.2 & 20.1 & 4.0 & 19.7 & 0.771 \\
\hline Note: *** p & & & & & \\
\hline
\end{tabular}

Note: $* * * p<0.01, * * p<0.05, * p<0.1$.

'-Too few households of this type are exposed to this shock.

${ }^{1}$ Earthquake is based only on earthquake-affected districts in sample (7 districts out of the 50 in the HRVS: Gorkha, Dhading, Nuwakot, Kavrepalanchok, Sindhupalchok, Dolakha, and Makwanpur). 
Annex Table 2: Exposure to shocks for households with children under five years of age

\begin{tabular}{|l|l|l|l|l|l|}
\hline Type of shocks & \multicolumn{2}{|c|}{$\begin{array}{c}\text { Households with } \\
\text { children under 5 }\end{array}$} & \multicolumn{2}{|c|}{$\begin{array}{c}\text { Households without } \\
\text { children under 5 }\end{array}$} & $\begin{array}{c}\text { Wilcoxon rank-sum } \\
\text { (Mann-Whitney) test }\end{array}$ \\
\hline & Mean & Std. Dev. & Mean & Std. Dev. & P-value \\
\hline Any shock & 53.8 & 49.9 & 55.3 & 49.7 & 0.245 \\
\hline Earthquake & 32.1 & 46.7 & 39.9 & 49.0 & $0.000^{* * *}$ \\
\hline Earthquake ${ }^{1}$ & 86.8 & 33.9 & 91.0 & 28.6 & $0.061^{*}$ \\
\hline Flood & 3.5 & 18.4 & 3.0 & 17.1 & 0.804 \\
\hline Landslide & 3.1 & 17.4 & 2.2 & 14.7 & 0.266 \\
\hline Drought & 22.2 & 41.6 & 17.2 & 37.8 & 0.283 \\
\hline Fire & 0.3 & 5.5 & 0.4 & 6.5 & $0.06 *$ \\
\hline Riots/blockages & 18.1 & 38.5 & 21.9 & 41.4 & 0.182 \\
\hline Death of a family member & 1.6 & 12.7 & 1.9 & 13.7 & 0.606 \\
\hline Diseases or injury of family member & 13.9 & 34.6 & 12.3 & 32.9 & 0.690 \\
\hline Breakup of family & 0.1 & 3.9 & 0.2 & 4.2 & 0.291 \\
\hline Fuel shortage & 2.1 & 14.3 & 2.1 & 14.4 & 0.902 \\
\hline Unexpected higher prices & 18.4 & 38.8 & 17.8 & 38.3 & $0.016^{* *}$ \\
\hline Livestock loss & 3.8 & 19.2 & 4.2 & 20.1 & 0.899 \\
\hline
\end{tabular}

Note: ${ }^{* * *} \mathrm{p}<0.01,{ }^{* *} \mathrm{p}<0.05, * \mathrm{p}<0.1$

'-Too few households of this type exposed to this shock

${ }^{1}$ Earthquake is based on earthquake-affected districts in sample (7 districts out of the 50 in the HRVS: Gorkha, Dhading, Nuwakot, Kavrepalanchok, Sindhupalchok, Dolakha and Makwanpur).

Annex Table 3: Exposure to shocks by age group of household head

\begin{tabular}{|c|c|c|c|c|c|c|c|}
\hline \multirow[t]{2}{*}{ Type of shocks } & \multicolumn{2}{|c|}{$\begin{array}{c}\text { Household head age } \\
\leq \text { median }\end{array}$} & \multicolumn{2}{|c|}{$\begin{array}{c}\text { Household head age }> \\
\text { median }<70 \text { years }\end{array}$} & \multicolumn{2}{|c|}{$\begin{array}{l}\text { Household head age } \\
70+\end{array}$} & \multirow{2}{*}{$\begin{array}{c}\text { Kruskal- } \\
\text { Wallis test } \\
\text { P-value }\end{array}$} \\
\hline & Mean & Std. Dev. & Mean & Std. Dev. & Mean & Std. Dev. & \\
\hline Any shock & 53.2 & 49.9 & 56.4 & 49.6 & 56.6 & 49.6 & $0.103 *$ \\
\hline Earthquake & 35.4 & 47.8 & 39.1 & 48.8 & 39.7 & 49.0 & $0.040 * *$ \\
\hline Earthquake $^{1}$ & 88.4 & 32.0 & 91.2 & 28.4 & 91.6 & 27.9 & 0.364 \\
\hline Flood & 3.1 & 17.4 & 3.5 & 18.3 & 1.7 & 13.0 & 0.836 \\
\hline Landslide & 2.3 & 15.0 & 2.7 & 16.1 & 3.0 & 17.1 & 0.953 \\
\hline Drought & 18.0 & 38.4 & 20.0 & 40.0 & 19.2 & 39.4 & 0.426 \\
\hline Fire & 0.5 & 7.2 & 0.3 & 5.3 & 0.0 & 0.0 & - \\
\hline Riots/blockages & 20.0 & 40.0 & 21.9 & 41.4 & 18.6 & 38.9 & 0.333 \\
\hline $\begin{array}{c}\text { Death of a family } \\
\text { member }\end{array}$ & 1.5 & 12.2 & 2.1 & 14.3 & 2.4 & 15.2 & 0.190 \\
\hline $\begin{array}{l}\text { Diseases or injury of } \\
\text { family member }\end{array}$ & 10.8 & 31.0 & 14.1 & 34.9 & 19.4 & 39.6 & $0.000 * * *$ \\
\hline Breakup of family & 0.2 & 4.4 & 0.1 & 2.8 & 0.4 & 6.6 & - \\
\hline Fuel shortage & 1.8 & 13.2 & 2.1 & 14.3 & 4.5 & 20.8 & $0.000 * * *$ \\
\hline $\begin{array}{l}\text { Unexpected higher } \\
\text { prices }\end{array}$ & 17.9 & 38.3 & 17.7 & 38.2 & 20.7 & 40.6 & 0.286 \\
\hline Livestock loss & 3.9 & 19.4 & 4.6 & 21.0 & 2.2 & 14.6 & $0.038^{* *}$ \\
\hline
\end{tabular}

Note: $* * * \mathrm{p}<0.01, * * \mathrm{p}<0.05, * \mathrm{p}<0.1$.

'-Too few households of this type exposed to this shock.

${ }^{1}$ Earthquake is based on earthquake-affected districts in sample (7 districts out of the 50 in the HRVS: Gorkha, Dhading, Nuwakot, Kavrepalanchok, Sindhupalchok, Dolakha, and Makwanpur). 


\section{Annex 2: Case Study Figures}

Annex Figure 1 DRM and ASP service delivery in event of flood

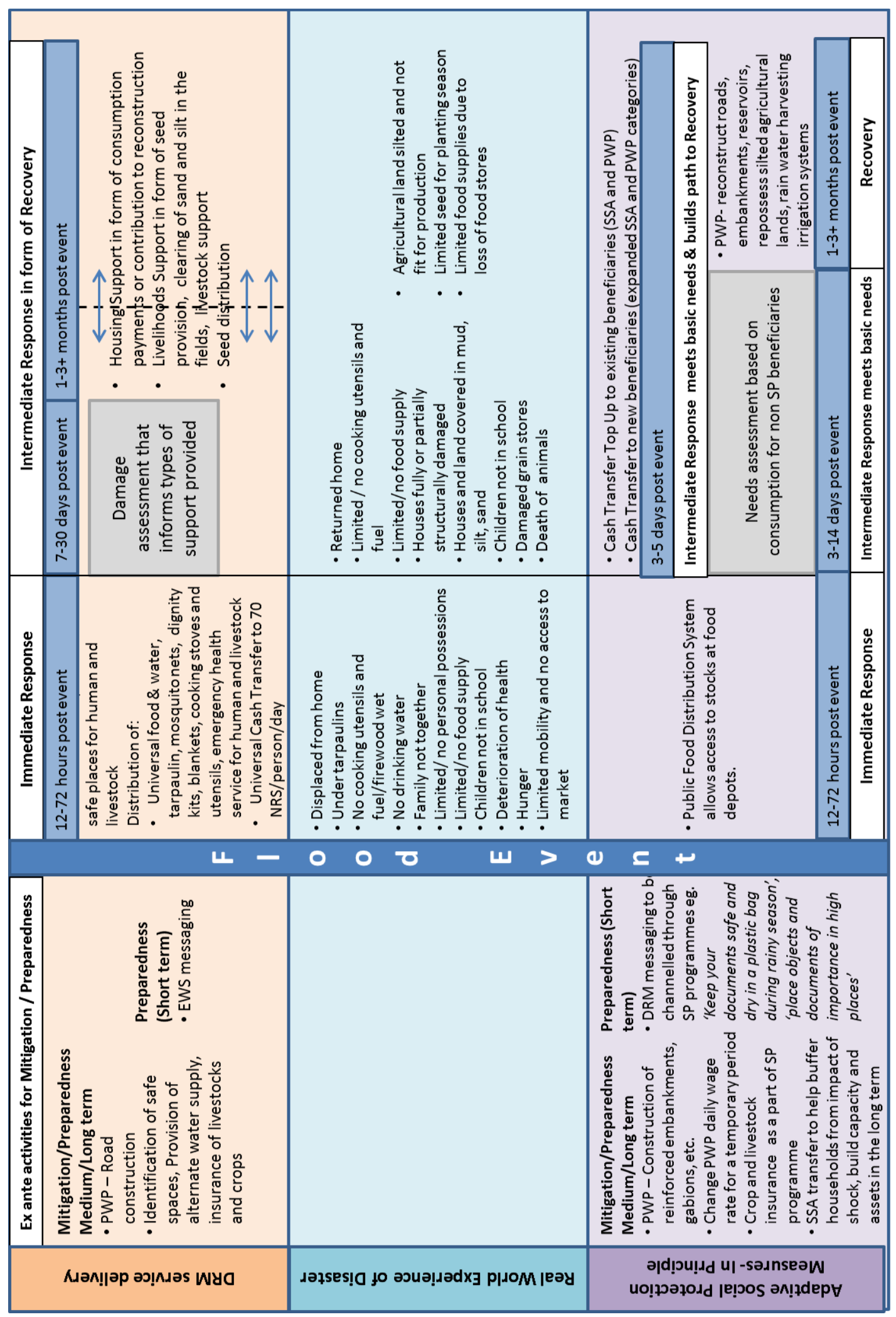


Annex Figure 2 DRM and ASP service delivery in event of earthquake

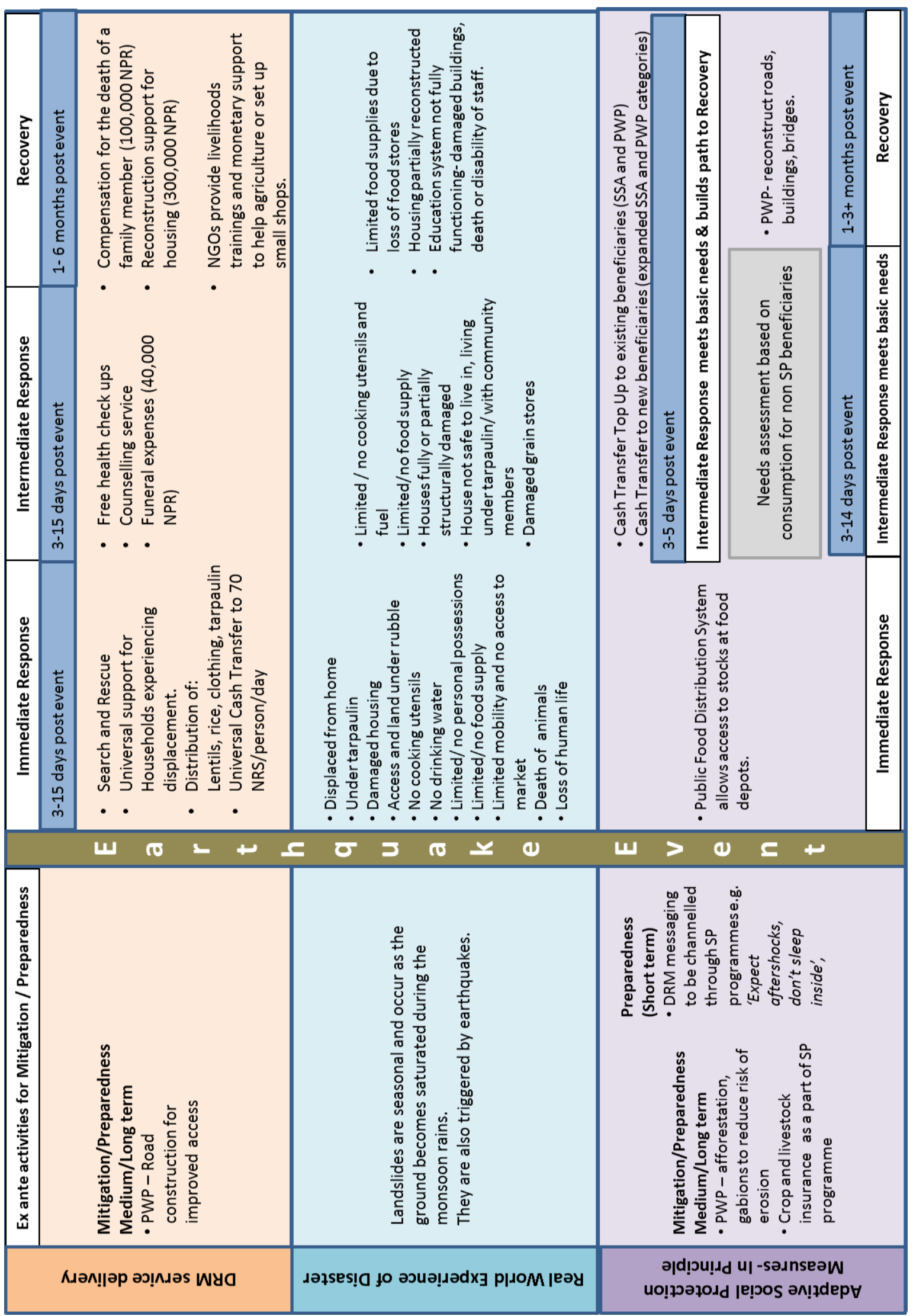


Annex Figure 3 DRM and ASP service delivery in event of drought

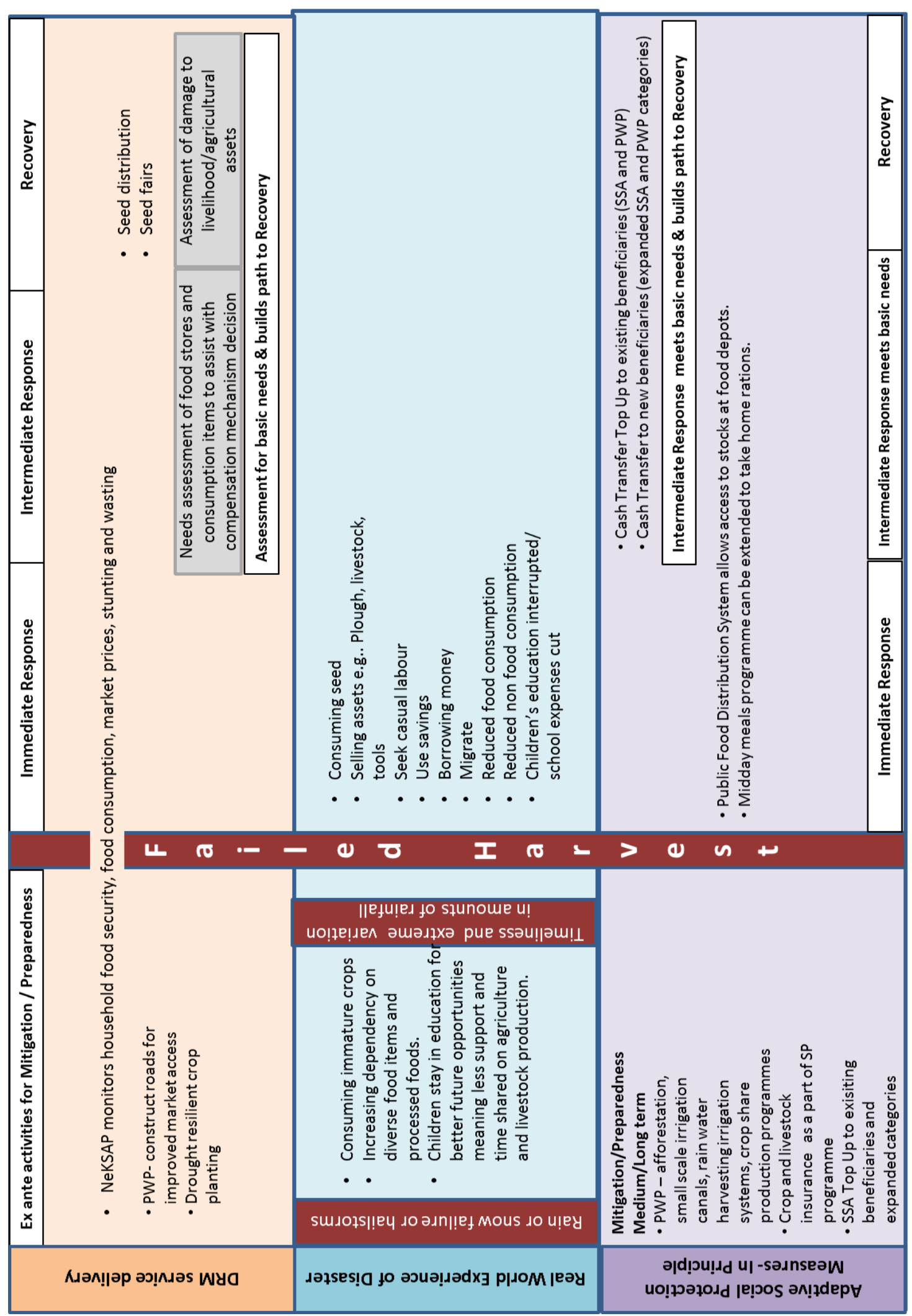


Annex Figure 4 DRM and ASP service delivery in event of landslide

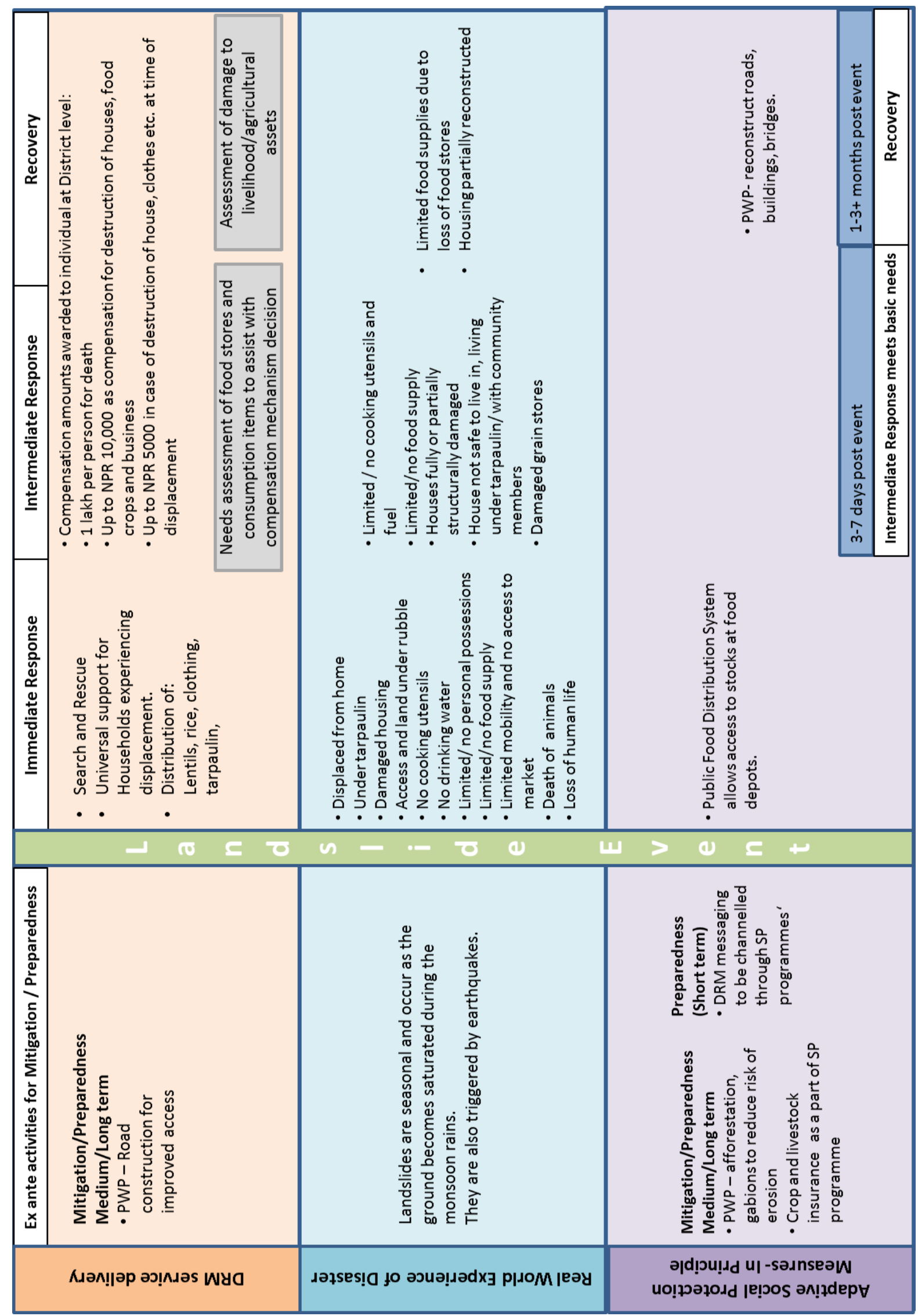


Annex Figure 5 DRM and ASP service delivery in event of fire

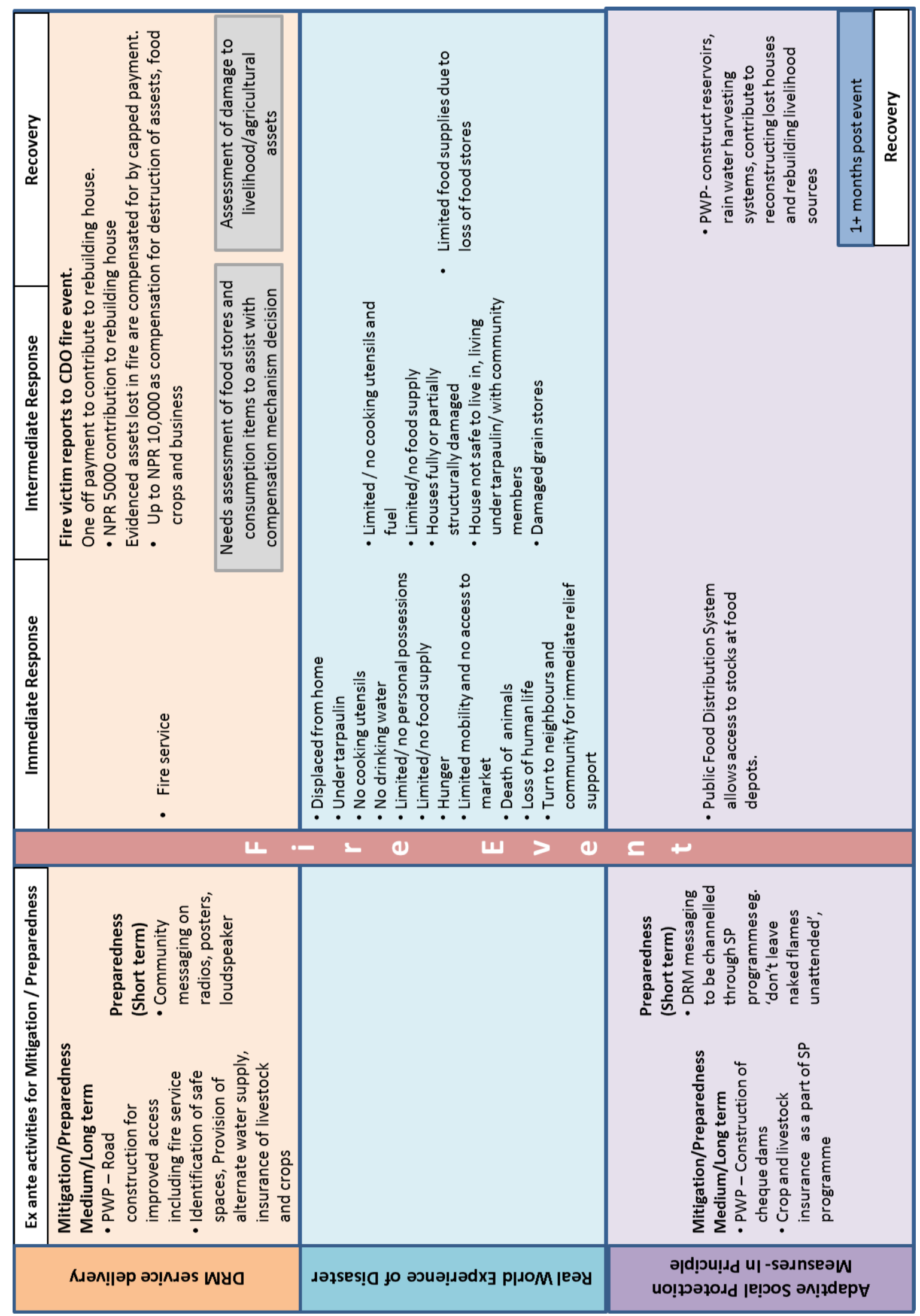

